NBSIR $7 \varepsilon-1547$

\title{
Methodology for Choosing Test Parameters to Evaluate Protective Headgear
}

Robert E. Berger

Nicholas J. Calvano

Product Safety Technology Division

Center for Consumer Product Technology

November 1978

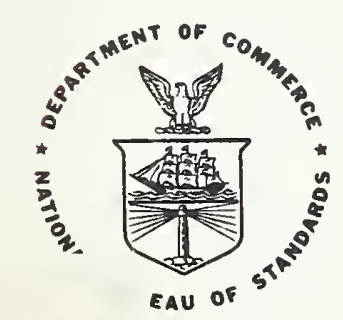

QC

100

EPARTMENT OF COMMERCE

.456

IAL BUREAU OF STANDARDS

78-1547

1978 

NBSIR 78-1547

․

\section{METHODOLOGY FOR CHOOSING TEST \\ PARAMETERS TO EVALUATE \\ PROTECTIVE HEADGEAR}

Robert E. Berger

Nicholas J. Calvano

Product Safety Technology Division

Center for Consumer Product Technology

November 1978

U.S. DEPARTMENT OF COMMERCE, Juanita M. Kreps, Secretary

Dr. Sidney Harman, Under Secretary

Jordan J. Baruch, Assistant Secretary for Science and Technology

NATIONAL BUREAU OF STANDARDS, Ernest Ambler, Director 
Table of Contents

I. INTRODUCTION 1

A. Head Injury and Tolerance 1

B. Test Methods 2

C. Methodology in Developing Test Methods 3

II. APPROACH

A. A Set of Test Parameters 5

B. Choice of Helmets 5

C. Limiting Averages 6

D. Determination of Effect of Changing Parameters 6

III. MATERIALS AND METHODS 1

A. Materials 8

B. Methods 9

IV. RESULTS 11

A. Summary of Data 11

B. Effect of Changing Test Parameters 11

V. DISCUSSION 14

A. Effect of Changing Parameters 14

B. Test Methods 17

C. Relation of this Work to Previous Studies 20

VI. SUMMARY 23

$\begin{array}{ll}\text { REFERENCES } & 24\end{array}$

$\begin{array}{ll}\text { APPENDIX } & 26\end{array}$ 



\section{List of Tables and Figures}

Table 1. Some Features of Selected Test Methods for Protective Headgear

Table 2. Limiting Average Data for Top Impacts, $V=V_{L}=4.5 \mathrm{~m} / \mathrm{sec}$

Table 3. Limiting Average Data for Back Impacts, $V=V_{L}=4.5 \mathrm{~m} / \mathrm{sec}$

Table 4. Limiting Average Data for $V=V_{H}=5 \mathrm{~m} / \mathrm{s}$

Table 5. Regression and Correlation Coefficients for Amax vs. SI $A_{\text {max }}=C_{1} S I+C_{2}$

Table 6. Effect of Changing Input Parameters - Summary of Test Conditions

Table 7. Regression and Correlation Coefficients for Effect of Changing Head form

Table 8. Regression and Correlation Coefficients for Effect of Changing Impact Surface

Table 9. Regression and Correlation Coefficients for Effect of Changing Velocity

Table 10. Relation Between Early Impacts and Limiting Average

Table 11. Comparison Data Between NOCSAE and ASTM Recommended Test Methods

Table 12. Comparison of Metal Headform with "Soft" Headform (Metal Headform Coated with Resilient Material) for Motorcycle Helmets, from Sourthwest Research Institute

Figure 1. Schematic of Focus for this Report

Figure 2. Wayne State University Tolerance Curve

Figure 3. Relationship Between HIC and SI

Figure 4. Limiting Average

Figure 5. Order of Tests on Soft and Hard Surfaces

Figure 6. Helmet Energy Absorbing Systems

Figure 7. Metal and Humanoid Headforms 
Figure 8. Force-Displacement Curves for Hard and Soft Test Surfaces

Figure 9. Metal Headform on Monorail

Figure 10. Ball/Socket, in Metal Headform

Figure 11-12 Typical Curves for Humanoid and Metal Headform

Figure 13-14 Fit of Power Law and Straight Line Curves to Data Points

Figure 15. SI vS. A Inax - Top Impacts

Figure 16. SI vs. A max - Back Impacts

Figure 17. Metal vs. Humanoid Headform - Hard and Soft Surfaces - Top Impacts

Figure 18. Metal vs. Humanoid Headform - Hard and Soft Surfaces - Back Impact.

Figure 19. Figure 18 and 19 combined

Figure 20. Hard vs. Soft Surfaces - Top Impact

Figure 21. Hard vs. Soft Surfaces - Back Impact

Figure 22. Hard vs. Soft Surfaces - Top and Back Impacts at High Velocity

Figure 23. Low vs. High Velocity - Metal Headforrn - Top Impact

Figure 24. Low vs. High Velocity - Metal Headform - Back Impact

Figure 25. Metal Headform/Soft Surface vs. Humanoid Headform/Hard Surface

Figure 26. Force vs. Displacement Curves for Helmeted Headforms

Figure 27. Humanoid Headform Rotation

Figure 28. Schematic Representation of Headform Rotation

Figure 29. Sensitivity of Test Method

Figure 30. HIC/Metal vs. HIC Humanoid 
I. INTROLUCTION

This report attempts to develop a methodology by which basic research concepts in head injury, human tolerance and the identification of environmental impact conditions can be utilized to develop test methods for protective headgear. The schematic in figure 1 illustrates how this work is intended to fill a gap between groups doing basic research and groups developing standards and test methods. The link between these groups has never been clear, though it is not unusual to see the same individuals as members of both. Engineers with the responsibility for developing test methods generally consider the basic research concepts before arriving at a set of conditions for testing headgear. However, the relationship between the test method and the research data is rarely straightforward. It is also rare for a test method to be accompanied by a technical rationale.

\section{A. Ilead Injury and Tolerance}

A review of basic research studies was presented earlier 1/; only those specific concepts which bear direct,ly on the present invéstigation will be addressed.

It is widely recognized that the translational (often called linear) component of the head acceleration, following an impact, is related to internal head injury 2/- $4 /$. All existing test methods are designed in such a way that only this component of head motion is reflected in the test method*. The widespread adoption of the Jinear acceleration as a head injury indicator is based on laboratory impact experiments with cadavers, where the head was observed to move relatively independent of the body, and on the fact that, in live subjects, the duration of impact was small compared to the neck muscle reaction time $5 /$.

* Of course, rotational accelerations have also been alleged to contribute to internal head injury, especially concussion. However, both translational and rotational accelerations tend to increase with increasing severity of blows to the head. (In fact, for a rigid body rotating about a single axis, the two components are proportional.) Therefore, it is conjectured that for some types of head impacts either component could be used as a measure of severity of impact. In any event, the development of test methods which measure the likelihood of injury from rotational accelerations is premature at this time and beyond the scope of this report. 
In the early sixties, Wayne State University (WSU) developed a human tolerance curve 6/ which relates concussive injury to linear head acceleration and duration of impact (figure 2). This curve was based on data obtained from studies with cadavers and sub-human primates. While the shortcomings of this tolerance curve have been rigorously discussed 7/ $9 /$, it remains the most widely accepted compendium of concussion tolerance. Using the Wayne State University Tolerance Curve, Gadd developed the Severity Index, which is expressed mathematically as:

$$
S I=\int_{\delta}^{T} a^{2.5} d t
$$

where a is the linear acceleration of the head, expressed as a multiple of the gravitational acceleration, and $\mathrm{T}$ is the duration of impact. According to Hodgson 10/:

"Gadd derived a critical value of 1000 (the units for SI are seconds, though they are rarely mentioned) as being the threshold of danger to life. - He recognized that the Severity Index may be a function of contact area. - Later on, Gadd suggested a critical value of SI equal to 1500. . . for distributed impact" 11/.

Another injury index, the head injury criterion, HIC, has been shown to be better related to the Wayne State data 12/. HIC was defined as

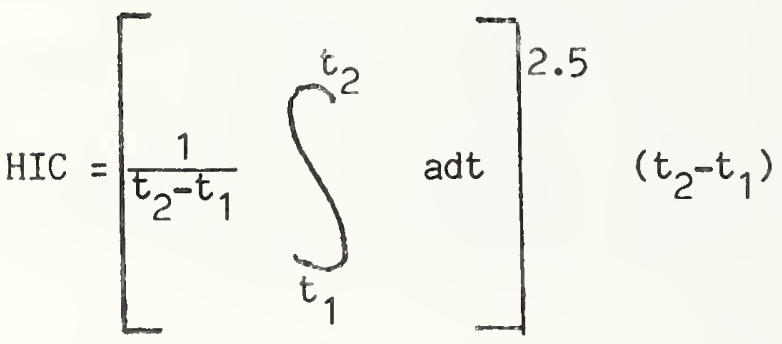

where $t_{1}$ and $t_{2}$ are those specific times during the duration of impact for which the above expression is a maximum. As shown in figure 3, with data taken from several sources, HIC is well correlated to SI. According to Hodgson, "the two are closely related for football helmet laboratory test impacts, with the severity index being typically 15-18\% higher than HIC" 5/.

\section{B. Test Methods}

There are many different standards and methods for testing protective headgear in the United States. All were developed to provide some measurable system for determining the suitability of a helmet for a particular job. Table 1 lists the various helmet standards and test methods currently available in this country. 
Some United States helmet standards make use of the WSU tolerance curve in setting rejection criteria, others do not. The helmet standard that makes maximum use of the biomedical information contained in the WSU curve is the NOCSAE (National Operating Committee on Standards for Athletic Equipment) standard for football helmets 5/. This standard was developed by Voigt Hodgson of Wayne State University under the sponsorship of NOCSAE. It utilizes an instrumented resilient headform which responds to impacts in a manner similar to human heads. The NOCSAE test method requires a relatively soft impact surface and uses a rejection criterion of SI > 1500 . Round robin tests have indicated that the NOCSAE test method does not meet reproducibility requirements which are normally demanded of standards $13 /$. Independent of reproducibility, there are other limitations which are discussed later.

Probably the best known standard for helmets in this country is the ANSI 290 motorcycle helmet standard 14/. The only similarity between the Z9O and NOCSAE standards is the fact that both require dropping an instrumented helmeted headform in guided free fall and measuring the response of the headform during impact. The 290 method requires a metal headform and a solid steel impact surface. To pass the 290 test, a helmet must attenuate sufficient impact energy to limit the headform acceleration to $400 \mathrm{~g}$. The impulse duration is also limited by the 290 standard.

Recently, the American Society for Testing Materials (ASTM) adopted a test method for football helmets which utilizes the metal headform and instrumentation of ANSI 290 15\%. Although performance criteria have not yet been established, laboratory tests 16/ have indicated that the ASTM method may rank football helmets differently than the NOCSAE method. Indeed, helmets may pass one test and fail the other. This could be of great concern to manufacturers who design their helmets to meet a standard or to consumers who are anxious to purchase helmets that meet a recognized standard.

\section{Methodology in Developing Test Methods}

The above discrepancy arises because no methodology exists for guiding test method development. A properly utilized methodology would give some degree of assurance to test method developers, and to producers and users, that the method correctly identifies inferior headgear. Without this assurance, each test method can only be regarded as one means of ranking helmets under a given set of impact conditions. In effect, the test methods are not now correlatable to absolute measures of effectiveness (i.e., to a ranking which corresponds to real life impact conditions).

The basic task in bridging the gap between "real life" and the test method is to identify the effect of changing impact parameters ( $r e f e r$ to figure 1). That is, we might consider any real life impact situation as a fixed set of impact conditions (which depend upon the activity; actually, 
there may be several sets of conditions for an activity). The corresponding test method is some other set of impact conditions which must be different from the real life set (e.g., human subjects cannot be used to test headgear - such a test would not be reproducible, anyway). The difference between the real life situation and the test method can then be regarded as a change in one or more impact parameters. The effect of these changes must be determined if the relationship between the real life situation and the test method is to be understood.

The main purpose of this report is to experimentally identify, in some limited cases, the effect of changing the most important test parameters. These include the following "input" parameters: the "head," or headform which holds the helmet, the impact surface with which the helmet makes contact, and the relative velocity between the helmet and impact surface. In addition, the "output" response, which determines the likelihood of head injury (and, therefore, the adequacy of the protective headgear), is another parameter which may differ among real life and various test methods. Table 1 illustrates the variety of test parameters which are used in existing protective headgear standards.

A systematic examination of the effect of changing test parameters was begun previously by mathematically modelling the components of the system: headform, helmet, impact surface 1/. The results of this report, then, can also be used for verification or modification of the model with experimental data. Thus, if the predictions of the model can be shown to agree with the experimental results for the limited parameter variations of the present study, it gives credence to its use under more general conditions. Then the model becomes a tool for incorporating the basic research studies into a proper set of test parameters. As the state-ofthe-art changes, modifications to the test method could be accomplished rapidly, without time consuming experimental programs. This re-examination of the model, in light of the experimental data, is beyond the scope of this report, but will be the subject of a future paper.

Among the questions that this report seeks to address are the following: What liberties may be taken in choosing a set of input parameters for a test method? How does one choose pass/fail levels for the test method output parameter which correspond to the injury tolerance level in real life? Can one determine in advance how sensitive the test method is in identifying inferior headgear? 


\section{APPROACH}

\section{A. A Set of Test Parameters}

Sets of test parameters were constructed by assigning values to each of five parameters: headform, impact surface, velocity, helmet impact site, and response (the output parameter). Each parameter could assume either of two values, as described below (with short-hand notation for referring to these values, also shown):

Headform*: Humanoid or Resilient (R), Metal (M)

Impact Surface*: Soft $(\mathrm{S})$, Hard $(\mathrm{H})$

Velocity*: $4.5 \mathrm{~m} / \mathrm{sec}\left(V_{L}\right), 5 \mathrm{~m} / \mathrm{sec}\left(V_{H}\right)$

Helmet Impact Site: Top (T), Back (B)

Response: Severity Index (SI), Peak Acceleration ( $a_{\max }$ )

The effect of changing the value of a single test parameter can be examined by changing from one of the above values of that parameter to the other while the values of all other parameters are fixed. Note that the effect of changing a single test parameter can be repeatedly examined for any combination of values of the other parameters. The choices of values for the above parameters were limited so that the total amount of data would not become unwieldy.

Any set of test parameters can be considered to be a set which simulates real life conditions, with one constraint: the humanoid headform must be a member of the set. This headform was specifically designed to reproduce the acceleration response of cadaver heads $\underline{5} /$ and thus represents our best laboratory simulation of a human head. Since all of the values for the other parameters can occur in the real life injury environment, any may be members of a set which is said to simulate a possible real life condition.

\section{B. Choice of Helmets}

To examine the effects of changing the input parameters, twelve different helmets with various types of energy absorbing systems were used. Football helmets were selected rather than other types of headgear because they are designed to take repeated impacts of relatively high levels on the top, front, sides and back without a substantial change in the properties of their energy absorbing systems. Also, a variety of designs are available in football helmets that are not found in other helmets,

*Vaiues to be described in more detail in chapter III. 
including webbing suspension, foamed plastic padding, pneumatic, and hydraulic systems.

\section{Limiting Averages}

To determine the effect of changing test parameters, some point of comparison must be established. With all test conditions held constant, the acceleration response of a new helmet is typically larger on the second drop than on the first. Those helmets with crushable foam liners (usually for vehicular use) will yield increasing acceleration responses on each successive drop until the liner has "bottomed." However, helmets with resilient liners, such as football helmets, are designed to recover after each impact.

Preliminary impact tests with football helmets showed that the energy absorption properties diminished after the first impact and continued to decrease for several impacts thereafter. Eventually the system leveled of $f$ (the number of impacts before the leveling off point varied with helmet) and the acceleration response became essentially constant. This effect is illustrated in figure 4. The average values of SI and $a_{\max }$ were taken from the impacts beyond the leveling off point (see figure 4 ). ${ }^{\text {max }}$ These averages are hereafter referred to as "limiting averages."

There was concern that the limiting averages for any given set of test parameters might be affected by earlier impacts with other sets of parameters, especially if a "soft" configuration follows a "hard" one. To investigate this possibility, impact tests were conducted on several helmets, with conditions changed from "soft" to "hard" and back to "soft" (see figure 5). It was observed that the limiting averages for the "soft" set of test parameters were the same whether or not the tests were preceded by the hard configuration.

\section{Determination of Effect of Changing Parameters}

Since differences in helmet design and materials may affect results, the effect of changing parameters must be determined by some averaging process which encompasses a large variety of helmets.

The effect of changing test parameters is determined by exhibiting twelve pairs of limiting averages (one pair for each helmet) on a graph where the designated output variable for one set of test parameters is plotted as a function of the designated output variable for the other set ( 


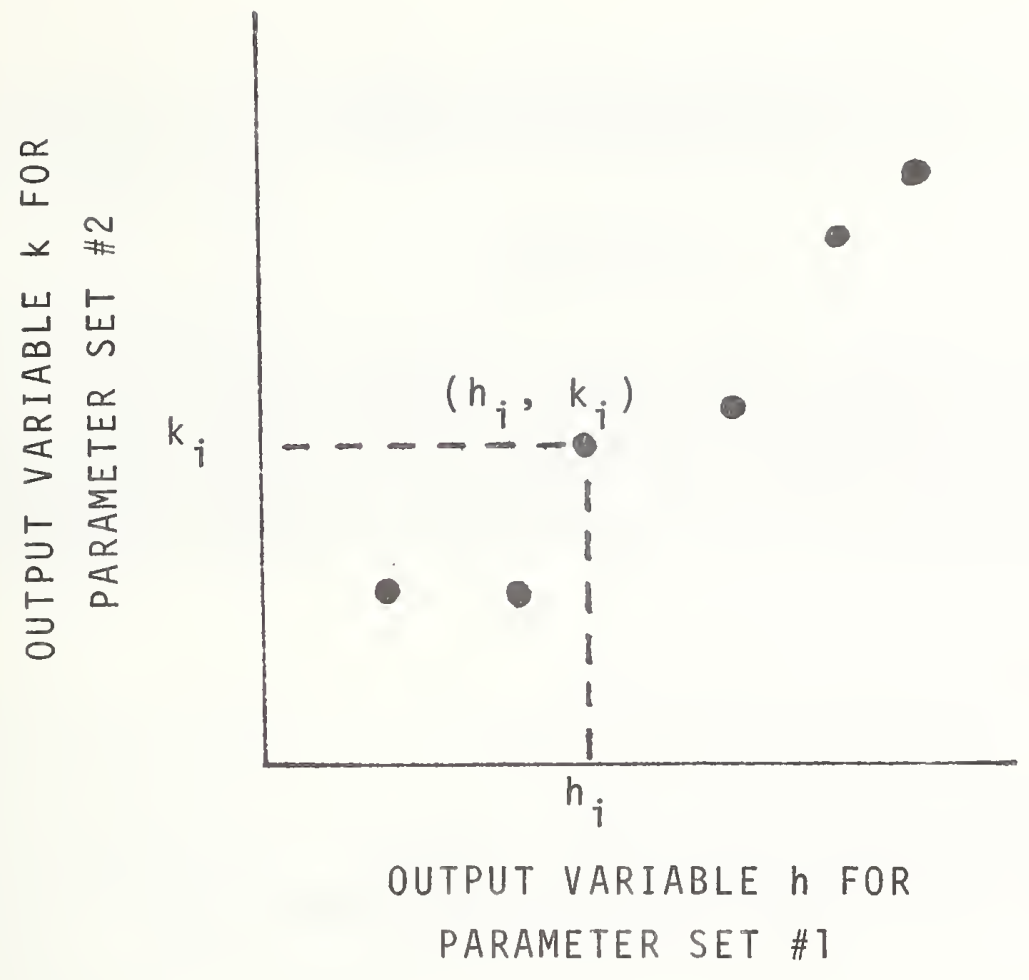

The higher the degree of association between the output variables (characterized by the correlation coefficient), the more distinguishable the effect of changing test method parameters becomes. The effect of such changes can then be expressed analytically by statistically fitting a curve through the twelve pairs of limiting average data points. 


\section{A. Materials}

\section{Helmets}

Twelve models of football helmets were purchased from four manufacturers about four months before testing began. The helmets are identified by a two letter code. The first letter of the code - A, B, C or $D$ - indicates the manufacturer. The second letter denotes the type of helmet as follows:

F - Fully padded

$P$ - Padded with top webbing suspension

I - Padded with top padded suspension

C - Fully padded with foamed plastic in segregated cells

$H$ - Hydraulic

S - Webbing suspension

The various helmet designs are shown in figure 6 .

\section{Head forms}

Metal. The metal headform is constructed of magnesium alloy KIIA in accordance with ANSI 290.1 14/. (See figure 7. )

Humanoid. The humanoid headform (see figure 7) is constructed of various materials which represent skin, skull and brain and was designed to simulate the response of human heads to impacts. This was accomplished by matching its mechanical impedance to the impedance of cadaver heads $5 /$. The headform was designed and built by Wayne State University $17 /$.

\section{Impact Surfaces}

Two impact surfaces were used in this study - "soft" and "hard." Each was cylindrical in shape, $15 \mathrm{~cm}$ ( 6 in) in diameter. The thickness of the pads were: hard, $1.9 \mathrm{~cm}$; soft, $2.1 \mathrm{~cm}$. Static force vs. displacement curves are shown in figure 8 for the two surfaces when loaded by the top of the metal headform. These curves can be represented by the following equations:

Soft: $F=4,902 d^{1.806}$

Hard: $F=43,579 d^{1.643}$ 
where $d$ is the displacernent in $\mathrm{cm}$, and $\mathrm{F}$ is the force in newtons. It is seen that the hard surface is an order of magnitude more difficult to compress then the soft surface. The Shore hardness was also measured: hard, 85; soft, 50 .

The above force/displacement relations were used to compare these surfaces to artificial impact surfaces which are used or proposed in some existing helmet test methods. The "hard" surface was somewhat more difficult to compress than those surfaces used in actual test methods; similarly, the "soft" surface was easier to compress. Therefore, it was thought that the "hard" and "soft" surfaces could be used to represent a broad range of impact surfaces.

\section{B. Methods}

\section{Drop Apparatus}

The headforms are mounted on a vertical rod which guides them during free fall (monorail drop apparatus, figure 9). This permits reproducible location of impact sites on the helmet.

The headforms ride on the rail by their attachment to separate "followers" (see figure 7). The ball and socket arrangement, which is used with the metal headform, allows impacts to be delivered to any site of a helmeted headform (see figure 10). The pin connections of the humanoid headform to its follower restrict the number of possible impact sites to six, of which only the top and back sites were used in this study.

A velocity meter measures the velocity immediately before impact.

The impact velocities reported in the previous chapter were chosen on the basis of preliminary experiments. The lower velocity, $V_{\text {, }}$, was chosen to be high enough to insure some severity index responses whlch approached or exceeded the injurious level of 1500. This was satisfied for $V_{1}=4.5$ $\mathrm{m} / \mathrm{sec}$. The higher velocity, $V_{H}$, was chosen so that the severity index responses would be significantly larger than those obtained using $V_{L}$. Only a small velocity change was required, $V_{H}=5.0 \mathrm{~m} / \mathrm{sec}$.

\section{Instrumentation}

The metal ( 290 ) headform was equipped with a piezoelectric linear accelerometer located at the center of mass of the headform.

The humanoid headform was equipped with a piezoresistive triaxial accelerometer which measures the acceleration in three orthogonal directions $\left(a_{x}, a_{y}, a_{z}\right)$.

The primary readout system was a Severity Index Analyzer developed at Wayne State University. When used with the triaxial accelerometer, the SI 
analyzer computes the resultant acceleration $\left(a^{2}=a^{2}+a^{2}+a^{2}\right)$ and gives a digital readout of the Severity Index and peak acceleration.

A storage oscilloscope, which displays a trace of the accelerationtime curve, was used simultaneously as a check on the digital readout produced by the SI analyzer.

\section{Procedure}

Top and back impact sites on each helmet were marked with the helmet positioned on the humanoid headform. indicator as shown in figure 11. When the helmet was tested with the metal headform, the helmeted headform was adjusted to insure that the same impact location on the helmet was struck.

For a fixed set of input parameters (headform, velocity, impact surface, and position) each helmet was impacted repeatedly until the measured headform outputs (SI and $a_{\max }$ ) leveled of $f$. In no case was a helmet impacted less than five times.

After obtaining data for all twelve test helmets, the set of input parameters was changed and the *est procedure repeated. Headforms and helmets were positioned carefully to ensure that impact sites on the helmets remained the same. 


\section{A. Summary of Data}

For each of the combinations of test method parameters, the limiting averages for severity index and maximum acceleration are shown in tables 2, 3 and 4. Several examples of typical oscilloscope traces are shown in figures 11 and 12 for top and back impacts, respectively.

\section{B. Effect of Changing Test Parameters}

\section{Choice of Curves for Representing Data}

As explained in section II.D, the effect of changing a test method parameter is determined by fitting a curve through twelve limiting average data points. For example, the effect of changing headforms might be determined by a plot of SI (metal) vs. SI (humanoid) with values of all other parameters fixed. In general, the degree of association between the variables will depend upon the type of curve chosen to represent the relationship. Two possibilities were considered:

$$
\begin{array}{ll}
\text { 1. } y=C_{1} x+C_{2} & \text { straight line } \\
\text { 2. } y=C_{1} x^{C_{2}} & \text { power law }
\end{array}
$$

where $\mathrm{x}$ and $\mathrm{y}$ are output variables from sets of data corresponding to different sets of test method parameters, and $C_{1}$ and $C_{2}$ are coefficients determined by a least-squares fit of the twelve pairs of data points ( $x_{i}$, $y_{i}$ ).

Both types of curves were fitted to the data for several typical examples, two of which are shown in figures 13 and 14 . Figure 13 is an example with a high degree of association: all input test method parameters were held fixed to examine the effect of changing the output parameter from SI to $a_{\text {. }}$. Each data point on this figure (and on the figures to follow) represents a pair of limiting averages for one of the twelve helmets (from tables 1,2, or 3) as described in section II.D. It is seen that, within the range of the data, both curves are equally capable of representing this effect, and that the corresponding correlation coefficients are nearly equal. Figure 14 examines the effect of changing headforms for back impacts. Here there is a relatively low degree of association of the data points with either curve. Again the curves nearly coincide in the range of interest and the correlation coefficients are nearly equal. Since both types of curves appear to be equally applicable for our purposes, for simplicity, the straight line least squares fit and 
associated correlation coefficients are used to examine the effect of changes in test method parameters*.

\section{Output Parameters}

In general, it is possible that the effect of changing one or more input parameters (headform, impact surface, velocity) may depend on which output parameter (SI, $a_{\text {max }}$ ) is chosen to characterize the response. However, it was observed that, for any fixed set of input test method parameters, the correlation between SI and $a_{\max }$ was very high. The regression and correlation coefficients are summarized in table 5, and composite scattergrams for the top and back impact sites are exhibited in figures 15 and 16. Because of the high degree of association between these two output parameters, we consider that either is appropriate for assessing the effect of changes in input test method parameters. Since the severity index, SI, has been more widely advocated as being related to the likelihood for internal head injury, it is used in the rest of the figures of this report.

\section{Input Parameters}

The effects of changing various input parameters are shown in figures 17-24, and a summary of the conditions examined is presented in table 6 . The regression coefficients (slope, intercept) and correlation coefficients for all combinations of output parameters are shown in tables 7, 8 and 9 . Note that, in examining the effect of any change in input test method parameters, the correlation coefficient is nearly independent of the choice of output parameters used to characterize the effect.

Headform. The effect of changing headforms is illustrated in figures 17 and 18 for top and back impacts, respectively. It is noted that the correlation coefficients for the back site are much less than those for the top site. By superimposing figures 17 and 18 (see figure 19) it is seen that for either impact surface, the effect of changing headforms also appears to depend upon the impact site; that is, when the impact surface is fixed, the difference between the SI response for humanoid and metal headforms is exaggerated for the back impact site.

Impact Surface. The effect of changing impact surfaces is shown in figures 20 and 21 for top and rear impacts, respectively. For the top impact site, the regression lines which describe this effect are similar for the two headforms. (For back impacts, the difference in the two regression lines is attributed to the fact that the lines were fitted over separate ranges of data; i.e., for the total range, the true relationship is probably not linear.) If the data from figures 20 and 21 are superimposed, it appears as though the same line fits the data for the two impact sites. For this effect, for the humanoid headform, the correlation coefficients are again less for the back site than for the top site.

\footnotetext{
*It is also noted that the rank correlation coefficients (as described in C. Lipson and N. Sheth, Statistical Design and Analysis of Engineering Experiments, p. 377, McGraw-Hill Book Co., New York, 1973) were nearly the same as those computed for linear regression.
} 
In figure 22, the effect of changing impact surfaces is shown for the higher velocity impacts (metal headform orly). Again the effect is apparently independent of impact site.

Velocity. The effect of changing the impact velocity is shown in figures 23 and 24, for top and back impacts, respectively (metal headform only). Two points are noteworthy. First, the severity index is substantially higher for the higher impact velocity, although the velocities are only slightly higher. Secondly, the correlations are much lower for the back impact site than for the top.

\section{Mixed Parameters}

In figure 25, an example is shown where two input test parameters, headform and impact surface, were changed simultaneously. The effect of this change appears to depend on impact site, but the correlation coefficients for the two sites are similar. 


\section{A. Effect of Changing Test Parameters}

Test methods are not expected to exactly duplicate real life situations. For protective headgear, a set of test parameters (headform, impact surface, velocity) is chosen for the purpose of providing a consistent laboratory evaluation of helmets. Usually this set is different from that which would have been chosen if the only goal of the test method were simulation. For example, a metal headform may be preferable to a humanoid surrogate because of increased reproducibility - an essential feature of any test method. Also, the velocity may differ from real life because of laboratory restrictions. Whatever the changes and reasons, it is essential that the chosen set of test parameters be traceable to the real life impact situation. Otherwise, the ranking and/or evaluation of helmets will be specific only to the particular set of test parameters, and the relationship to the likelihood of injury reduction will be unknown.

When a parameter is changed from its real life value (or simulation value) to a test method value, an identifiable relationship will exist only when the correlation is sufficiently high. Then the test method can be considered suitable for use in determining which products are likely to protect against injury*. If the correlation is too low, the test method is invalid - it bears no relationship to the real life impact/injury situation. The major purpose of this work is to begin to identify these relationships for the three test parameters for protective headgear: the headform, the impact surface, and the velocity.

1. Impact Surface

The effect of changing impact surfaces was the easiest to identify (figures 20 to 22). The effect was essentially independent of which headform was used or which impact site was selected; that is, the same curve appears to describe all cases. Correlations were consistently high in all cases. Since the characteristics of the impact surfaces can be quantified (as described in section III.A.3), predictions of the behavior of other impact surfaces are possible. These predictions can be made by using mathematical models such as the one described in reference 1.

\section{Velocity}

The effect of changing impact velocities is also not difficult to identify, at least for the top impact site (figure 23). For the back site, poor correlations seem to obliterate any distinguishable effect.

For football helmets, the stopping distance is the distance between the head (or headform) and the outer shell of the helmet. This distance is usually smaller at the back impact site than the top. The more severe the impact, the greater the displacement of the shell toward the head. At some

*The ability of the test method to make this determination is called the sensitivity which, of course, depends on the correlation. This will be discussed in detail in section V.B.2. 
displacement, there is a dramatic change in characteristics of the energy absorbing system, an effect which is illustrated by the static force displacement curves of figure 26. Essentially, the helmet liner has suddenly become more rigid. Since this effect is sensitive to material and design, its onset and magnitude will be different for different helmets, and, therefore, is expected to contribute to lower correlations. At a given helmet impact site, as the velocity is increased, some helmets begin to perform in this "increased rigidity" range, and there is a possibility of poor correlations between velocities. Because of the smaller stopping distance, this effect is first noticed at the back site.

It also appears that, for the football helmets used in this study, the poor correlations are associated with values of SI which are beyond the usually accepted tolerance values. It is felt that our understanding of the effect of increasing impact velocities is incomplete and should be the subject of a future study.

\section{Headform}

As expected, the effect of changing headforms leads to the worst correlations. This is because those features of the metal headform which make it reproducible (rigidity, simplicity) and, therefore, desirable are so much different from the real life surrogate, the humanoid headform. To further complicate the identification of this effect, it was found that the correlation was worse, and the regression lines different, for the back site and the top. Why should the effect of changing headforms depend so strongly on impact site? Could these differences be accounted for solely by the differences in headform geometry and resiliency at the two sites?

One other observation appeared to be related to these questions: it was observed that for back impacts with the humanoid headform, there was little or no rebound (in the top position, the rebound was comparable to that found at either site with the metal headform). That is, the change in velocity was smaller than if a rebound had occurred. Since velocity change is related to acceleration, it is conjectured that some mechanism caused the humanoid headform to decelerate more gradually in the back position than it would have if it had rebounded. It would follow that this mechanism was, therefore, absorbing energy that would have otherwise been available for deforming the helmet liner and impact surface. (The noiselike occurrence at the tail end of the oscilloscope traces (see figure 12), may also be related to this energy absorbing mechanism.) It is expected that part of this energy would have been returned by the elastic components as kinetic energy in rebound.

Therefore, high speed motion picture studies of the impacts of both headforms at both sites has recently begun. This work is both preliminary and qualitative, and a more detailed analysis will follow as the subject of a future paper. One observation is strikingly clear: when the humanoid headform impacts at the back position, there is a definite bending that occurs in the vicinity of the neck region (see figure 27). 
This phenomenon is thought to be due to the vertical misalignment of the headform center of gravity (c.g.) and the impact point when the humanoid headform is impacted at the back. In the top impact position, these two points fall on the same vertical line (in fact, the top position is the only impact position for which there is no offset) 18/. For the back position, the offset is about five centimeters 18/. Because of this offset, there is a tendency for the drop system to rotate (see figure 28 ).

A similar phenomenon was reported by Henderson 18/ in his study of the NOCSAE football helmet test system. Using a guide wire apparatus, it was found that these $\mathrm{c} . \mathrm{g}$. offsets led to a rotation of the entire drop assembly, headform plus carriage, with an accompanying bending of the guide wires. It was suggested then that these difficulties "may be overcome through the use of a drop guide system which is not sensitive to c.g. and impact center misalignment. . ( Which) would result by the combination of the NOCSAE (humanoid) headform with the monorail concept." 18/

We now find that this is not the case. With the monorail drop system, the same result (undesirable energy absorption) follows from the same cause (c.g. offsets); only the mechanism of energy absorption changes. With the monorail, the entire carriage system is prevented from rotating by the bearings on the rail. For this system, energy is absorbed by bending in the neck area. As pointed out by Henderson, "This results in a reduction of the force or acceleration." $18 /$

The corresponding values of severity index, SI, are also reduced by the action of this neck-bending mechanism. Furthermore, it is suspected that as the measured acceleration increases, so does the absorbed energy. Therefore, in correcting for this effect, the severity index should be increased over the recorded values when the humanoid headform is impacted at the back impact site. In terms of figure 17, the regression curves for back impacts would shift toward those established for top impacts. That is, we believe that the effect of changing headforms is not as strongly dependent on impact site as was first suspected. Rather, this dependence is more an artifact of the humanoid headform mounting system. Therefore, in identifying the effect of changing headforms, we suggest that the regression curves for the top position be regarded as more representative.

In addition, the neck bending effect is probably the cause of the relatively poor correlation coefficients for the back impact site as compared to the top site. That is, the energy absorption effect is also likely to be dependent on helmet design and would therefore introduce wider excursions in the data than would have occurred otherwise.

These findings thus present another criticism of the use of humanoid headforms in test methods to evaluate protective headgear. For all impact sites except the top, the acceleration response will be lower than if no neck bending had occurred. 
In response to these charges, advocates of such systems have argued that human necks may also absorb energy in the real life situation. These arguments must be rejected on two counts:

1. If neck bending is considered to have an important effect in the real life situation, then the bending characteristics of test method necks must be demonstrated to correspond to those of human necks. The "necks" of humanoid headforms which are used or proposed in test methods, especially the NOCSAE headform used in this study, have not met this criterion. Rather, these necks were designed to provide a means for securing the headform to the drop assembly.

2. According to Hodgson, the concept of the dropped headform test presupposes that, in the real life situation "the head moves independent of the body" $5 /$ (emphasis ours) and that the "impact will undoubtedly be over before the neck muscle reaction time." 5/ It follows then that neck reactions are particularly undesirable in a test method which records the linear acceleration response.

\section{B. Test Methods}

1. Choosing Test Parameters and Using the Relationships

To Identify Suitable Pass/Fail Levels

We will now illustrate how the relationships developed in this study can be used to choose a set of test parameters, and associated pass/fail values. For this illustration, we will consider developing a test method to evaluate football helmets.

Velocity. In choosing test parameters the first step is to identify typical impact velocities in the injury situation. As head injuries have been observed in football games when players are upended and strike the playing surface, the ensuing impact velocity may be reasonable for representing a real life injury situation. Other modes of impact have also been identified (e.g., helmet to helmet, helmet to knee, etc.). The relationship between these latter modes and the dropped headform test method is less straightforward, and has been investigated by mathematical modelling $1 /$.

In order to continue with this illustration and to make use of the relationships already developed in this report, we will assume that the velocity, $V_{L}$, is a representative impact velocity to a massive surface.

Headform. As discussed earlier, metal headforms are presently considered to be more reliable and reproducible than humanoid headforms 
(section I.B). Yet the humanoid headform is considered to be a better simulant of real heads. We would therefore use a graph like those shown on 17 or 18 to infer a value for SI for use with the metal headform which corresponds to the critical value with the humanoid headform, 1500 (section I.A.). Because of the neck bending problems associated with the humanoid headform at the back site (section V.A.3), we will use the relationships developed for the top (figure 17). Therefore, for the purposes of this illustration, the least squares line of figure 17 will be used to suggest a value of severity index which can be used with metal headforms in a test method. In particular, it is seen that when the SI with the humanoid headform is 1500, the corresponding value of SI with metal headforms is approximately 1800 .

Impact Surface. Lastly, the impact surface in the real life situation must be quantified (e.g., by the methods described in chapter III). If a similarly resilient impact surface can be fabricated for use in a test method, no further adjustments to the pass/fail value of the test method response parameter are required. If the test method impact surface is softer (or harder) than the real life surface, the pass/fail level for the test method response parameter must be adjusted downward (or upward).

For example, if the hard impact surface of this study were characteristic of the real life surface and the soft surfaces were used in the test method, it is seen from figure 20 that the hard surface pass/fail level of 1800 would correspond to a soft surface pass/fail level of approximately 1200. One could have obtained this same result directly from figure 25, where the effect of changing two parameters is illustrated. It is seen that when the severity index for the humanoid headform/hard surface is 1500 , the severity index for metal/soft is 1200 .

\section{Sensitivity of a Test Method}

Having chosen pass/fail levels on the basis of linear regression curves, where correlation coefficients are on the order of 0.8 to 0.9 , it is now required that we evaluate the usefulness of the test method. That is, how much correlation is enough? In the absence of perfect correlation, there is always a possibility that products which offer an adequate degree of protection may fail the test, while inferior products may pass. However, with higher correlation coefficients, fewer products are expected to be so misclassified.

It is possible to calculate a sensitivity for a given test method. That is, given that a product is considered to be inadequate, and based on the data collected in this report, the sensitivity is the probability that the test method will correctly identify it as inadequate.

We will calculate this probability for two hypothetical examples, both of which were alluded to in the previous section, and both of which utilize the metal headform in the test method: 
Example 1. Let us assume, for the purpose of this example, that the soft impact surface, described in this report, is comparable to surfaces in the field (in football, this may be valid if artificial turf or a muddy field is considered to be a representative impact/injury surface). Then the data of figure 17 are used in the calculations.

Example 2. We assume that the hard impact surface is considered to be typical of the field (say for hard frozen fields), but that it is desirable to use the soft impact surface in the test method. Then the data of figure 25 (for top impacts) is used in the calculations.

For both of these examples, it is assumed that the borderline injury level in the real life simulation (humanoid headform) is $S I_{C R}=1500$. The pass/fail level for the helmets in the test method is therefore SI' $\mathrm{CR}=$ 1800 for example 1 and $S I^{\prime} C R=1200$ for example 2 (where primes refer to SI values measured in the test' method; also refer to sketch below).

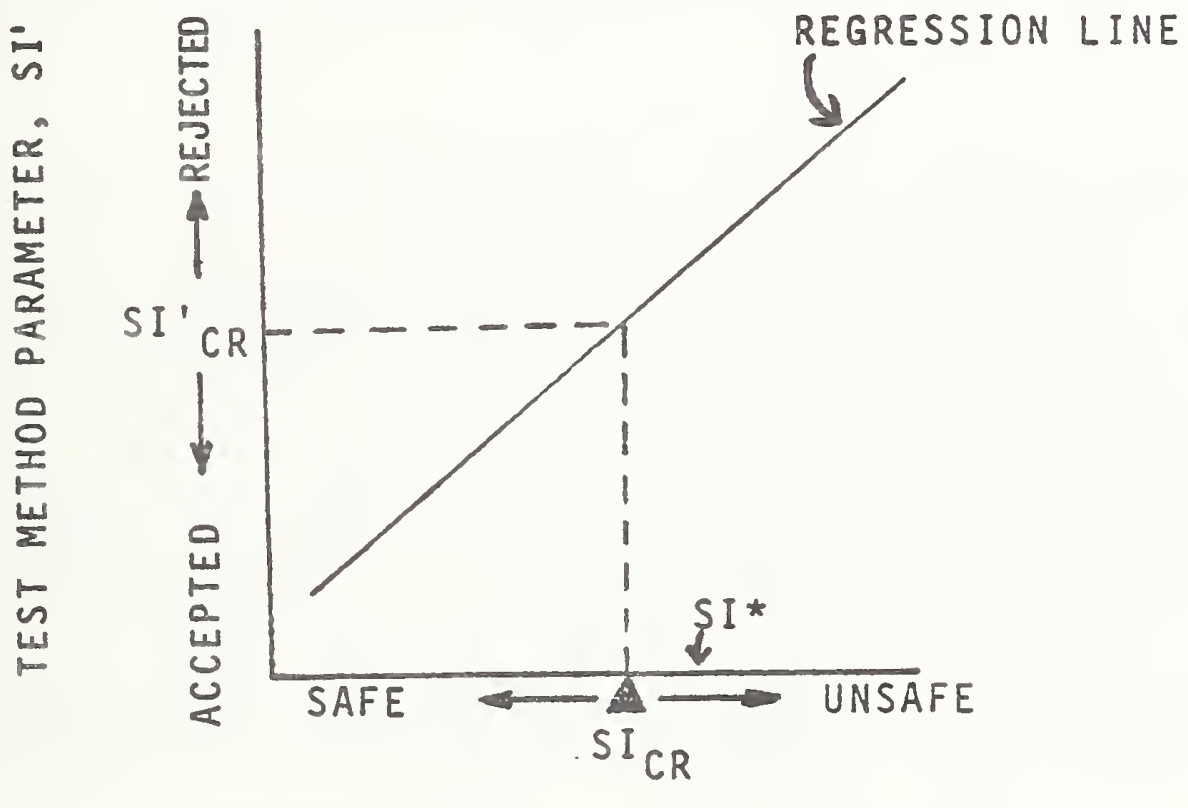

REAL LIFE SIMULATION PARAMETER, SI

Unknown helmets subjected to the test method can theoretically be characterized by the SI value that would result if the helmet were tested under conditions of the real life simulation. If such a test were possible, the helmet would be labelled inadequate if SI were greater than

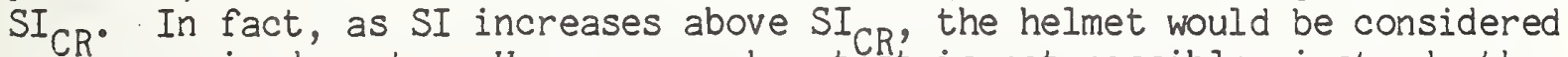
evên more inadequate. However, such a têst is not possible; instead, the helmets are subjected to the test method, where helmets are rejected if SI' is greater than SI' $\mathrm{CR}^{*}$ For any value $\mathrm{SI}^{*}$ greater than $\mathrm{SI}_{\mathrm{CR}}$, (refer to above sketch), it is possible to calculate the fraction of all helmets with SI greater than SI* which we expect to be correctly identified by the test method. We call this fraction the sensitivity. That is, of all helmets for which $\mathrm{SI}>\mathrm{SI}^{*} \geq \mathrm{SI}_{\mathrm{CR}}$, we calculate the fraction for which SI'> $S I^{\prime} C R^{*}$ 
Details of this calculation are shown in the Appendix, and the results are shown in figure 29. It is seen that, for example 1, we can expect a correct identification of $68 \%$ of helmets with SI $>1500 ; 88 \%$ of all helmets with SI $\geq 1600 ; 98 \%$ of all helmets with SI $\geq 1700$; etc. For example 2 , these percentages are nearly as high.

\section{Test Method Output Parameters}

The results indicate that, for the range of football helmets tested, the correlation between the maximum acceleration and the severity index was very high (.95). In addition, the relationship between $a_{\max }$ and SI seemed to be the same regardless of headform or impact position (max ligures 15 and 16), despite the fact that the oscilloscope traces for top and rear impacts were decidedly different. For the purpose of a test method response parameter, it appears that the maximum acceleration should be considered to be a reasonable substitute for the severity index, though the latter is more often advocated in the biomechanical literature. For the two examples discussed in the previous section it is noted that $\mathrm{SI}^{\prime}{ }_{\mathrm{CR}}=1800$ corresponds to $a_{\max }=260 \mathrm{~g}$ (example 1) and and $S I^{\prime}{ }_{C R}=1200$ corresponds to $a_{\max }=200$ g.

Regardless of what is used as a output parameter, the limiting average concept used throughout this report may not be practical in most football helmet test method situations. Only a few impacts per site would be preferred. Therefore, it is desirable to know if information obtained from a few impacts can be used to reflect the limiting average and if, for a range of helmets, a suitable correlation exists. To determine this effect, impact tests were conducted on a virgin site, the top, of twelve football helmets that were previously tested at the back site. The data for the first three impacts and the limiting average are summarized in table 10. The correlations between each of the first three impacts and the limiting average, and between the average of the first three impacts and the limiting average, are shown. These correlation coefficients increase with the number of impacts and are already very high by the second impact; the average of the first three impacts also correlates very well with the limiting average. It is, therefore, concluded that useful information can indeed be obtained with a few impacts at each site.

\section{Relation of This Work to Previous Studies}

There are a few examples where other investigators have studied the effect of changing one or more test parameters in impact testing of protective headgear.

Andrews 16/ tested eleven football helmets according to procedures described in two different test methods: one promulgated by ASTM (F429-75) and the other by NOCSAE (section I.B). The most obvious differences between these test methods are in the headform (NOCSAE uses the same humanoid headform as in this study; ASTM the same metal headform) and in 
the hardness of the impact surface (Shore durometer: ASTM, 70; NOCSAE, 35). Other differences from the present study should also be noted: 1) The ASTM test method required a cone-shaped (pointed upward), rather than flat, impact surface; this change has the effect of softening the impact as well as introducing a source of variability, depending on whether or not the impact point coincides with the tip of the cone. 2) The helmets received only two impacts with the NOCSAE procedure and three with ASTM (the order of administering the test methods was not reported). 3) A guide wire system, rather than a monorail was used in all tests. 4) The severity index was measured only in the NOCSAE configuration, as the ASTM procedure did not require this measurement.

Andrews' data is summarized in table 11 for the top and back impact positions. Correlation coefficients were computed from these data and are also reported in table 11. Despite the many differences between that study and the present one, some general results were similar. There was excellent correlation between the severity index and the maximum acceleration when input test parameters were held fixed. Regarding the differences between the top and rear sites, relatively high correlations at the top site and poor correlations at the back were calculated. Again, it is suspected, as described in section V.A.3, that the vertical misalignment of the center of gravity and the impact point, when the humanoid headform was impacted at the rear, was largely responsible for these poor correlations at the back site.

In another study, the Southwest Research Institute developed a "soft" headform by coating a metal headform with resilient material 19/. Fourteen models of motorcycle helmets were impact tested using both the soft headform and the usual metal headform. The data for back impacts are summarized in table 12; each data point is the mean of results of the second impact on four helmets of the same model (For each helmet model, a separate group of four helmets were used with each headform*.) The head injury criterion, HIC, was reported in this study. The data of table 12 are plotted in figure 30, where it is seen that the correlation coefficient between the HIC values for the soft and metal headforms is high (.92). This should not be unexpected, even for back impacts, because the soft headform used in this study maintains its c.g. in vertical alignment with the impact point.

The evidence in this and other studies continues to suggest that test procedures using metal headforms correlate sufficiently well to those using humanoid headforms, and so, in view of their superior reproducibility and lack of $\mathrm{c} . \mathrm{g}$. offset problems, metal headforms should not be avoided in test methods for protective headgear. Nevertheless, criticism of the use of metal headforms is widespread 5/, 20/ and it is interesting to inspect the data which are used to support these criticisms. Sometimes only a few selected data points are extracted from a larger collection to support these arguments. For example, in a recent article $20 /$ the data from only three of the fourteen types of motorcycle helmets in the SWRI study 19/ were reported (and then only two helmets of each type). The limited data

\footnotetext{
*The limiting average concept is not applicable for motorcycle helmets since they are designed to protect against a single impact and nay then sustain permanent damage. A point of comparison must be obtained by averaging the results of several helmets.
} 
were chosen to illustrate the point that there may be occasions when pairs of helmets are ranked in reverse order by two different procedures. But as discussed above, the larger collection of data suggest that the correlation between the two headform is satisfactory.

Occasional reversals in the order of helmet performance is an acceptable trade-off for a reproducible, reliable test method. We contend, as described in section V.B.2, that if the overall correlation is sufficiently high, then the test method is useful in identifying potentially inadequate products. If it can be shown that a significant fraction of these inadequate products will be removed from the marketplace by a well conceived test method, the users of these products will be better protected. 
VI. SUMMARY

The concept of using limiting averages for a range of helmets was established as a viable means of comparing one impact situation with another. It was demonstrated that the limiting averages correlated well with results obtained from two or three impacts.

For any set of test parameters, the maximum acceleration was shown to correlate very well with the severity index.

The humanoid headform displayed some deficiencies that had not been reported previously. At all but the top impact sites, vertical misalignment of the center of gravity and the impact point causes lower headform response.

The effects of changing test parameters was identified in some limiting cases:

The correlation between headforms (for the top impact site, the only impact site where the humanoid headform performs reliably) appears to be sufficiently high to justify the use of metal headforms in test methods - at least until such time as acceptable human simulations are available.

The correlation between impact surfaces is very high.

The correlation between velocities appear to degrade under conditions which lead to high acceleration responses. This effect was noticed for back impacts (where the stopping distance was small) at the higher velocity and requires more study.

A procedure has been presented for determining pass/fail values of test method output parameters, and for estimating the value of a test method by calculating its sensitivity. 



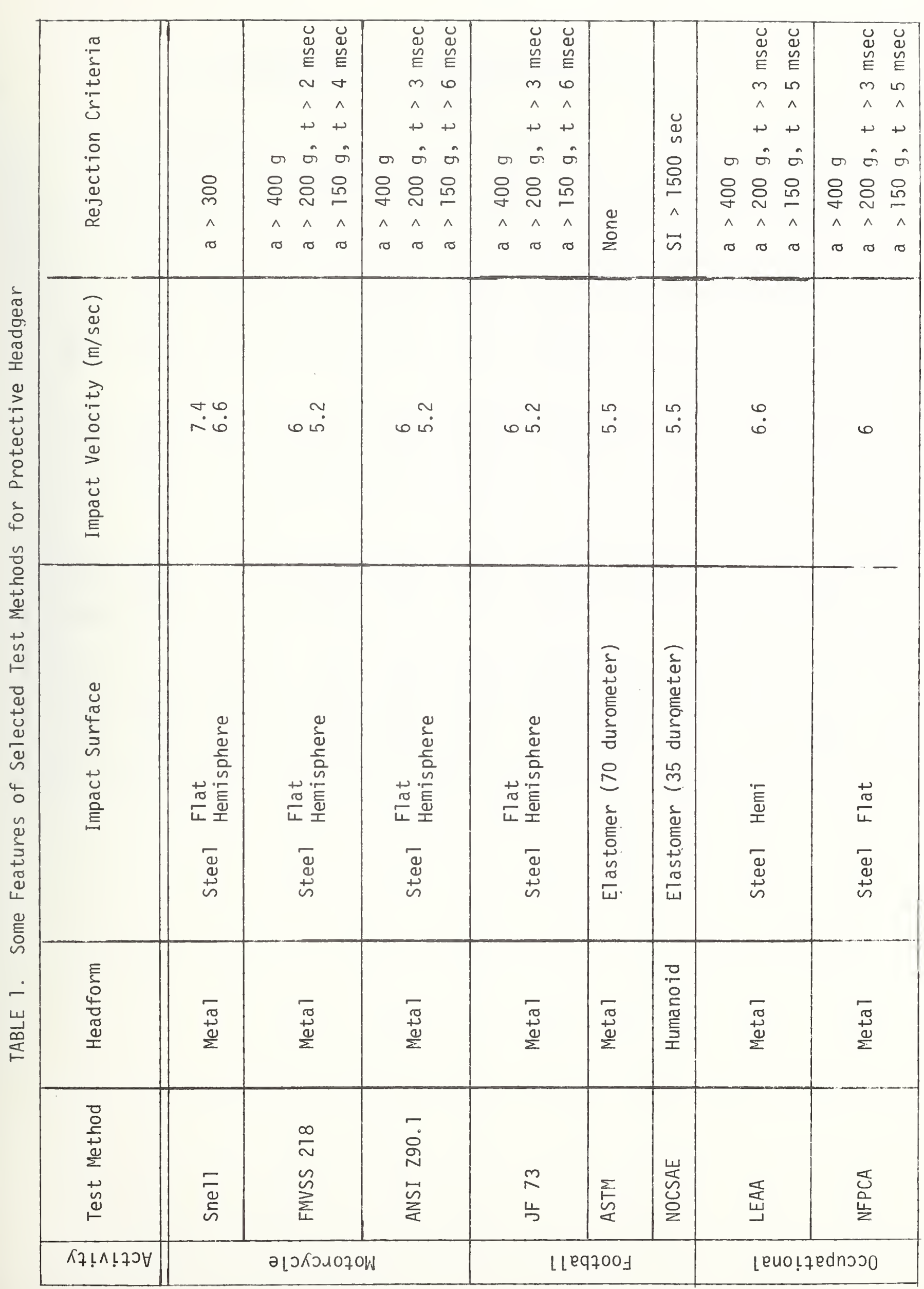


TABLE 2. Limiting Average Data for Top Impacts, $V=V_{L}=4.5 \mathrm{~m} / \mathrm{sec}$

\begin{tabular}{|c|c|c|c|c|c|c|c|c|c|}
\hline \multirow{2}{*}{\multicolumn{2}{|c|}{$\begin{array}{c}\text { Headform } \\
\text { Impact Surface }\end{array}$}} & \multicolumn{4}{|c|}{ Humanoid } & \multicolumn{4}{|c|}{ Metal } \\
\hline & & \multicolumn{2}{|c|}{ Hard } & \multicolumn{2}{|c|}{ Soft } & \multicolumn{2}{|c|}{ Hard } & \multicolumn{2}{|c|}{ Soft } \\
\hline & Output & SI & A & SI & A & SI & $A$ & SI & A \\
\hline & $A F-1$ & 665 & 125 & 601 & 124 & 557 & 104 & 542 & 105 \\
\hline & AP- 1 & 925 & .158 & 730 & 137 & 690 & 130 & 700 & 122 \\
\hline & AT- 1 & 1540 & 227 & 975 & 166 & 1210 & 184 & 960 & 154 \\
\hline & $B C-1$ & 1380 & 208 & 990 & 164 & 1425 & 230 & 865 & 153 \\
\hline$\vdash$ & $B P-1$ & 1650 & 217 & 1250 & 180 & 2776 & 298 & 1630 & 224 \\
\hline 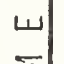 & BT- 1 & 545 & 114 & 520 & 110 & 750 & 122 & 570 & 108 \\
\hline$\omega$ & $\mathrm{CH}-1$ & 680 & 132 & 660 & 130 & 965 & 151 & 760 & 130 \\
\hline 工 & $C P-1$ & 465 & 120 & 455 & 118 & 690 & 132 & 500 & 115 \\
\hline & CS- 1 & 1190 & 188 & 910 & 172 & 1950 & 275 & 1270 & 208 \\
\hline & $D C-1$ & 860 & 140 & 855 & 145 & 945 & 145 & 675 & 130 \\
\hline & $\mathrm{DH}-1$ & 480 & 114 & 390 & 105 & 500 & 103 & 420 & 98 \\
\hline & DS-1 & 950 & 175 & 741 & 152 & 850 & 150 & 700 & 136 \\
\hline
\end{tabular}


TABLE 3. Limiting Average Data for Back Impacts, $V=V_{L}=4.5 \mathrm{~m} / \mathrm{sec}$

\begin{tabular}{|c|c|c|c|c|c|c|c|c|c|}
\hline & & & Hum & & & & & & \\
\hline & Tmpact Surface & $\mathrm{Ha}$ & & So & & & & & \\
\hline & Output & SI & A & SI & A & SI & A & SI & A \\
\hline & $A F-2$ & 575 & 137 & 574 & 137 & 1924 & 278 & 927 & 158 \\
\hline & $A P-2$ & 980 & 196 & 723 & 149 & 2562 & 300 & 1513 & 220 \\
\hline & AT-2 & 652 & 150 & 670 & 148 & 1841 & 268 & 1247 & 194 \\
\hline & $B C-2$ & 493 & 119 & 411 & 108 & 1374 & 237 & 795 & 157 \\
\hline เ & BP-2 & 865 & 169 & 672 & 134 & 3423 & 359 & 1677 & 233 \\
\hline 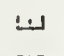 & BT-2 & 589 & 132 & 632 & 139 & 1417 & 238 & 882 & 147 \\
\hline$w$ & $\mathrm{CH}-2$ & 439 & 111 & 428 & 109 & 491 & 108 & 543 & 116 \\
\hline I & $C P-2$ & 601 & 131 & 548 & 125 & 2254 & 289 & 1317 & 205 \\
\hline & CS-2 & 683 & 150 & 603 & 124 & 2109 & 256 & 1457 & 191 \\
\hline & $D C-2$ & 763 & 150 & 932 & 163 & 1358 & 229 & 1143 & 182 \\
\hline & $\mathrm{DH}-2$ & 358 & 100 & 394 & 104 & 1347 & 220 & 830 & 153 \\
\hline & DS-2 & 714 & 147 & 727 & 141 & 3377 & 330 & 1221 & 190 \\
\hline
\end{tabular}


TABLE 4. Limiting Average Data for

$V=V_{H}=5 \mathrm{~m} / \mathrm{s}$

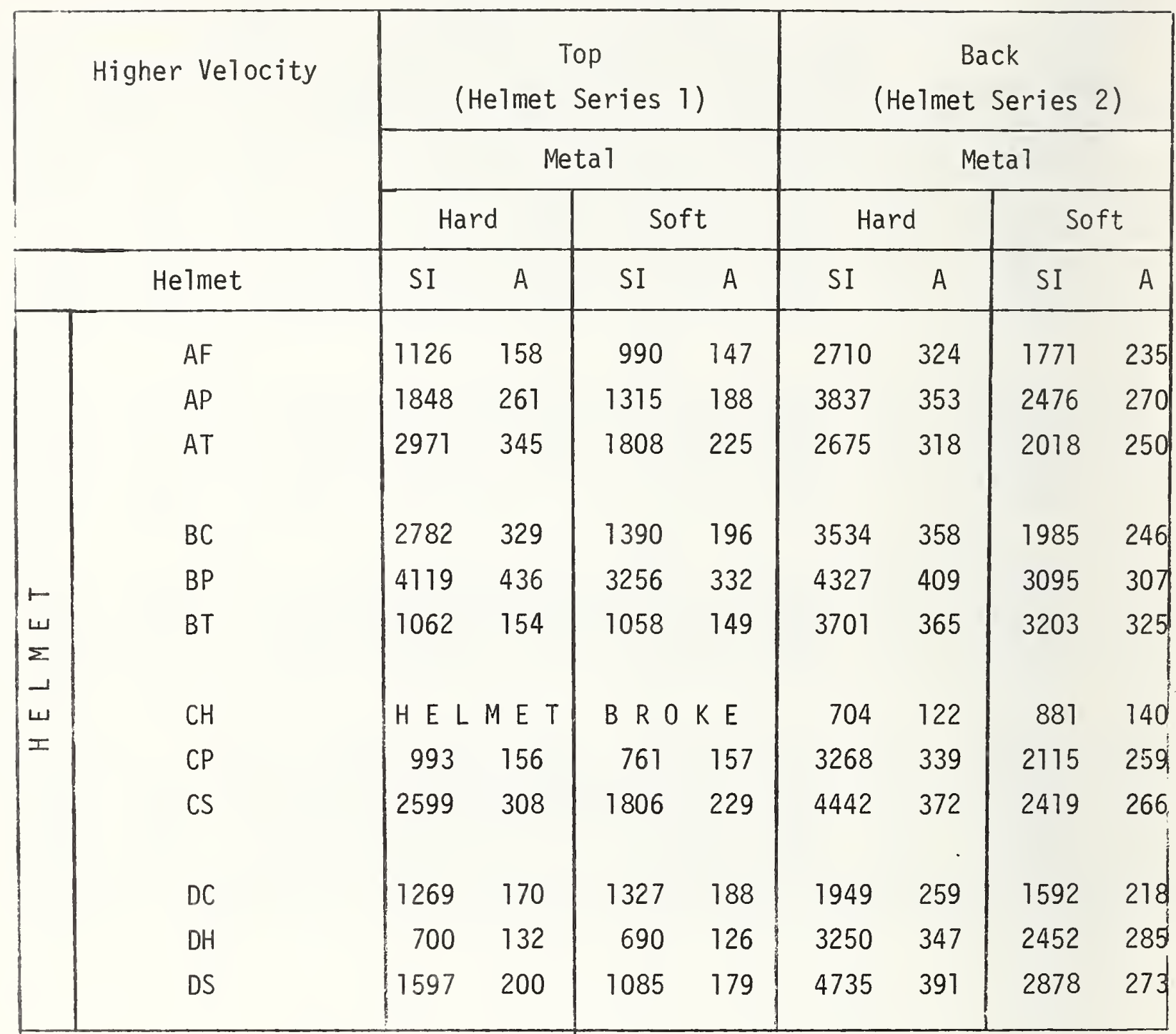


TABLE 5. Regression and Correlation Coefficients for $A_{\max }$ Vs. SI $\quad A_{\max }=C_{1}$ SI $+C_{2}$

\begin{tabular}{|c|c|c|c|c|c|c|}
\hline \multicolumn{4}{|c|}{ Values of Input Parameters } & \multirow[b]{2}{*}{$c_{1}$} & \multirow[b]{2}{*}{$c_{2}$} & \multirow[b]{2}{*}{$\begin{array}{l}\text { Correlation } \\
\text { Coefficient }\end{array}$} \\
\hline Headform & Surface & Velocity & Site & & & \\
\hline$R$ & $\mathrm{H}$ & $V_{L}$ & $T$ & .100 & 66 & .98 \\
\hline$R$ & $S$ & $V_{L}$ & $T$ & .096 & 70 & .96 \\
\hline M & $\mathrm{H}$ & $V_{L}$ & $T$ & .095 & 64 & .97 \\
\hline M & $S$ & $V_{L}$ & $T$ & .112 & 51 & .97 \\
\hline$R$ & $\mathrm{H}$ & $V_{L}$ & B & .145 & 48 & .97 \\
\hline$R$ & $S$ & $V_{L}$ & B & .112 & 63 & .96 \\
\hline M & $H$ & $V_{L}$ & B & .070 & 123 & .94 \\
\hline M & $S$ & $V_{L}$ & B & .095 & 72 & .89 \\
\hline M & $H$ & $V_{H}$ & $T$ & .094 & 61 & .95 \\
\hline M & $S$ & $V_{H}$ & $T$ & .078 & 83 & .98 \\
\hline$M$ & $\mathrm{H}$ & $V_{H}$ & B & .063 & 124 & .95 \\
\hline$M$ & $S$ & $V_{H}$ & $B$ & .068 & 104 & .96 \\
\hline
\end{tabular}


TABLE 6. Effect of Changing Input Parameters Summary of Test Conditions

\begin{tabular}{|c|c|c|c|c|c|c|}
\hline \multirow{2}{*}{$\begin{array}{c}\text { Parameter } \\
\text { Being Examined }\end{array}$} & \multicolumn{4}{|c|}{ Values of 0ther Parameters } & \multirow{2}{*}{ Figure } & \multirow{2}{*}{$\begin{array}{l}\text { SI vs. SI } \\
\text { Correlation } \\
\text { Coefficient }\end{array}$} \\
\hline & Velocity & Site & Headform & Surface & & \\
\hline \multirow[t]{4}{*}{ Headform } & $V_{L}$ & $T$ & - & $\mathrm{H}$ & 7 & .80 \\
\hline & $V_{L}$ & $T$ & - & $S$ & 7 & .88 \\
\hline & $V_{L}$ & B & - & $H$ & 8 & .69 \\
\hline & $V_{L}$ & B & - & S & 8 & .61 \\
\hline \multirow[t]{6}{*}{ Impact Surface } & $V_{L}$ & $\mathrm{~T}$ & $\mathrm{R}$ & - & 10 & .96 \\
\hline & $V_{L}$ & $\mathrm{~T}$ & M & - & 10 & .98 \\
\hline & $V_{L}$ & B & $R$ & - & 11 & .77 \\
\hline & $V_{L}$ & B & M & - & 11 & .96 \\
\hline & $V_{H}$ & T & M & - & 12 & .92 \\
\hline & $V_{H}$ & B & M & - & 12 & .88 \\
\hline \multirow[t]{4}{*}{ Velocity } & - & $T$ & $M$ & $H$ & 13. & .91 \\
\hline & - & $T$ & $M$ & $S$ & 13 & .96 \\
\hline & - & B & $M$ & $\mathrm{H}$ & 14 & .78 \\
\hline & - & B & $M$ & $S$ & 14 & .54 \\
\hline
\end{tabular}


TABLE 7. Regression and Correlation Coefficients for Effect of Changing Headform

$\left[\begin{array}{c}\text { Output Parameter } \\ \text { For Metal } \\ \text { Headform }\end{array}\right]=C_{7}\left[\begin{array}{c}\text { Output Parameter } \\ \text { For Humanoid } \\ \text { Headform }\end{array}\right]+C_{2}$

\begin{tabular}{|c|c|c|c|c|c|c|c|}
\hline \multicolumn{3}{|c|}{$\begin{array}{l}\text { Values of Other } \\
\text { Input Parameters }\end{array}$} & \multicolumn{2}{|c|}{ Output Parameters } & \multicolumn{2}{|c|}{$\begin{array}{l}\text { Regression } \\
\text { Coefficients }\end{array}$} & \multirow[t]{2}{*}{$\begin{array}{l}\text { Correlation } \\
\text { Coefficient }\end{array}$} \\
\hline Surface & Velocity & Site & Metal & Humanoid & $c_{1}$ & $c_{2}$ & \\
\hline \multirow[t]{4}{*}{$H$} & $V_{L}$ & $T$ & SI & SI & 1.30 & -718 & .80 \\
\hline & & & $A_{\max }$ & $A_{\max }$ & 1.24 & -30 & .80 \\
\hline & & & SI & $A_{\max }$ & 11.7 & -758 & .74 \\
\hline & & & $A_{\max }$ & SI & .13 & 45 & .82 \\
\hline \multirow[t]{4}{*}{$S$} & $V_{L}$ & $\mathrm{~T}$ & SI & SI & 1.23 & -128 & .88 \\
\hline & & & $A_{\max }$ & $A_{\max }$ & 1.41 & -59 & .90 \\
\hline & & & SI & $A_{\max }$ & 12.0 & -905 & .76 \\
\hline & & & $A_{\max }$ & SI & .14 & 37 & .89 \\
\hline \multirow[t]{4}{*}{$H$} & $V_{L}$ & B & SI & SI & 3.37 & -212 & .69 \\
\hline & & & $A_{\max }$ & $A_{\max }$ & 1.59 & 35 & .65 \\
\hline & & & SI & $A_{\max }$ & 22 & -1144 & .66 \\
\hline & & & $A_{\max }$ & SI & .250 & 99 & .68 \\
\hline \multirow[t]{4}{*}{$S$} & $V_{L}$ & B & SI & SI & 1.23 & 374 & .61 \\
\hline & & & $A_{\max }$ & $A_{\max }$ & .91 & 59 & .49 \\
\hline & & & SI & $A_{\max }$ & 9.26 & -91 & .50 \\
\hline & & & $A_{\max }$ & SI & .118 & 107 & .57 \\
\hline
\end{tabular}


TABLE 8. Regression and Correlation Coefficients for Effect of Changing Impact Surface

$$
\left[\begin{array}{c}
\text { Output Parameter } \\
\text { For Soft } \\
\text { Impact Surface }
\end{array}\right]=c_{1}\left[\begin{array}{c}
\text { Output Parameter } \\
\text { For Hard } \\
\text { Impact Surface }
\end{array}\right]+C_{2}
$$

\begin{tabular}{|c|c|c|c|c|c|c|c|}
\hline \multicolumn{3}{|c|}{$\begin{array}{l}\text { Values of 0ther } \\
\text { Input Parameters }\end{array}$} & \multicolumn{2}{|c|}{ Output Parameters } & \multicolumn{2}{|c|}{$\begin{array}{l}\text { Regression } \\
\text { Coefficients }\end{array}$} & \multirow[t]{2}{*}{$\begin{array}{l}\text { Correlation } \\
\text { Coefficient }\end{array}$} \\
\hline Headform & Velocity & Site & Soft & Hard & $c_{1}$ & $c_{2}$ & \\
\hline \multirow[t]{4}{*}{ M } & \multirow{4}{*}{$V_{L}=4.5$} & \multirow[t]{4}{*}{$T$} & SI & SI & .512 & 232 & .98 \\
\hline & & & $A_{\max }$ & $A_{\max }$ & .59 & 40.2 & .97 \\
\hline & & & SI & $A_{\max }$ & 5.0 & -53.8 & .94 \\
\hline & & & $A_{\max }$ & SI & .05 & 76.1 & .84 \\
\hline \multirow[t]{4}{*}{$R$} & \multirow{4}{*}{$V_{L}$} & \multirow[t]{4}{*}{$T$} & SI & SI & .584 & 205 & .96 \\
\hline & & & $A_{\max }$ & $A_{\max }$ & .56 & 51.9 & .93 \\
\hline & & & SI & $A_{\max }$ & 5.39 & -106 & .90 \\
\hline & & & $A_{\max }$ & SI & .058 & 87.4 & .95 \\
\hline \multirow[t]{4}{*}{ M } & \multirow[t]{4}{*}{$V_{L}$} & \multirow[t]{4}{*}{ B } & SI & SI & .352 & 490 & .96 \\
\hline & & & $A_{\max }$ & $A_{\max }$ & .450 & 61.9 & .85 \\
\hline & & & SI & $A_{\max }$ & 4.32 & 7.8 & .81 \\
\hline & & & $A_{\max }$ & SI & .032 & 115 & .82 \\
\hline \multirow[t]{4}{*}{$R$} & \multirow[t]{4}{*}{$V_{L}$} & \multirow[t]{4}{*}{ B } & SI & $S I$ & .683 & 170 & .77 \\
\hline & & & $A_{\max }$ & $A_{\max }$ & .510 & 59.8 & .72 \\
\hline & & & SI & $A_{\max }$ & 4.25 & 9.28 & .71 \\
\hline & & & $A_{\max }$ & SI & .077 & 82.0 & .74 \\
\hline
\end{tabular}


TABLE 8. Continued

\begin{tabular}{|c|c|c|c|c|c|c|c|}
\hline \multicolumn{3}{|c|}{$\begin{array}{l}\text { Values of Other } \\
\text { Input Parameters }\end{array}$} & \multicolumn{2}{|c|}{ Output Parameters } & \multicolumn{2}{|c|}{$\begin{array}{l}\text { Regression } \\
\text { Coefficients }\end{array}$} & \multirow[t]{2}{*}{$\begin{array}{l}\text { Correlation } \\
\text { Coefficient }\end{array}$} \\
\hline Headform & Velocity & Site & Soft & Hard & $c_{1}$ & $c_{2}$ & \\
\hline \multirow[t]{4}{*}{$M$} & $V_{H}=5.0$ & $\mathrm{~T}$ & SI & SI & .615 & 229 & .92 \\
\hline & & & $A_{\max }$ & $A_{\max }$ & .510 & 69.4 & .91 \\
\hline & & & SI & $A_{\max }$ & 6.09 & -161.5 & .86 \\
\hline & & & $A_{\max }$ & SI & .018 & 97.5 & .93 \\
\hline \multirow[t]{4}{*}{ M } & $V_{H}$ & B & SI & SI & .511 & 573 & .88 \\
\hline & & & $A_{\max }$ & $A_{\max }$ & .562 & 70.7 & .91 \\
\hline & & & SI & $A_{\max }$ & 7.65 & -281 & .87 \\
\hline & & & $A_{\max }$ & SI & .034 & 144 & .82 \\
\hline
\end{tabular}


TABLE 9. Regression and Correlation Coefficients for Effect of Changing Velocity

$\left[\begin{array}{c}\text { Output Parameter } \\ \text { For } V_{L}\end{array}\right]=C_{1}\left[\begin{array}{c}\text { Output Parameter } \\ \text { For } V_{H}\end{array}\right]+C_{2}$

\begin{tabular}{|c|c|c|c|c|c|c|c|}
\hline \multicolumn{3}{|c|}{$\begin{array}{l}\text { Values of 0ther } \\
\text { Input Parameters }\end{array}$} & \multicolumn{2}{|c|}{ Output Parameters } & \multicolumn{2}{|c|}{$\begin{array}{l}\text { Regression } \\
\text { Coefficients }\end{array}$} & \multirow[t]{2}{*}{$\begin{array}{l}\text { Correlation } \\
\text { Coefficient }\end{array}$} \\
\hline eadform & Surface & Site & $V_{L}$ & $V_{H}$ & $c_{1}$ & $c_{2}$ & \\
\hline \multirow[t]{4}{*}{$M$} & $H$ & T & SI & SI & .589 & -7 & .91 \\
\hline & & & $A_{\max }$ & $A_{\max }$ & .60 & 27 & .80 \\
\hline & & & SI & $A_{\max }$ & 6.02 & -328 & .87 \\
\hline & & & $A_{\max }$ & SI & .057 & 60.1 & .80 \\
\hline \multirow[t]{4}{*}{ M } & S & $T$ & SI & SI & .490 & 113 & .96 \\
\hline & & & $A_{\max }$ & $A_{\max }$ & .68 & 10.5 & .96 \\
\hline & & & SI & $A_{\max }$ & 6.25 & -400 & .97 \\
\hline & & & $A_{\max }$ & SI & .052 & 68.2 & .93 \\
\hline \multirow[t]{4}{*}{ M } & $H$ & B & SI & SI & .592 & 25 & .78 \\
\hline & & & $A_{\max }$ & $A_{\max }$ & .707 & 26 & .84 \\
\hline & & & SI & $A_{\max }$ & & -546 & .64 \\
\hline & & & $A_{\max }$ & SI & .044 & 116 & .79 \\
\hline \multirow[t]{4}{*}{ M } & $S$ & B & SI & SI & .259 & 546 & .54 \\
\hline & & & $A_{\max }$ & $A_{\max }$ & .351 & 89.0 & .49 \\
\hline & & & SI & $A_{\max }$ & 1.60 & 734 & .22 \\
\hline & & & $A_{\max }$ & SI & .025 & 122.4 & .49 \\
\hline
\end{tabular}


TABLE 10. Relation Between Early Impacts and Limitina Average

\begin{tabular}{|c|c|c|c|c|c|}
\hline & 1st Drop & 2nd Drop & 3rd Drop & $\begin{array}{l}\text { Average of } \\
\text { lst } 3 \text { Drops }\end{array}$ & $\begin{array}{l}\text { Limiting } \\
\text { Average }\end{array}$ \\
\hline Helmet & $\mathrm{SI}_{1}$ & $\mathrm{SI}_{2}$ & $\mathrm{SI}_{3}$ & $\overline{\text { SI }}$ & SI \\
\hline$A F-2$ & 652 & 661 & 670 & 661 & 671 \\
\hline AP-2 & 502 & 744 & 795 & 680 & 790 \\
\hline AT-2 & 645 & 886 & 977 & 836 & 1099 \\
\hline$B C-2$ & 514 & 662 & 662 & 613 & 751 \\
\hline$B P-2$ & 1043 & 1299 & 1308 & 1217 & 1421 \\
\hline BT-2 & 515 & 559 & 574 & 549 & 571 \\
\hline $\mathrm{CH}-2$ & 596 & 671 & 670 & 646 & 693 \\
\hline$C P-2$ & 481 & 487 & 488 & 485 & 503 \\
\hline CS-2 & 697 & 741 & 759 & 732 & 787 \\
\hline$D C-2$ & 714 & 848 & 888 & 817 & 873 \\
\hline $\mathrm{DH}-2$ & 492 & 466 & 477 & 478 & 478 \\
\hline DS-2 & 491 & 567 & 568 & 542 & 568 \\
\hline
\end{tabular}

B. Regression and Correlation Coefficients

$$
\begin{array}{ccrrc}
y=c_{1} x+c_{2} & & & \\
y & x & c_{1} & c_{2} & \text { Correlation Coefficient } \\
\hline \mathrm{SI}_{1} & \mathrm{SI} & .52 & 213 & .87 \\
\mathrm{SI}_{2} & \mathrm{SI} & .82 & 85 & .98 \\
\mathrm{SI}_{3} & \mathrm{SI} & .87 & 72 & .99 \\
\overline{\mathrm{SI}} & \mathrm{SI} & .74 & 123 & .98
\end{array}
$$


TABLE 11. Comparison Data Between NOCSAE and ASTM Recommended Test Methods

A. Data, from Ref. 16/

\begin{tabular}{|c|cc|c|cc|c|}
\hline \multirow{2}{*}{ Site } & \multicolumn{3}{|c|}{ Top } & \multicolumn{3}{c|}{ Back } \\
\hline Test Method & \multicolumn{2}{|c|}{ NOCSAE } & ASTM & NOCSAE & ASTM \\
\hline Output & SI $_{N}$ & $A_{\operatorname{maxN}}$ & $A_{\operatorname{maxA}}$ & SI $_{N}$ & $A_{\operatorname{maxN}}$ & $A_{\operatorname{maxA}}$ \\
\hline A11 & 704 & 113 & 134 & 796 & 138 & 120 \\
C33 & 783 & 120 & 102 & 757 & 132 & 190 \\
D10 & 1116 & 168 & 184 & 1017 & 174 & 192 \\
G501 & 743 & 118 & 148 & 919 & 152 & 152 \\
G402 & 638 & 117 & 146 & 701 & 135 & 290 \\
H10 & 742 & 139 & 126 & 1009 & 152 & 224 \\
H11 & 703 & 126 & 116 & 963 & 147 & 238 \\
C10 & 638 & 116 & 104 & 810 & 139 & 320 \\
C11 & 686 & 120 & 108 & 822 & 140 & 320 \\
G20 & 906 & 144 & 212 & 525 & 116 & 290 \\
G21 & 1094 & 166 & 208 & 541 & 105 & 252 \\
\hline \hline
\end{tabular}

B. Regression and Correlation Coefficients

$$
y=c_{1} x+c_{2}
$$

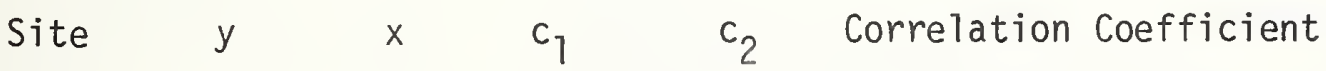

$\begin{array}{llrrrr}\text { Top } & A_{\operatorname{maxN}} & S_{N} & .111 & 43 & .94 \\ \text { Back } & A_{\max } & S_{N} & .101 & 57 & .93 \\ \text { Top } & A_{\max } & S_{N} & .188 & -5 & .79 \\ \text { Back } & A_{\max } & S_{N} & -.143 & 350 & -.36\end{array}$


TABLE 12. Comparison of Metal Headform with "Soft" Headform (Metal Headform Coated with Resilient Material) for Motorcycle Helmets, from Southwest Research Institute 19/

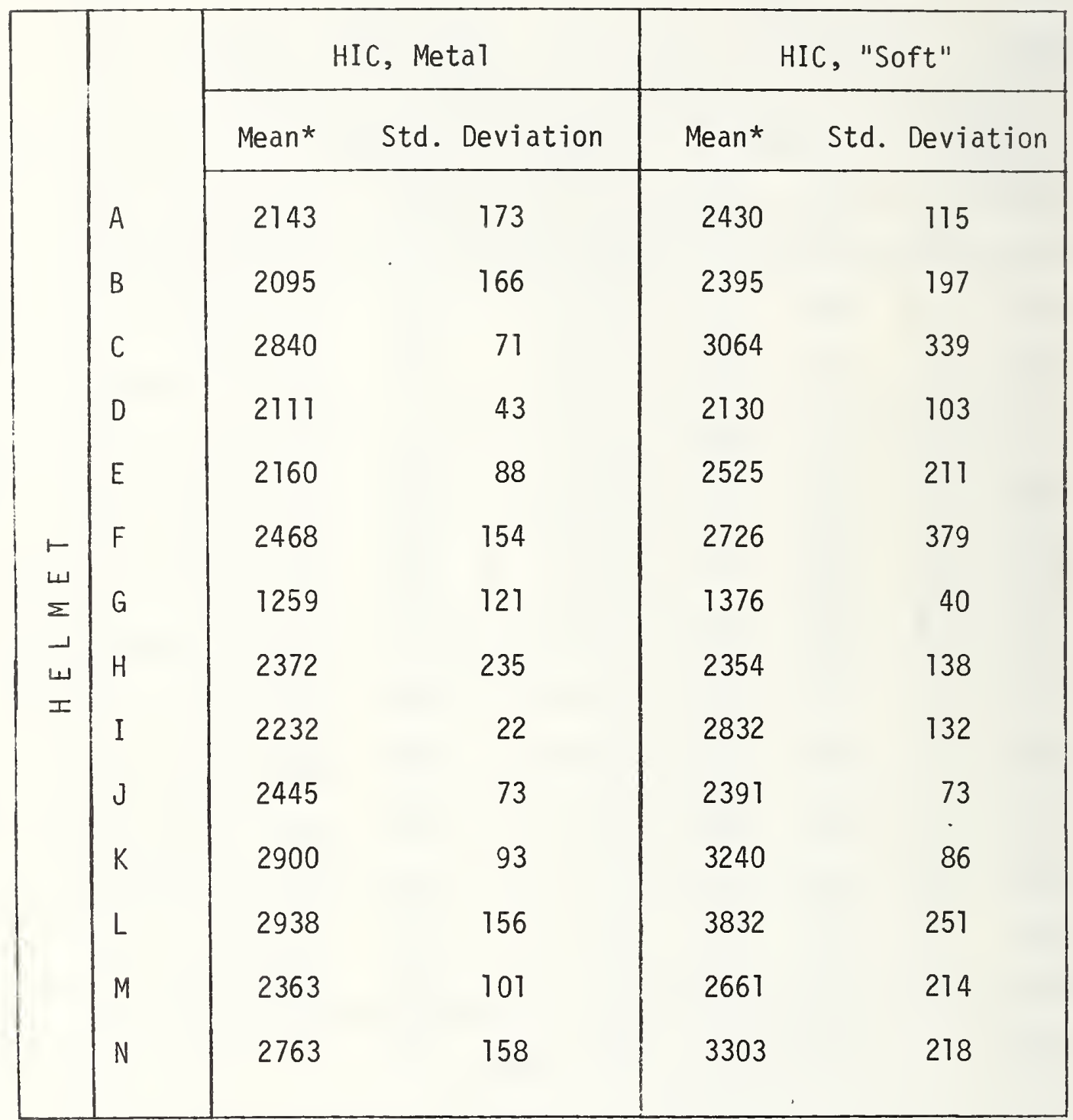

*Average of four helmets, 2nd impact on each, back impact site.

$\mathrm{HIC}($ meta $)=.68 \mathrm{HIC}($ soft $)+556$

correlation coefficient $=.92$ 


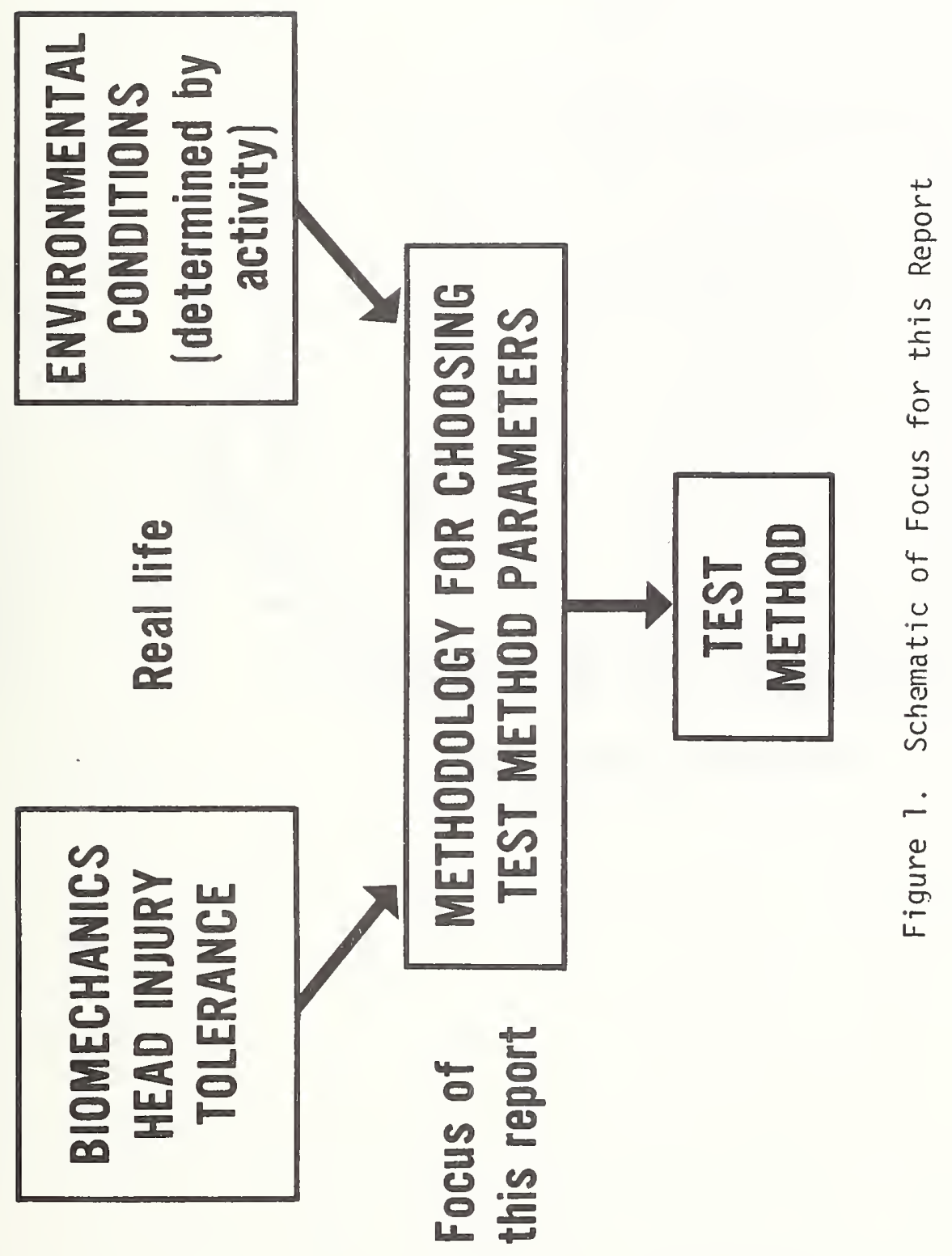




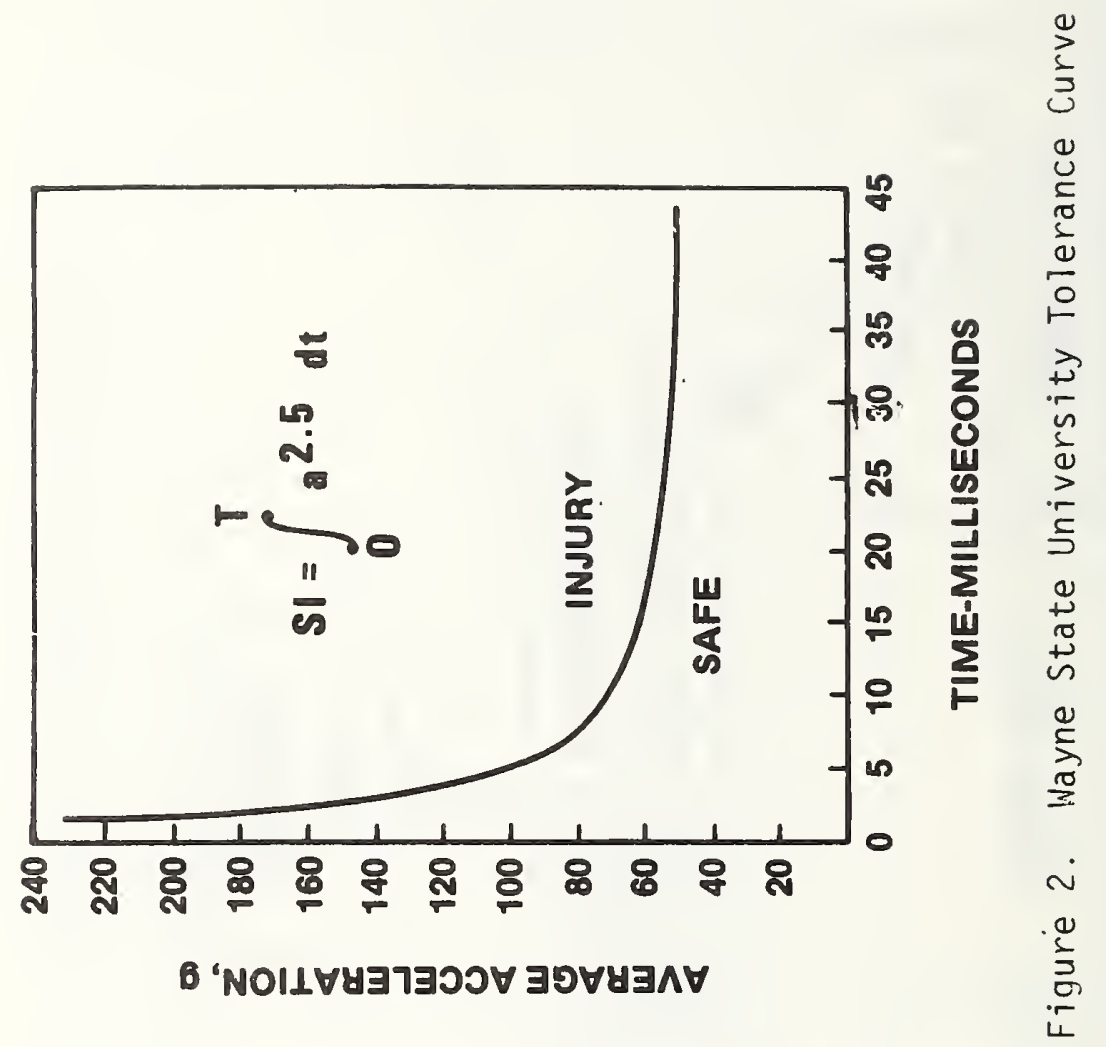




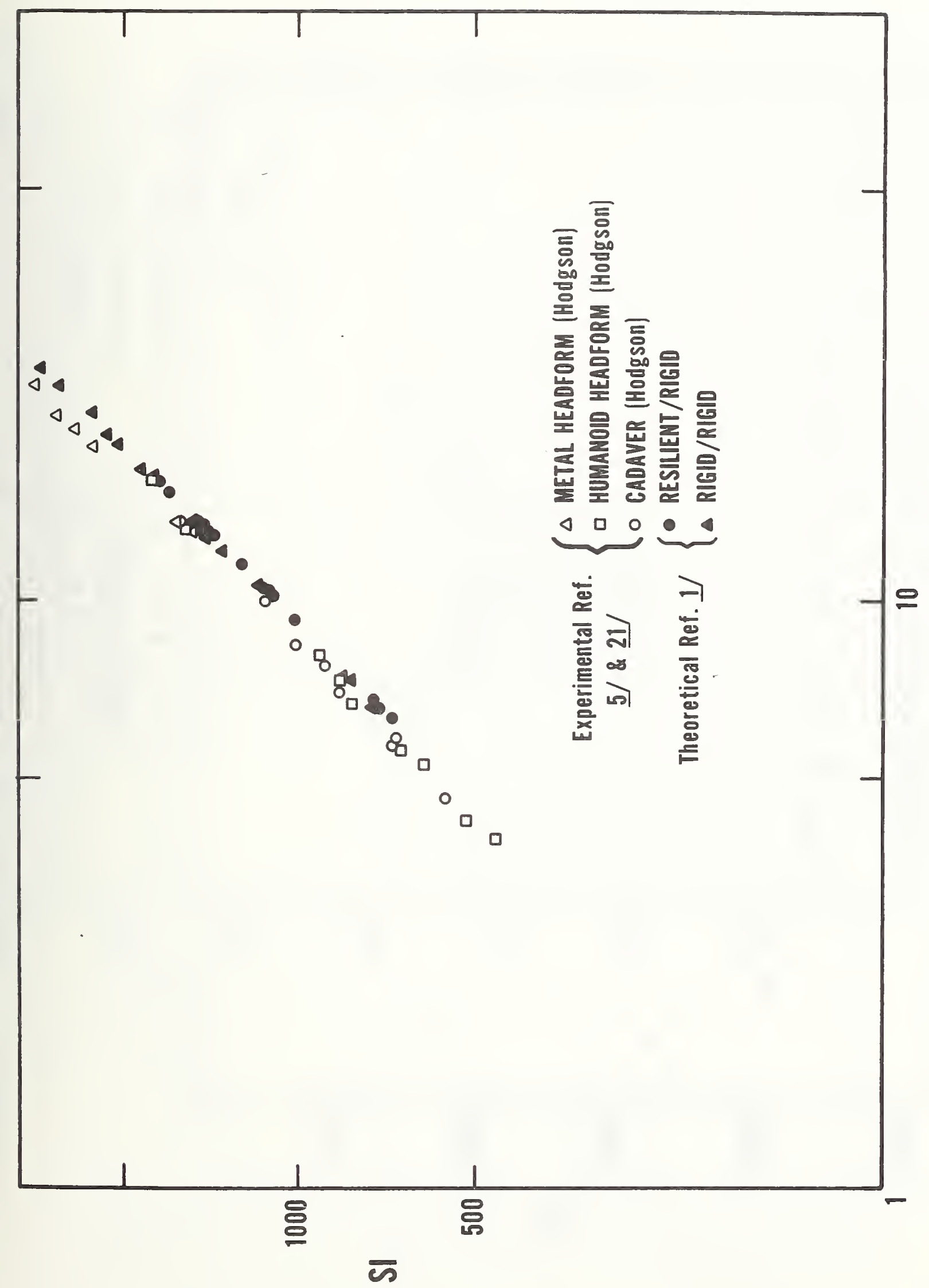




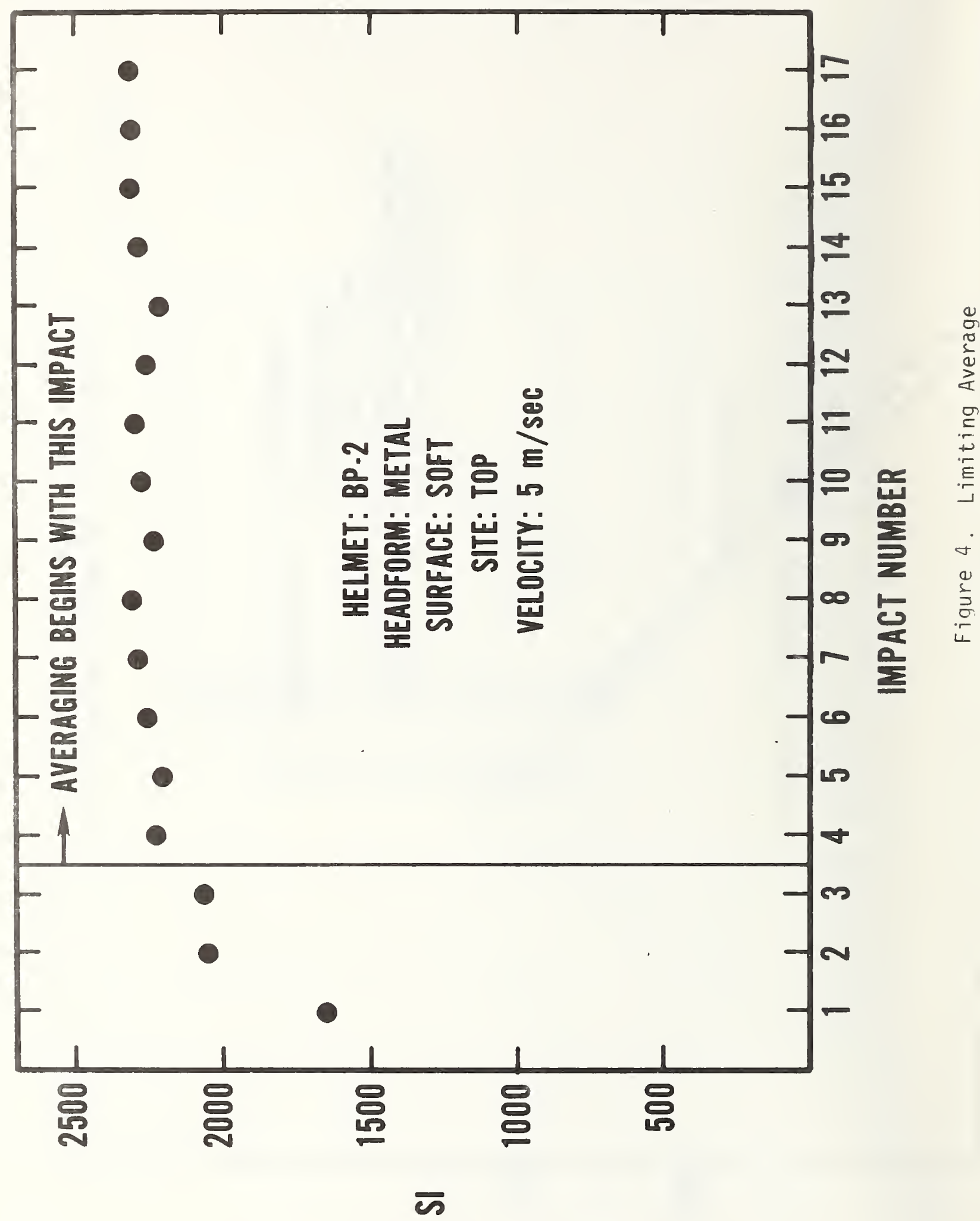




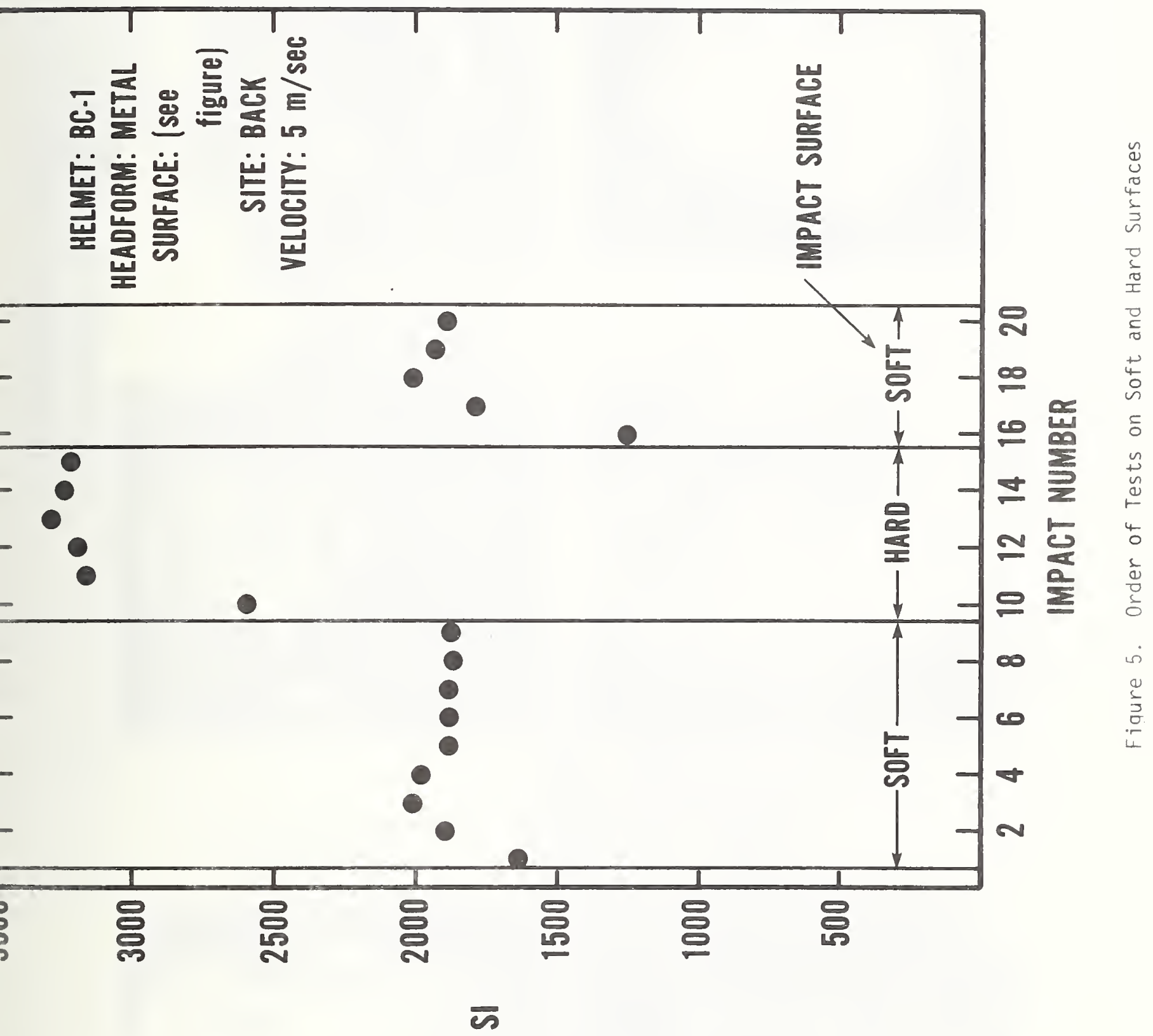




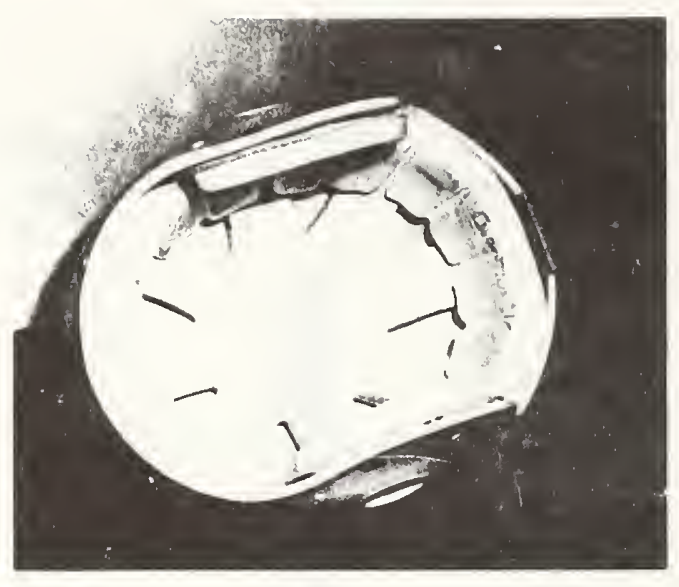

Padded with top padded suspension

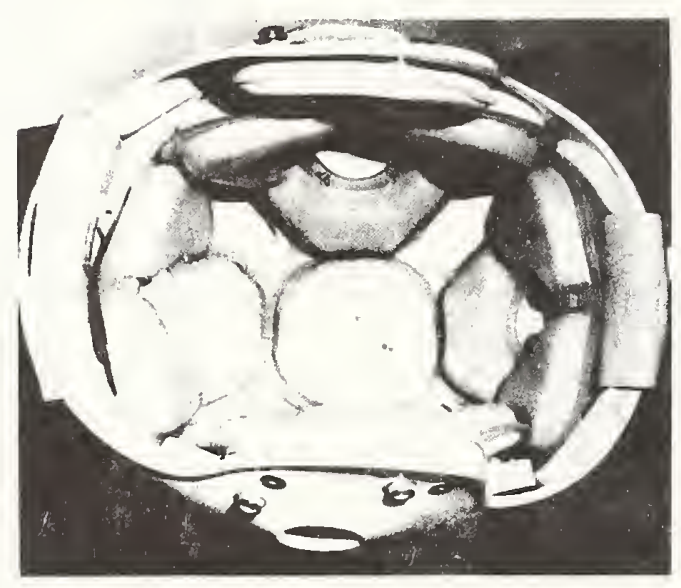

Hydraul ic

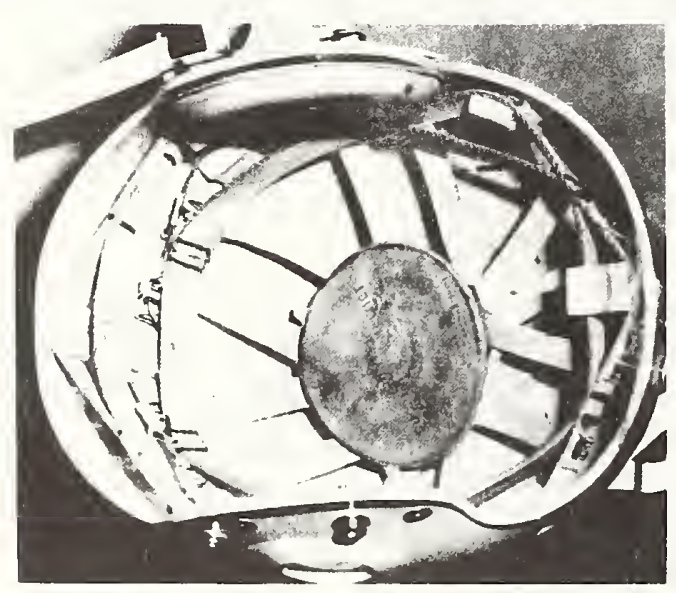

!lebbing suspension

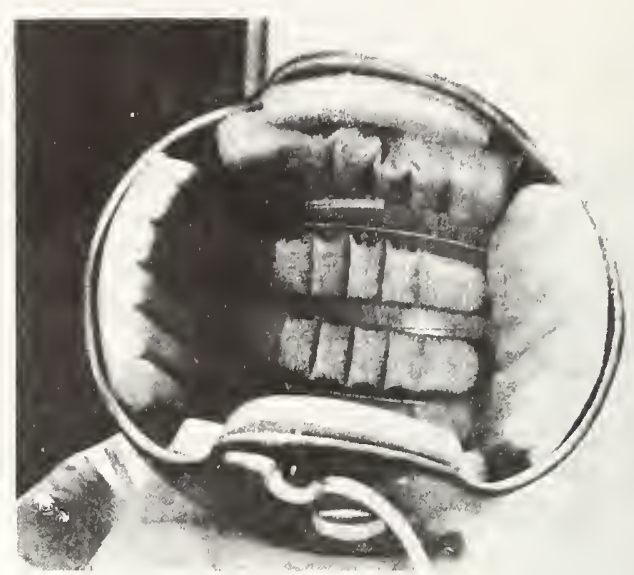

Fully padded

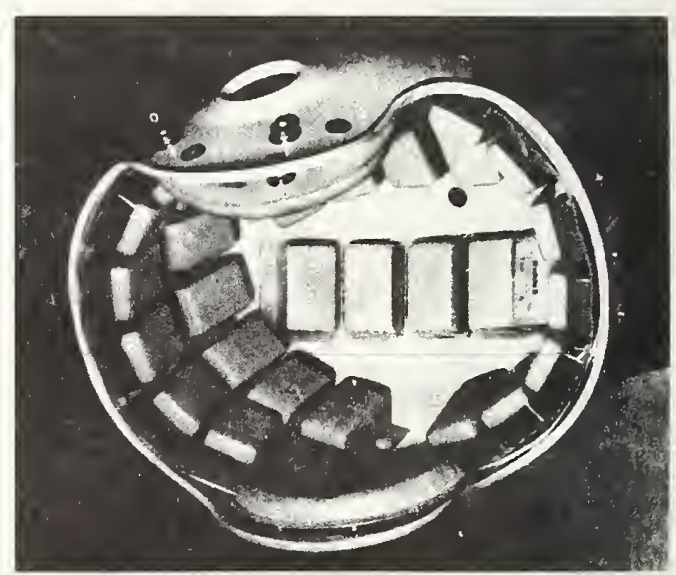

Fully padded with foamed plastic in segregated cells

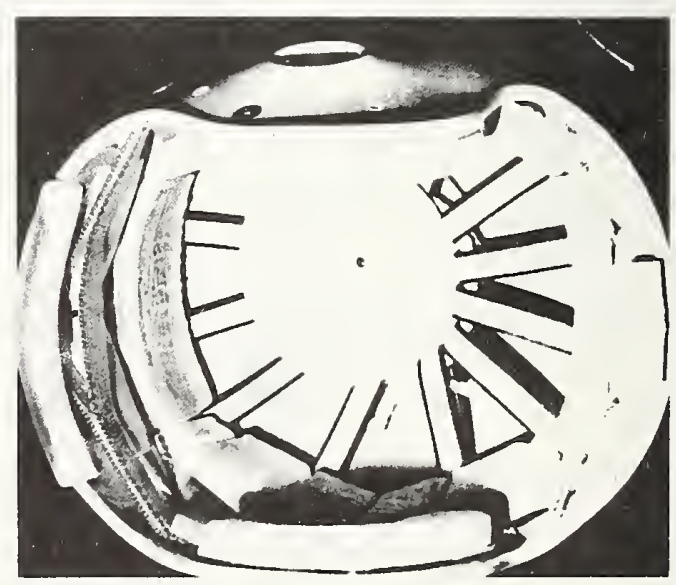

Padded with top webbing suspension 


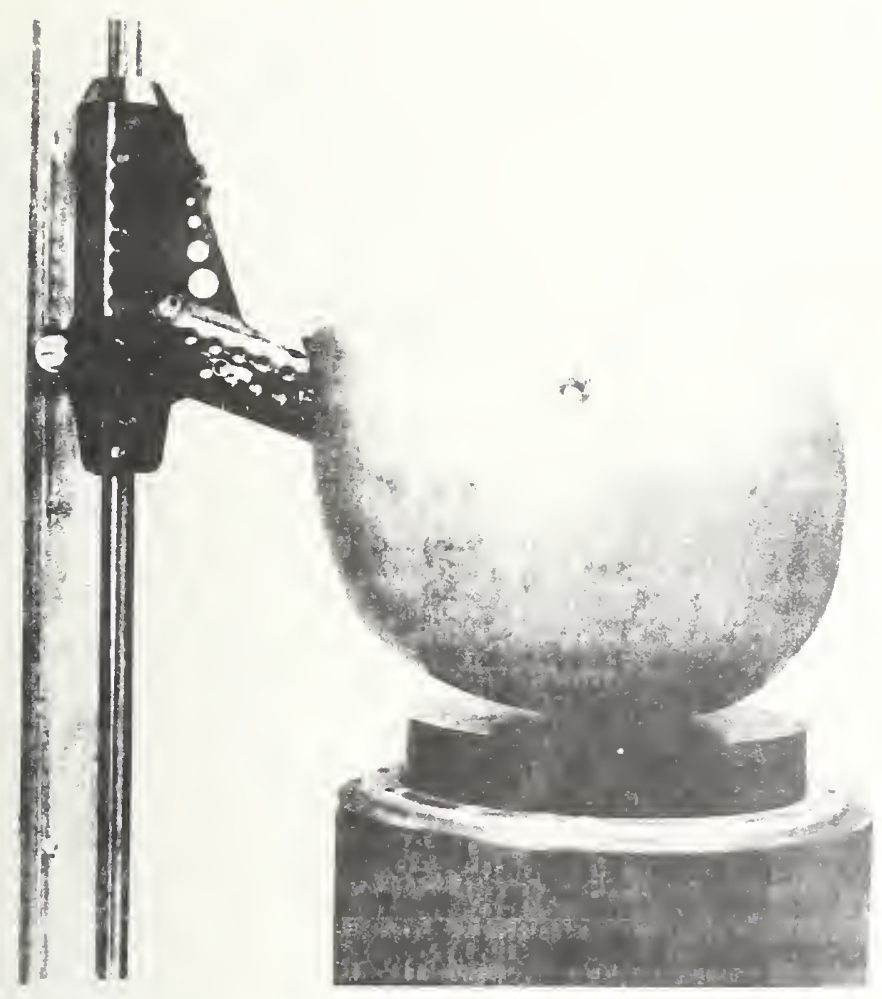

iletal headform with follower

llumanoid headform with follower

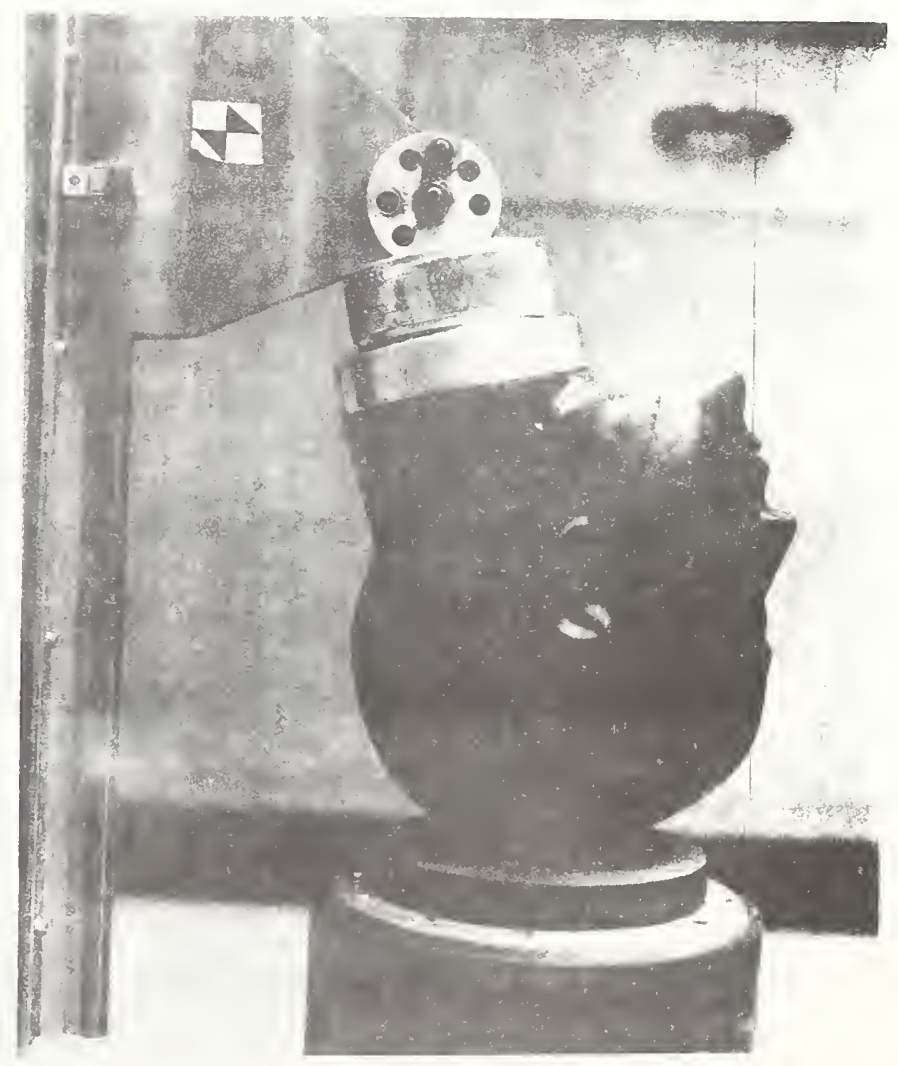

Figure 7. Metal and Humanoid Headforms 


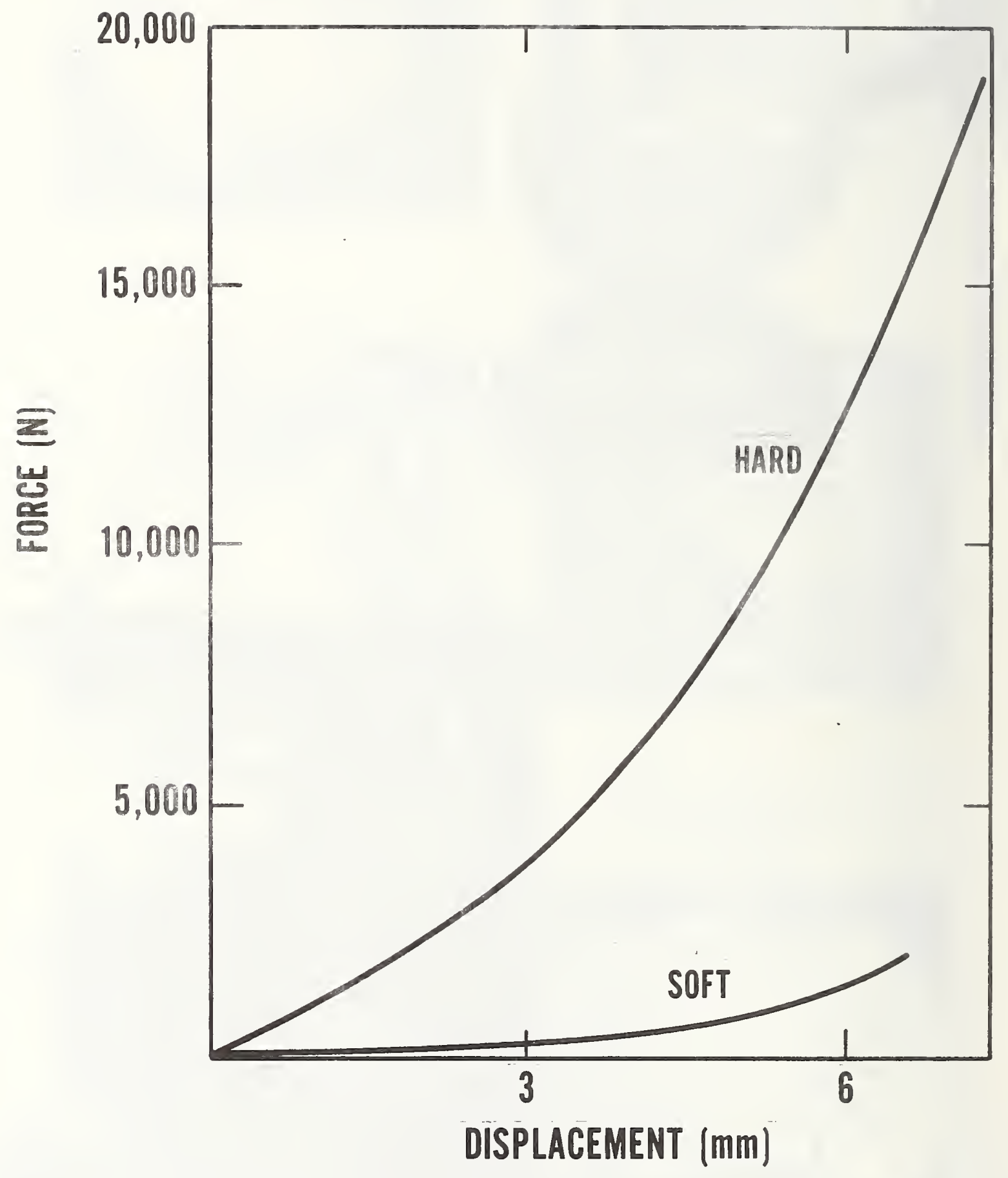

Figure 8. Force - Displacement Curves Hard and Soft Test surfaces 


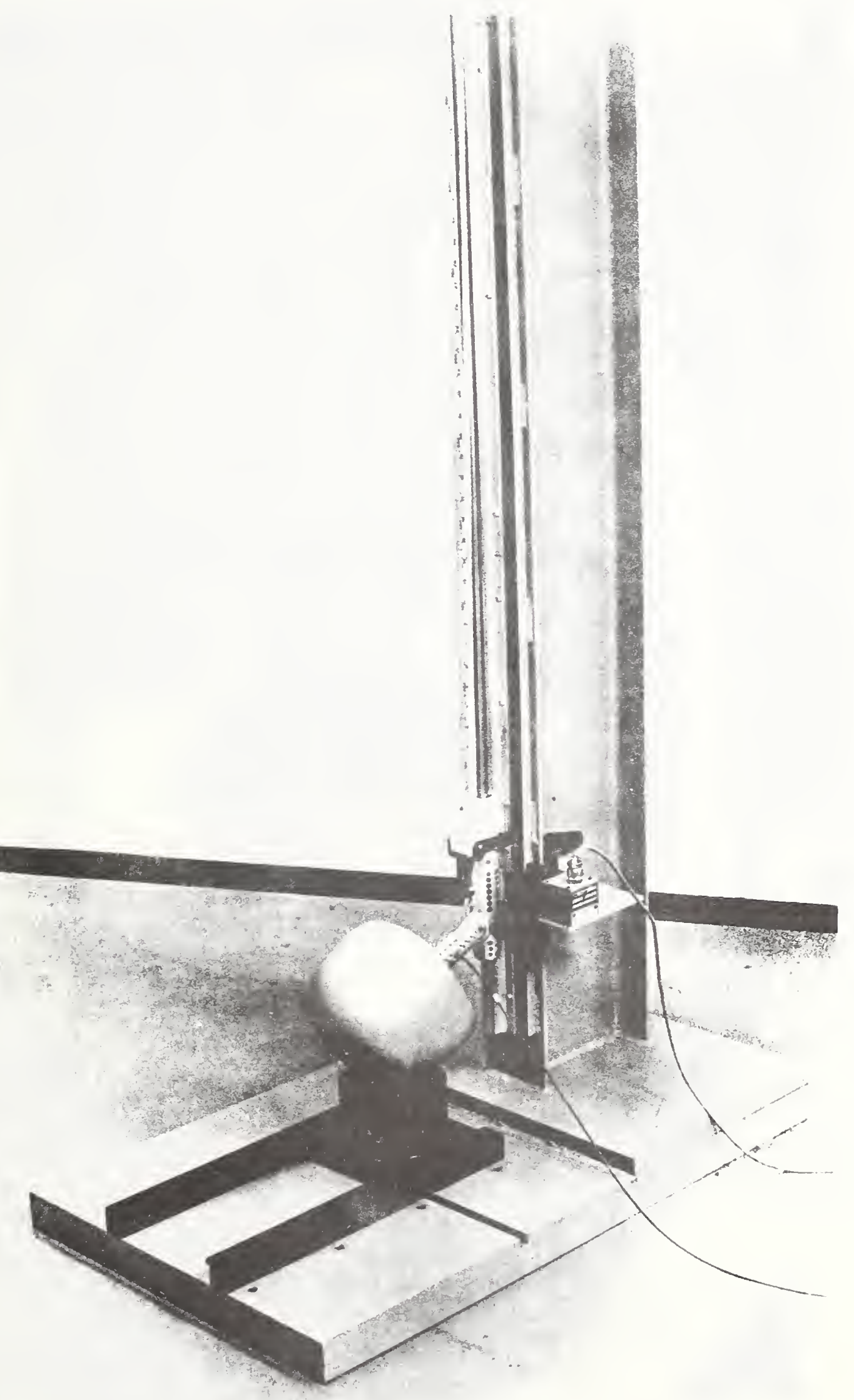

Figure 9. Metal Headform on Monorail 


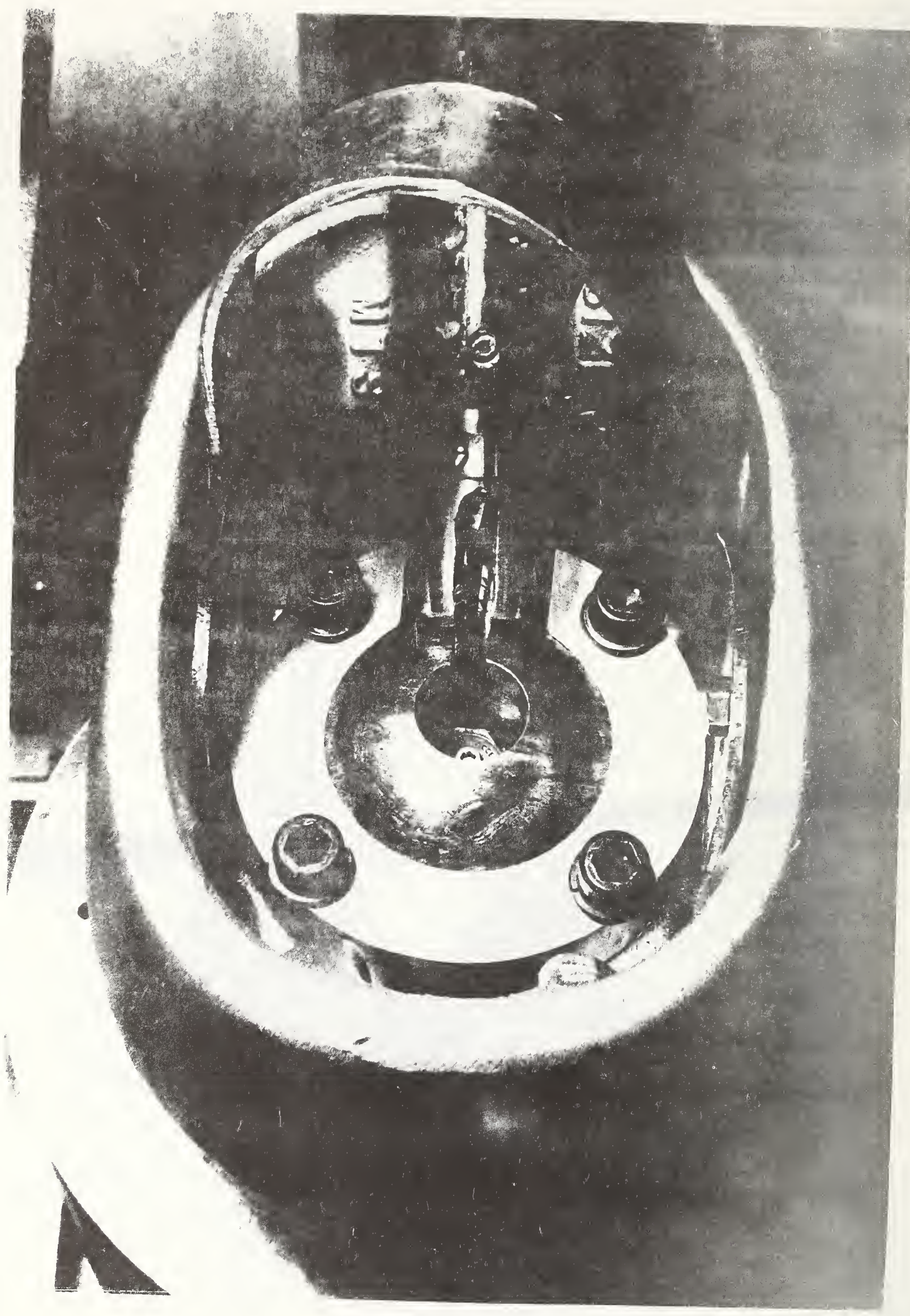

Fiqure 10. Bal1/Socket. In Metal Headform 
HUMANOID HEADFORM

$50 \mathrm{~g} / \mathrm{div}$
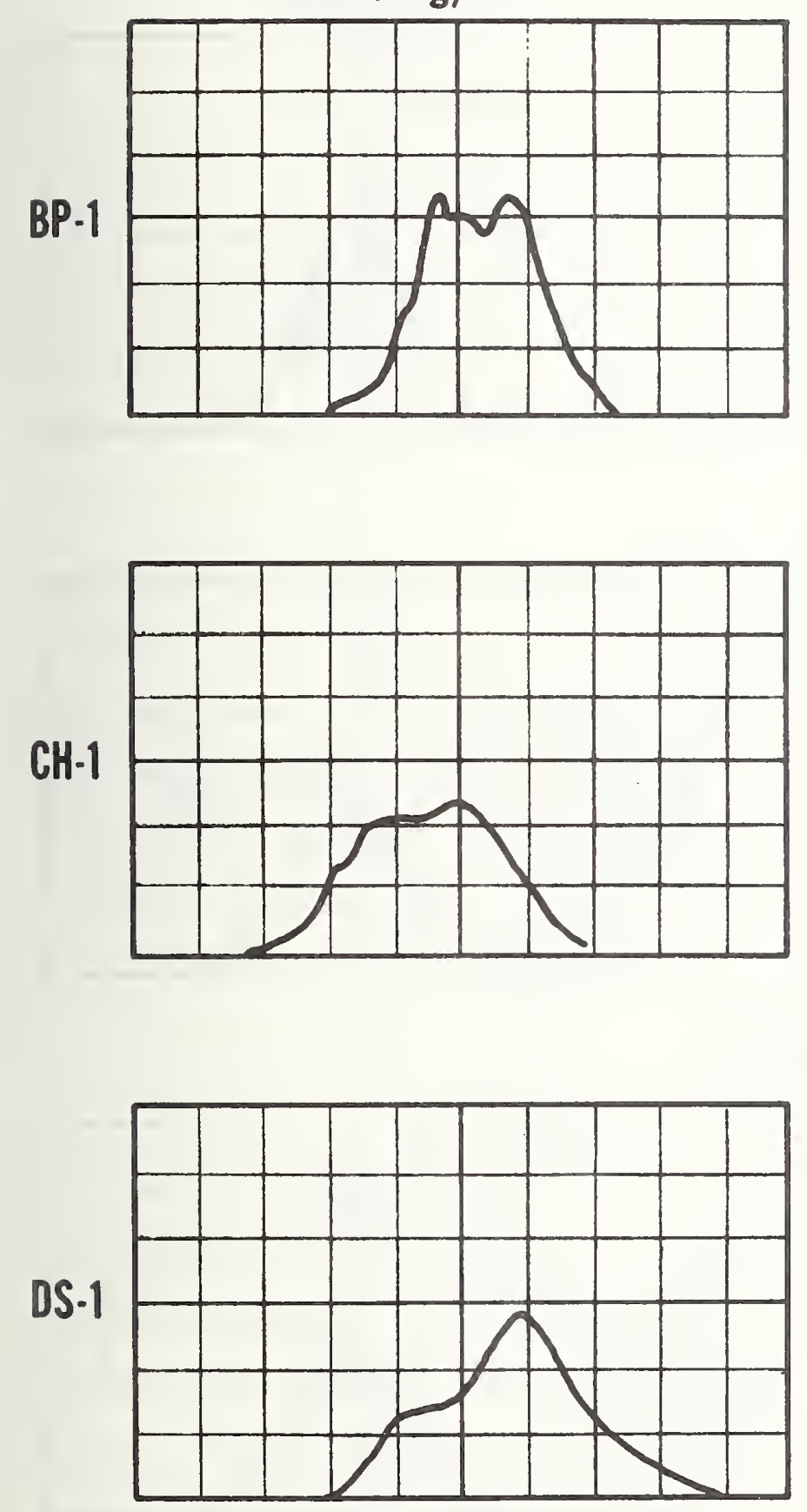

METAL HEADFORM

$60 \mathrm{~g} / \mathrm{div}$
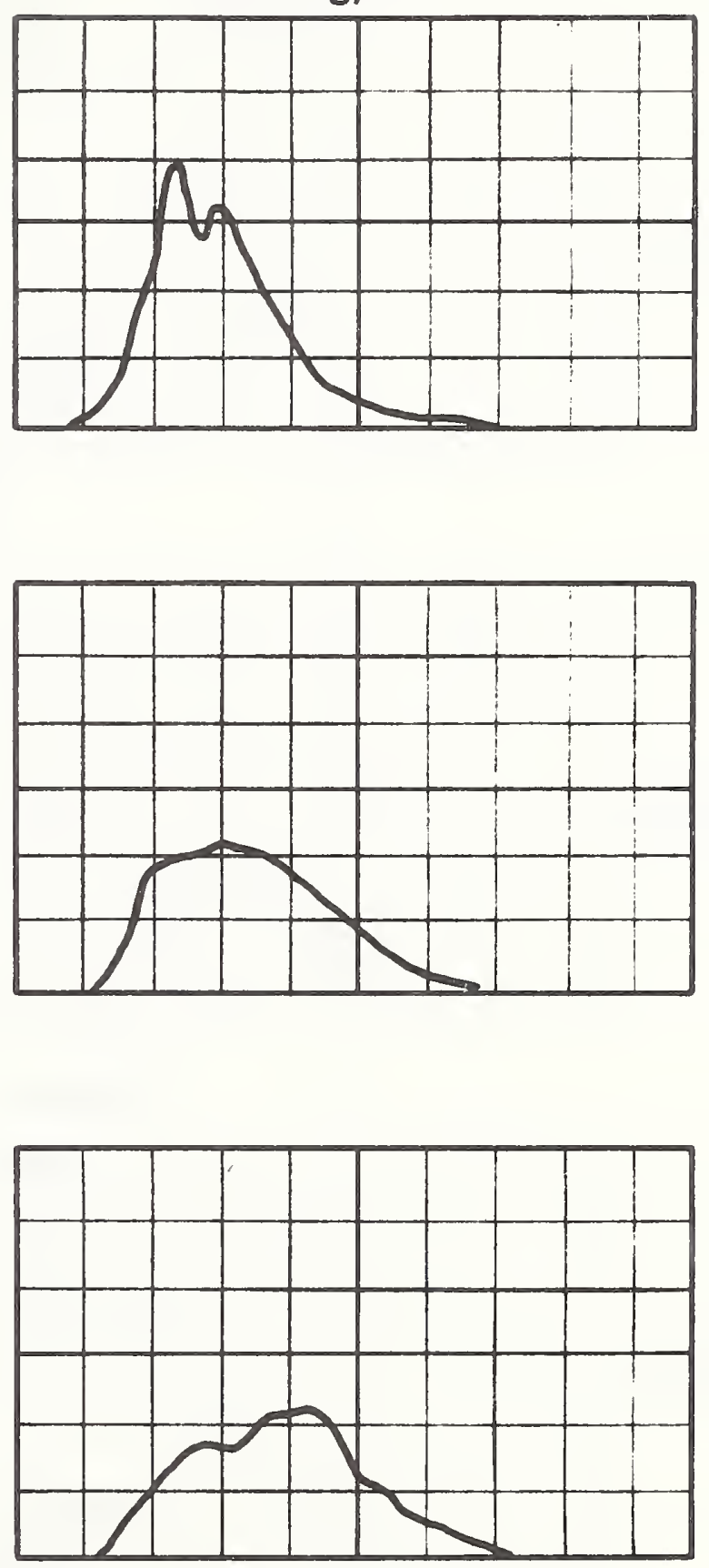

Figure 11. Typical Curves for Humanoid and Metal Headform 
HUMANOID HEADFORM

$50 \mathrm{~g} / \mathrm{div}$

AP. 2

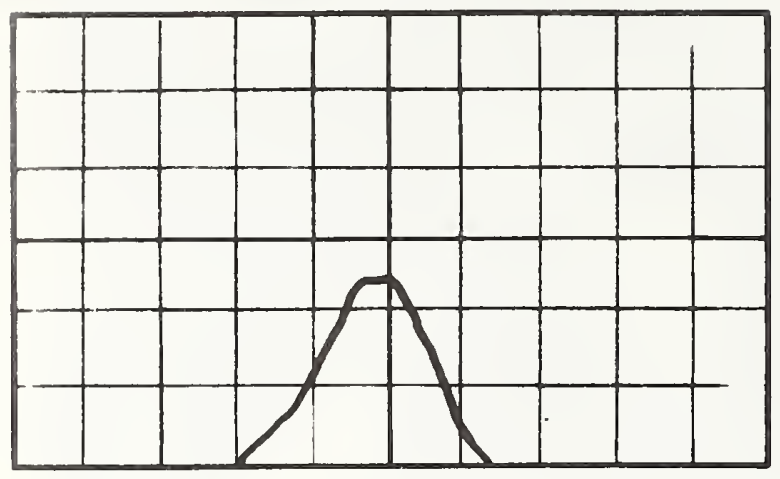

BC-2
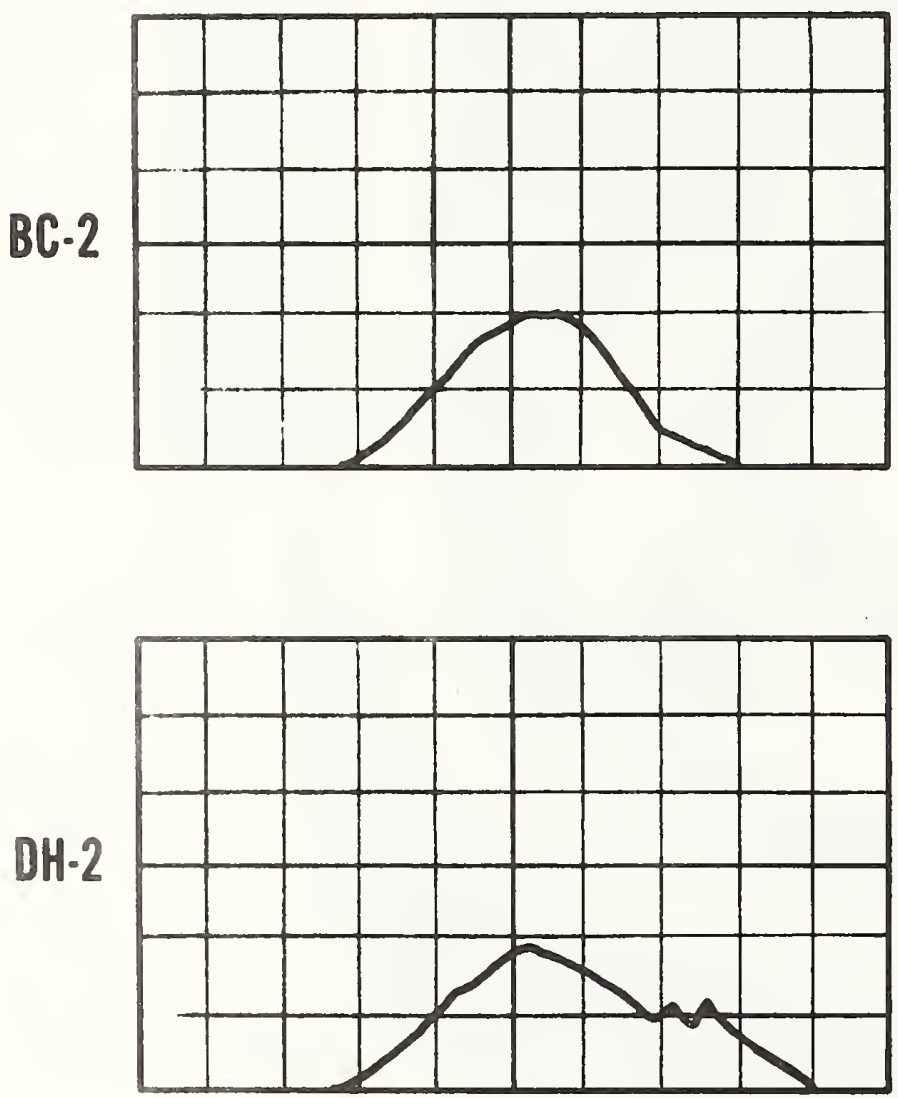

METAL HEADFORM

$60 \mathrm{~g} / \mathrm{div}$
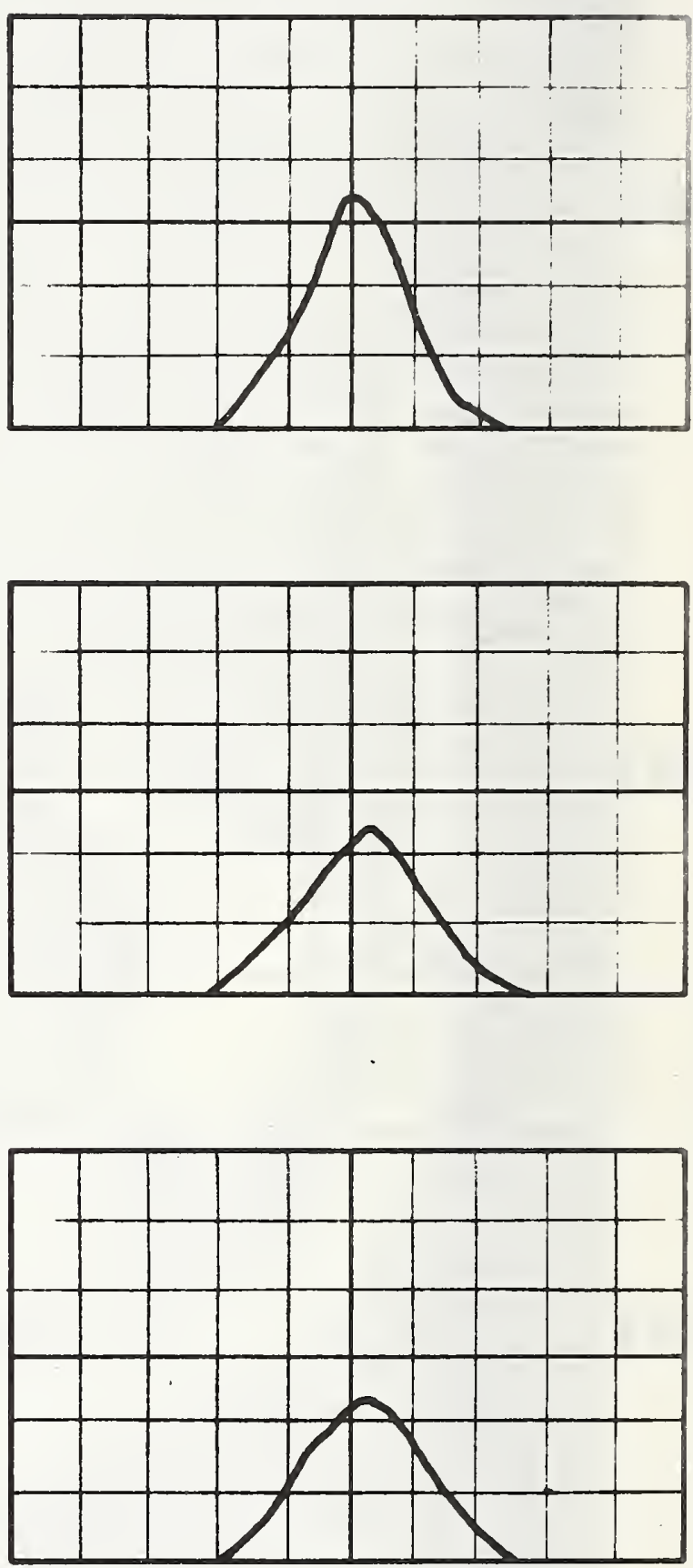

Figure 12. Typical Curves for Humanoid and Metal Headform 


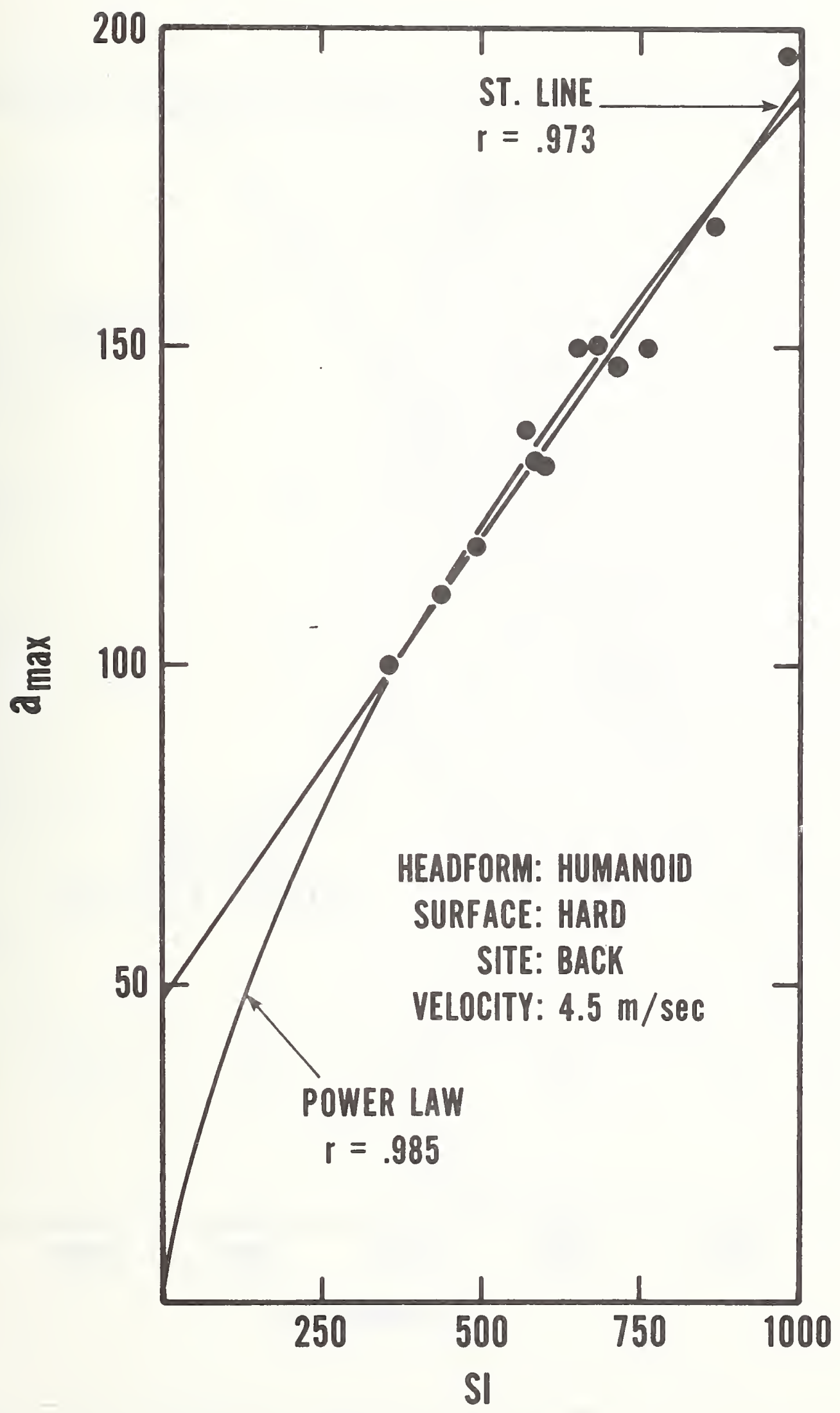

Fiqure 13. Fit of Power Law and Straight Line Curves to Data Points 


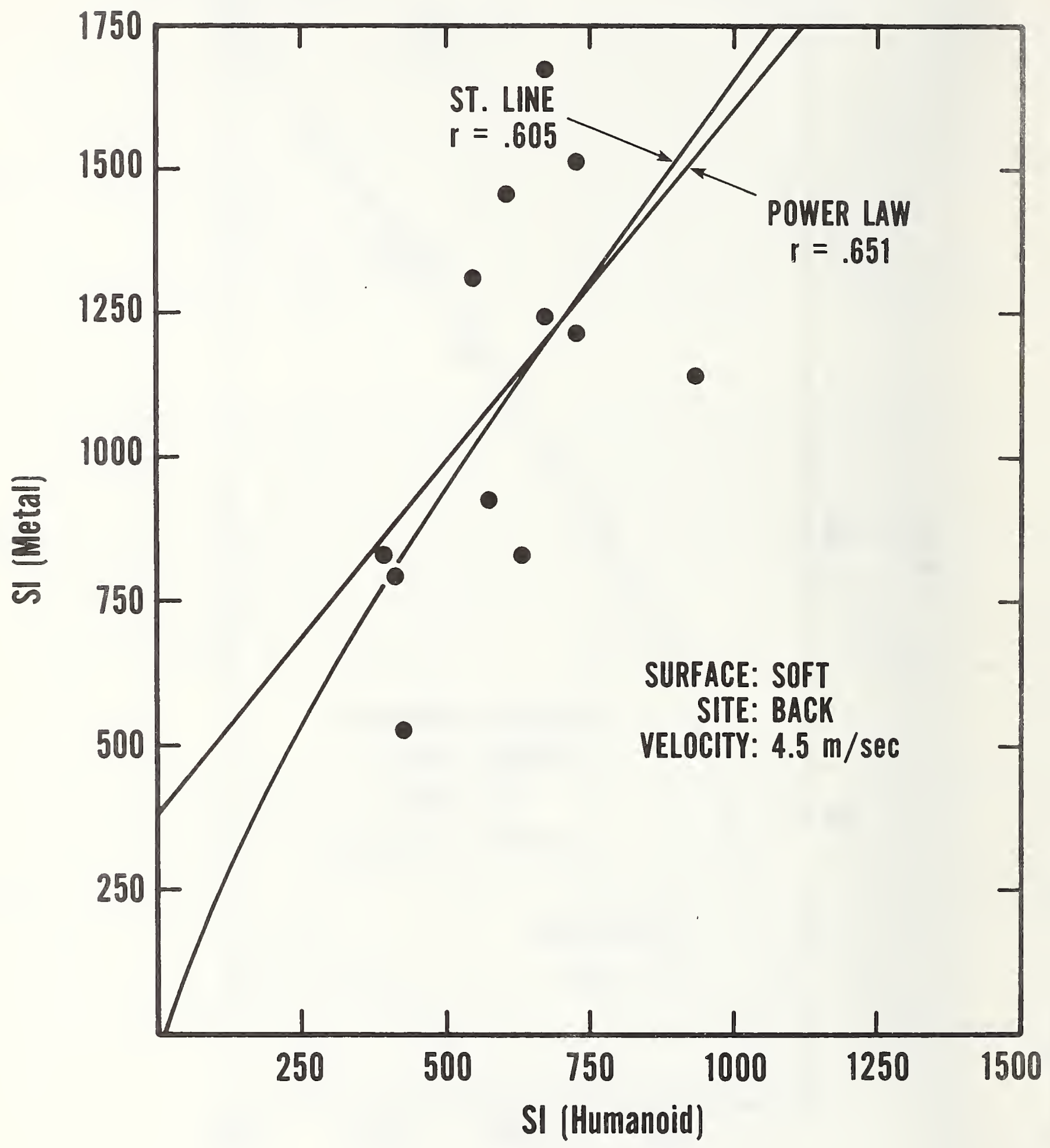

Fiqure 14. Fit of Power Law and Straight Line Curves to Data Points 


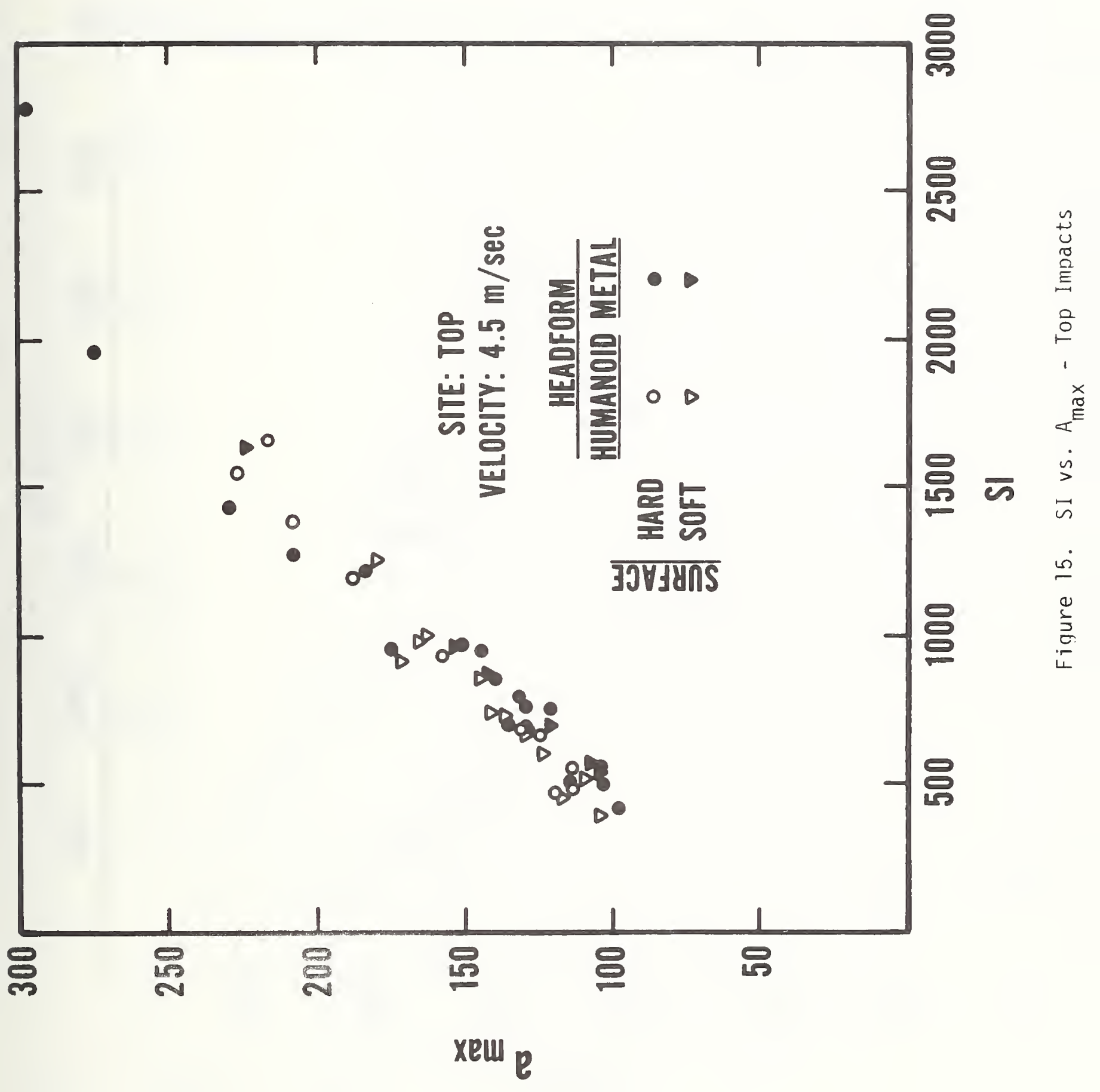




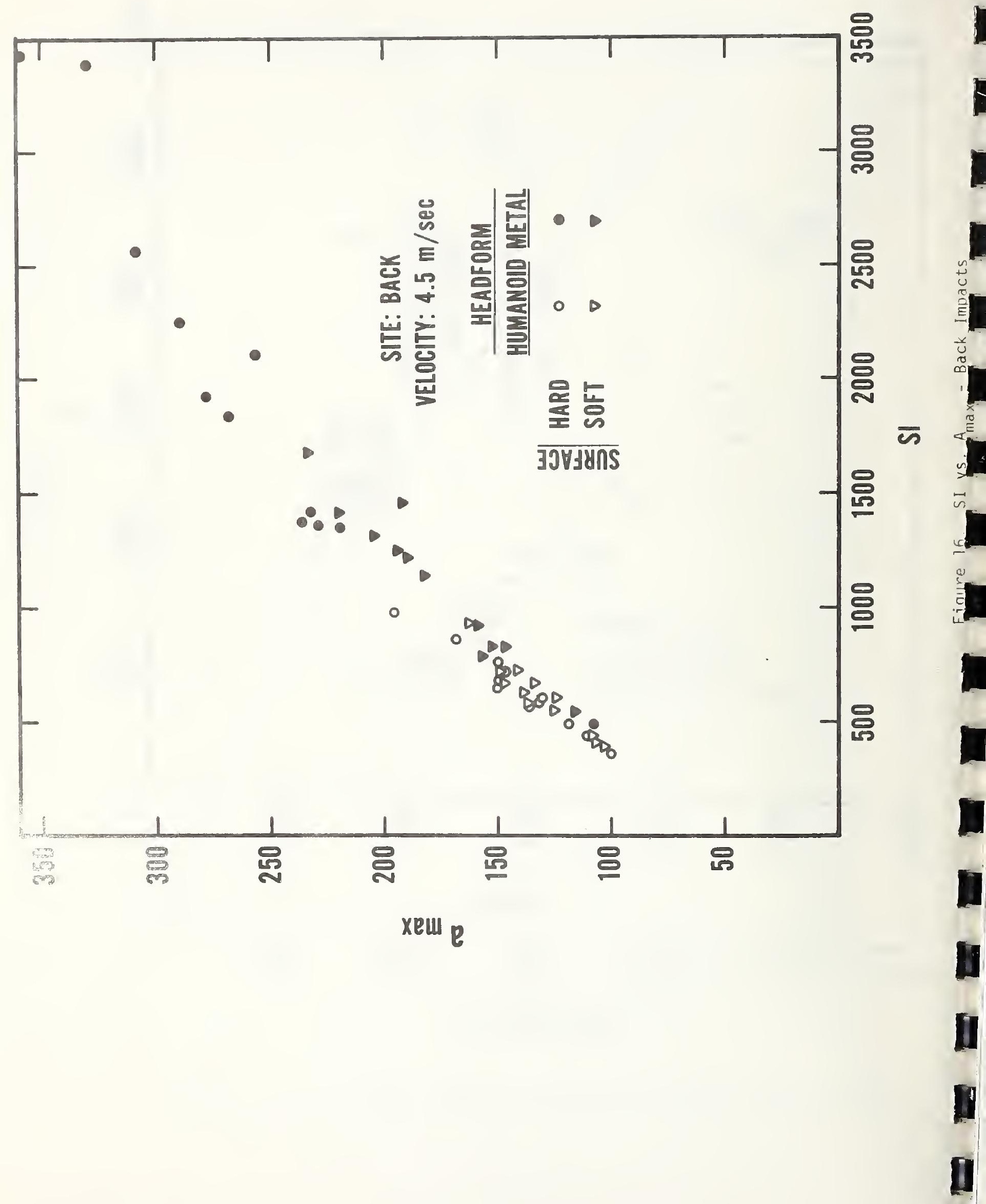




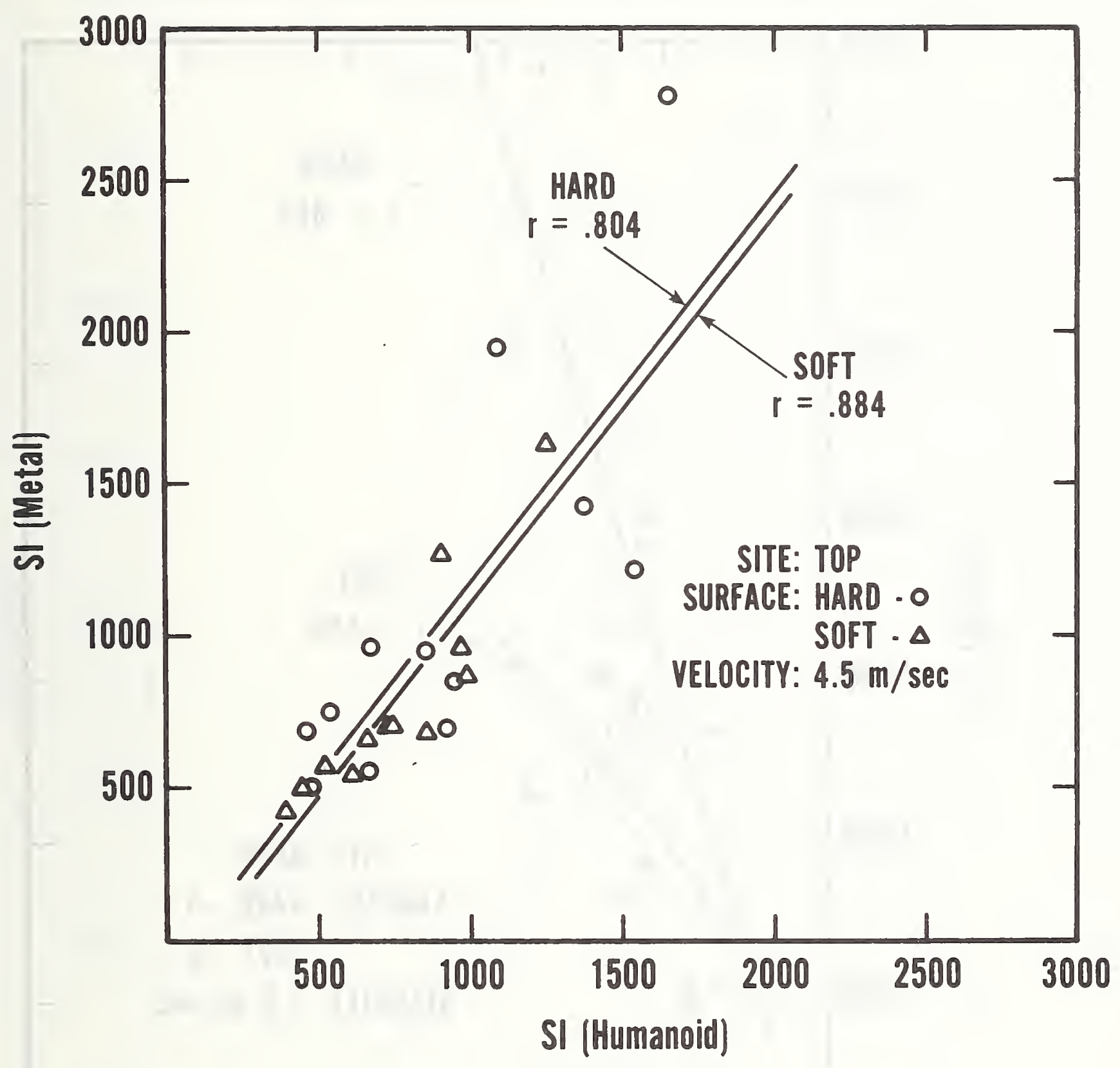

Fiqure 17. Metal vs. Humanoid Headform - Hard and Soft Surfaces - Top Impacts 


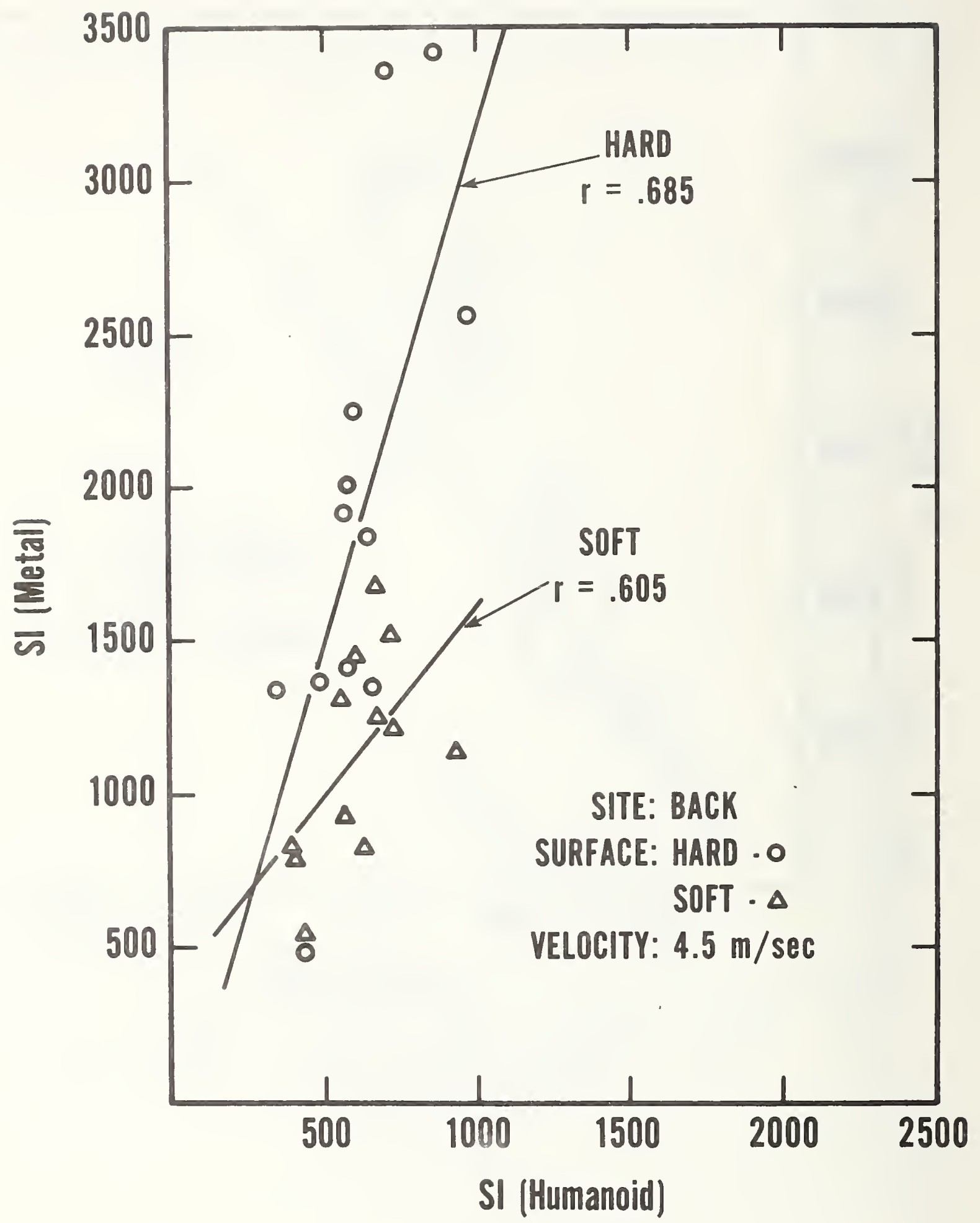

Figure 18. Metal vs. Humanoid Headform - Hard and Soft Surfaces - Back Impact 


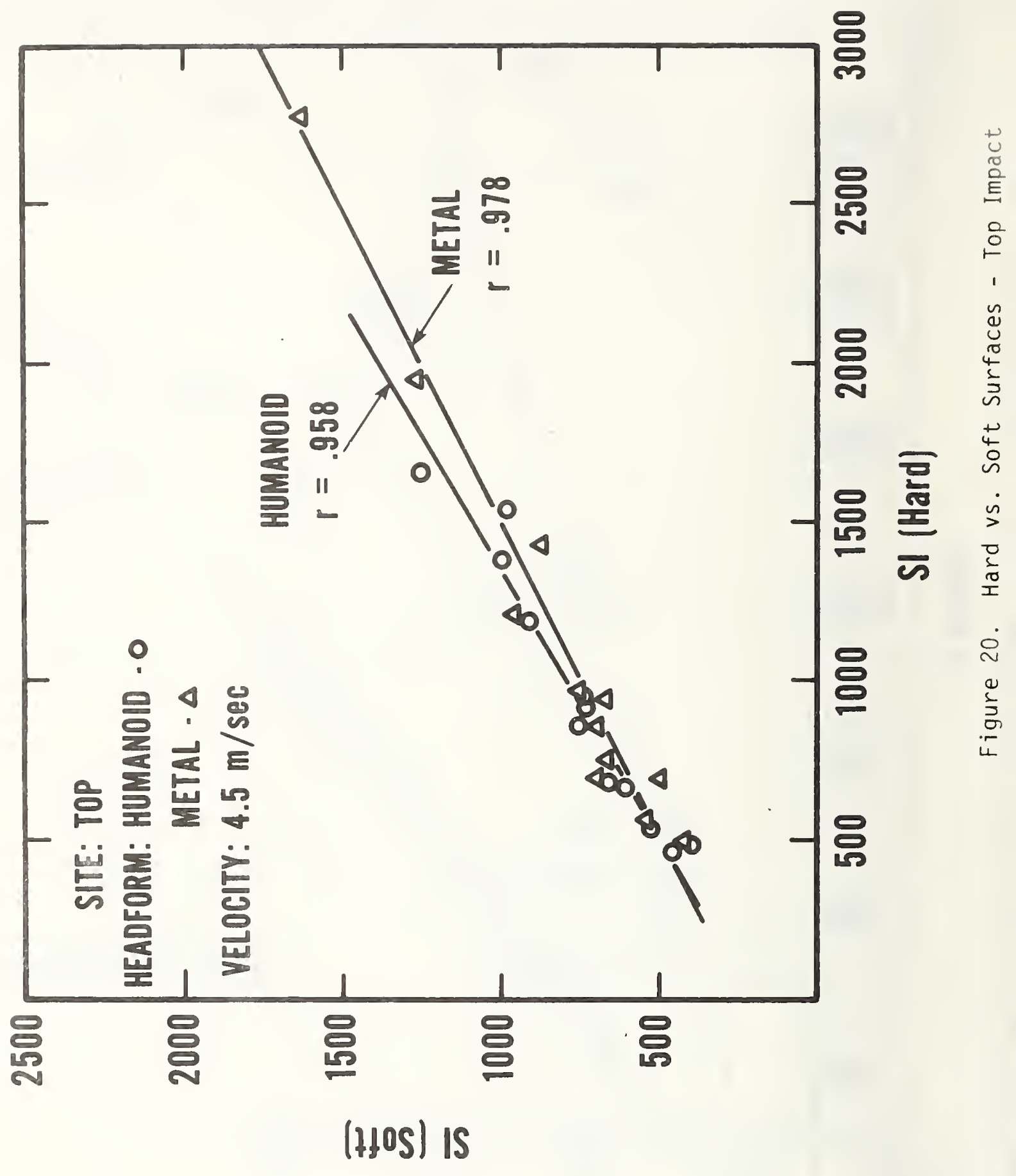




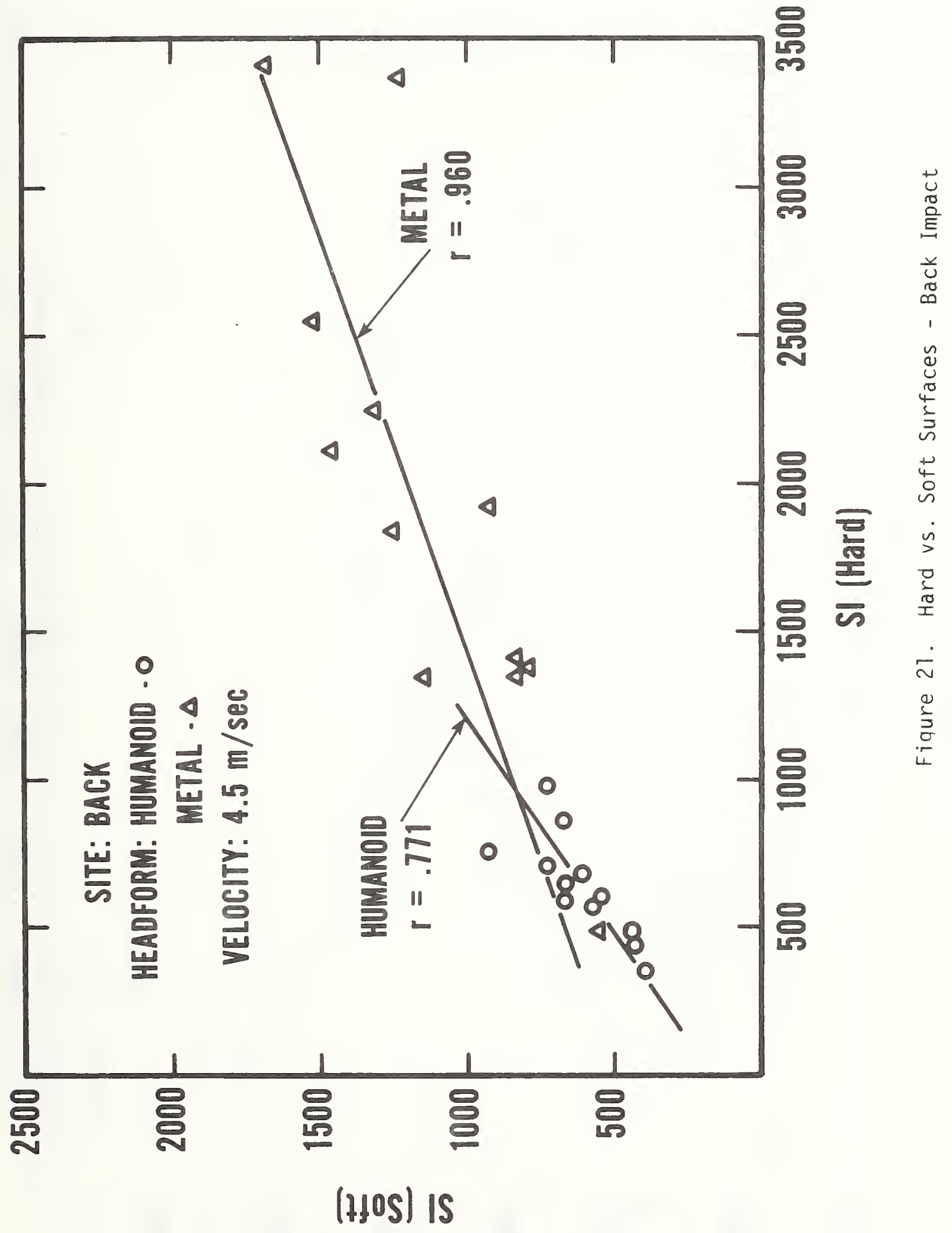




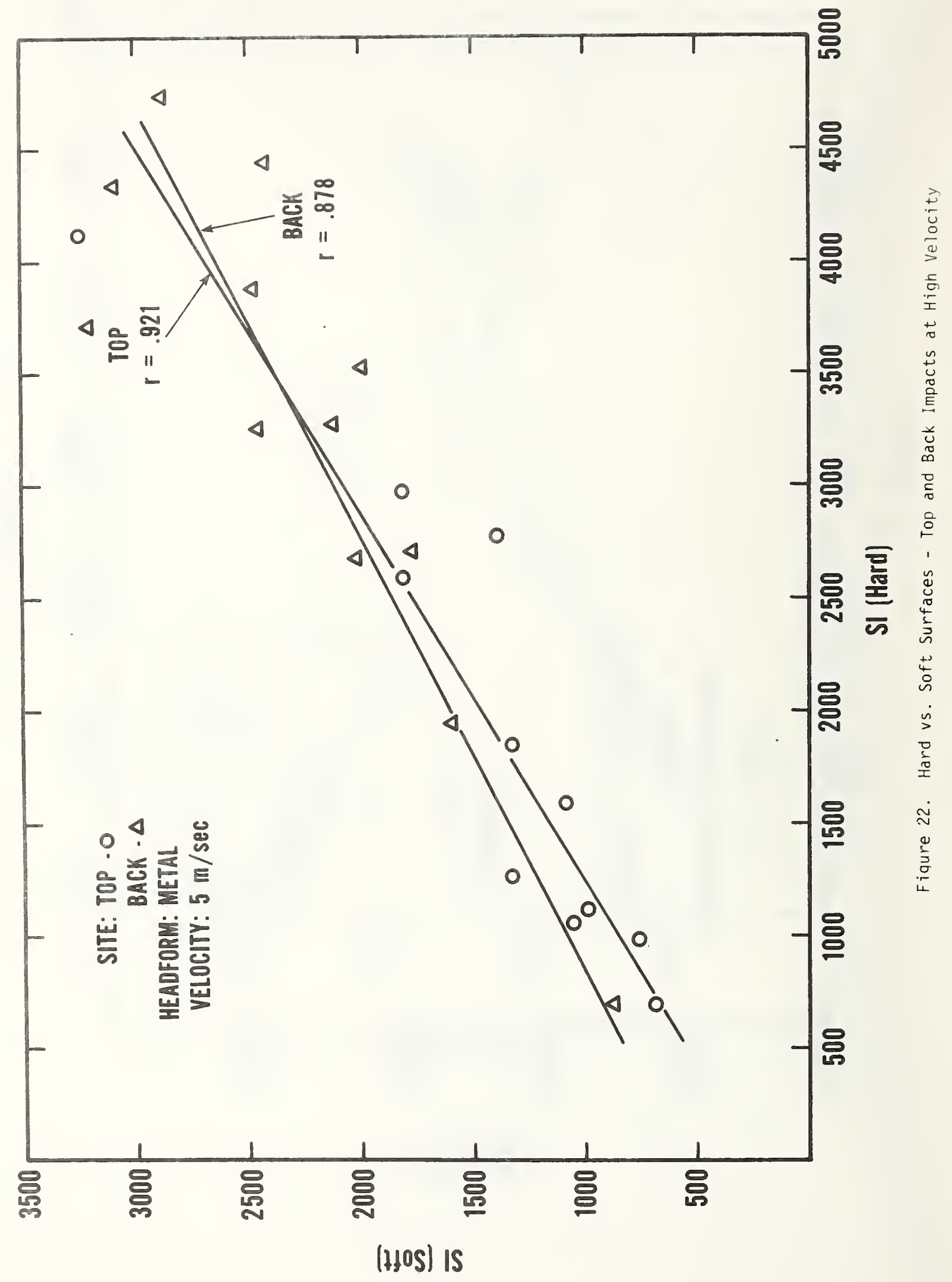




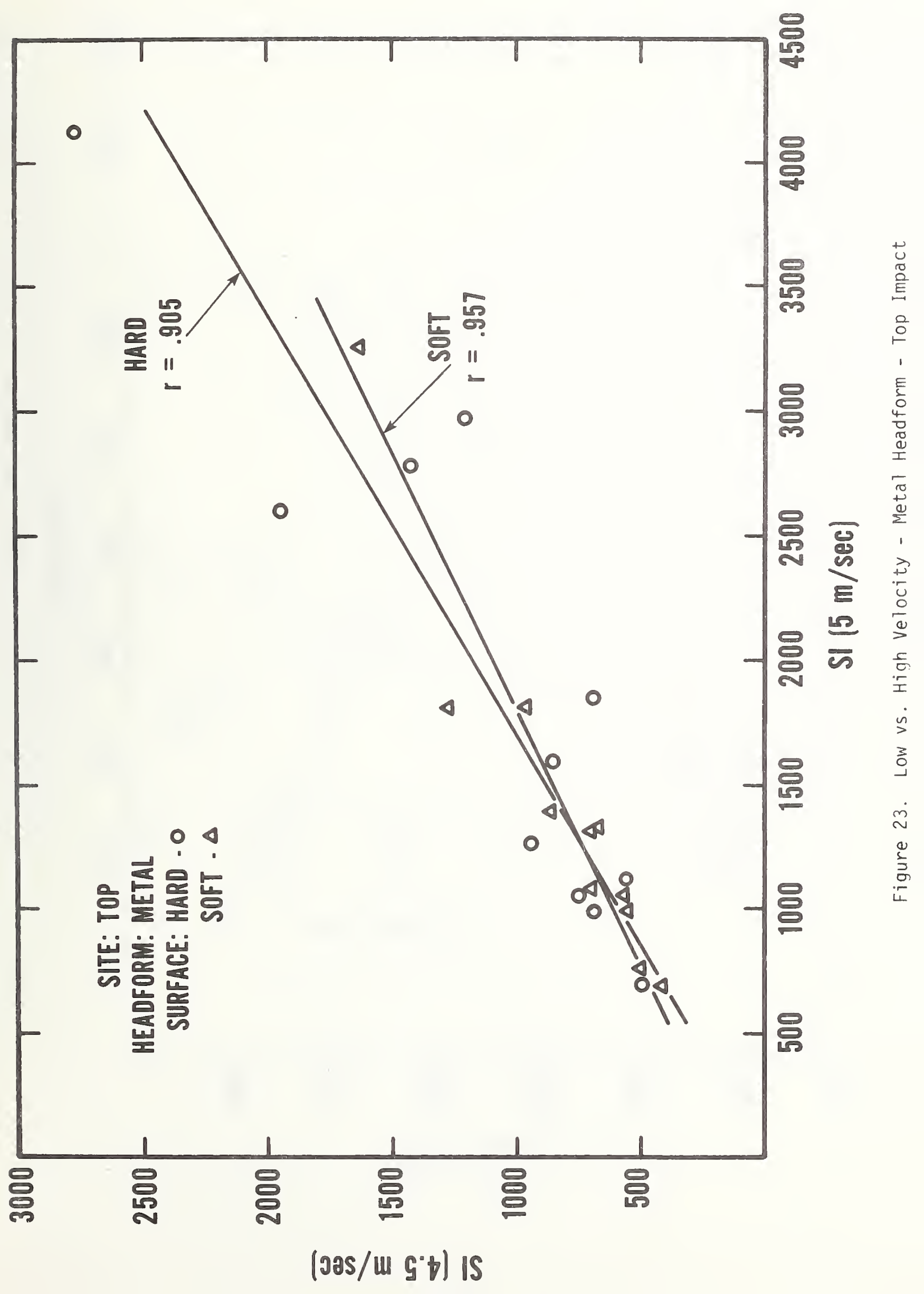




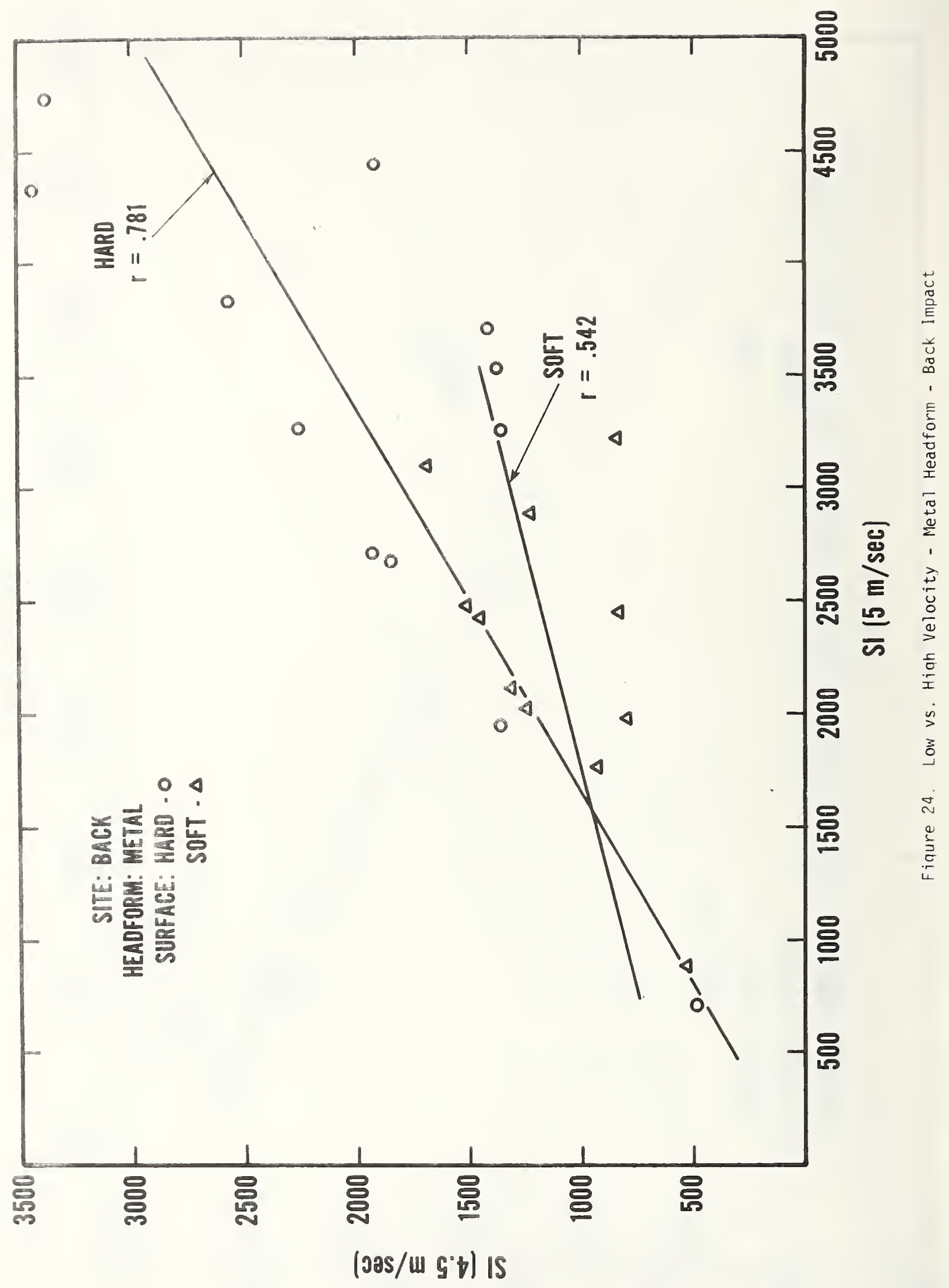




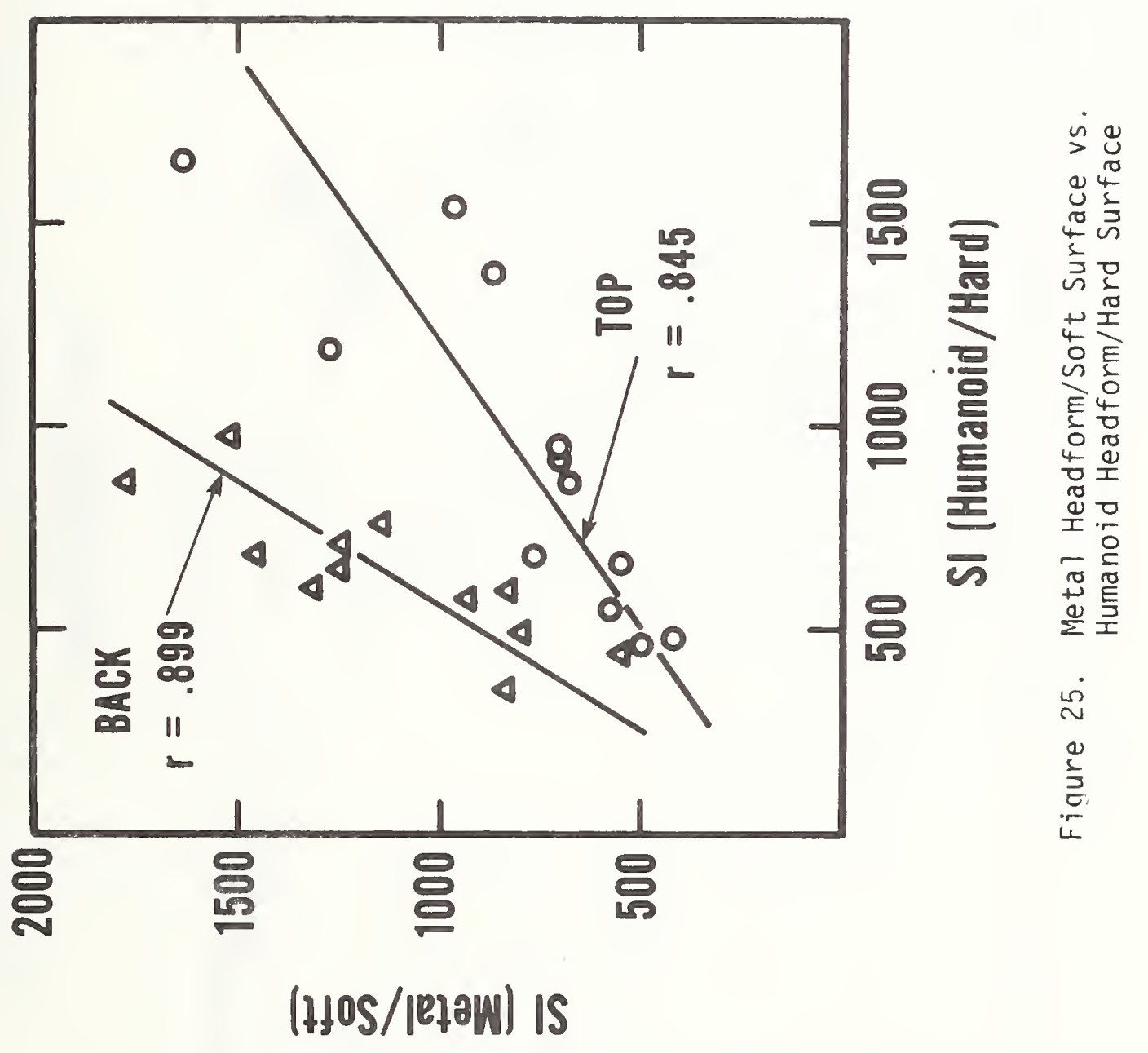




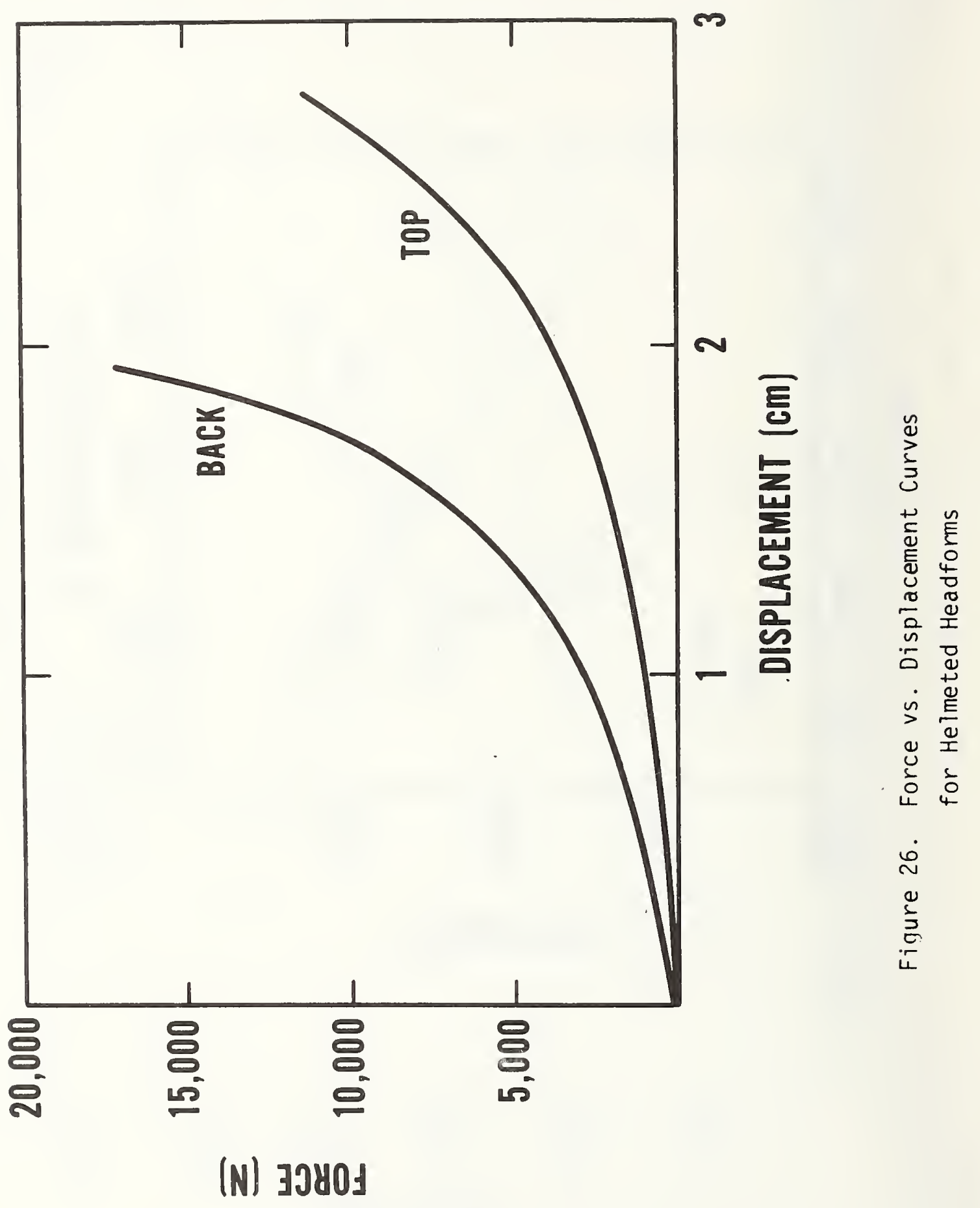




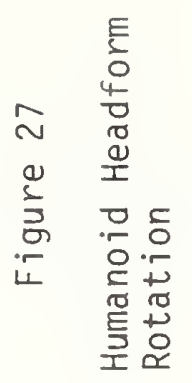
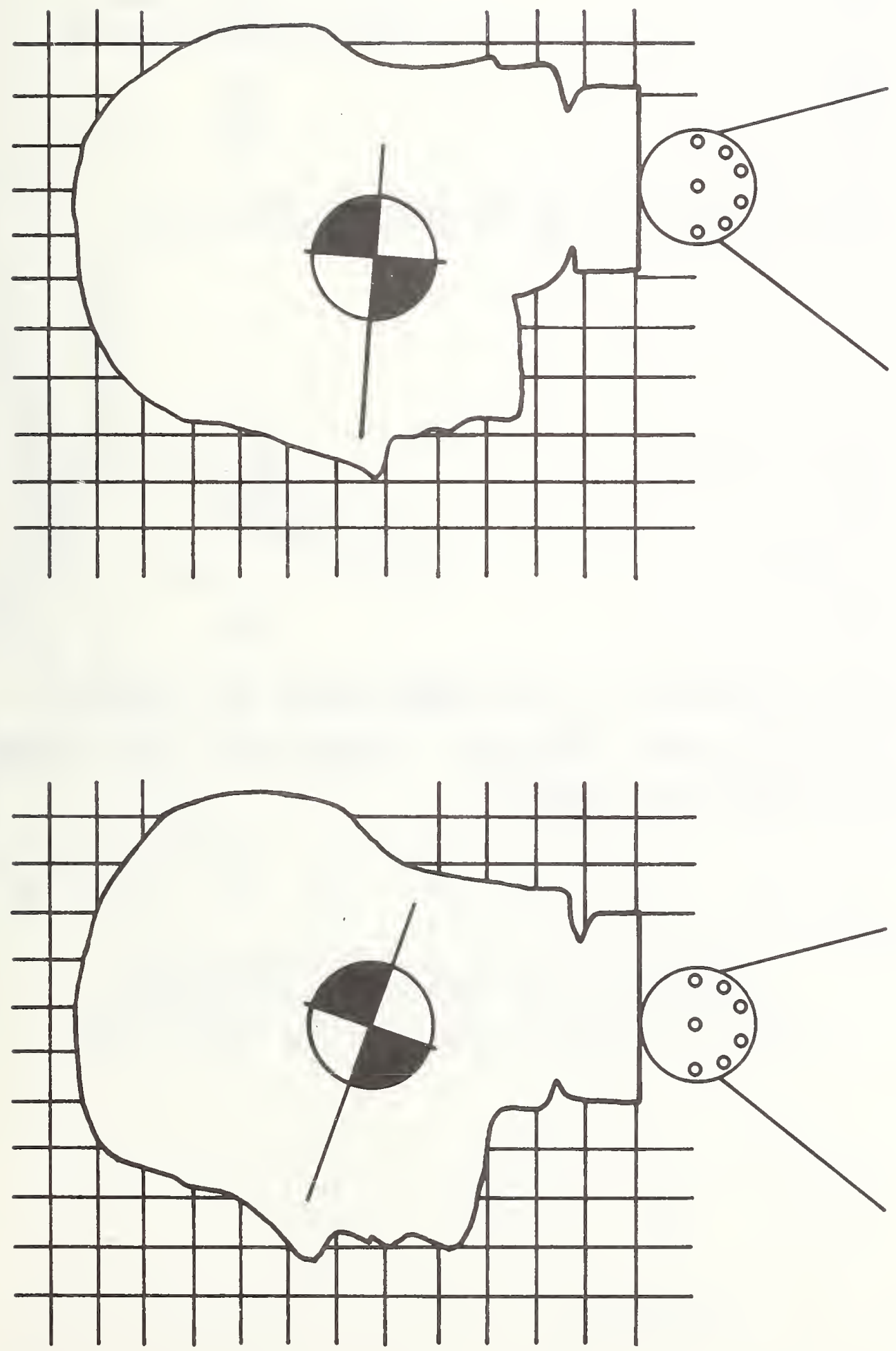


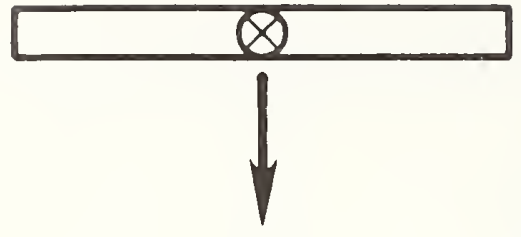

(a)

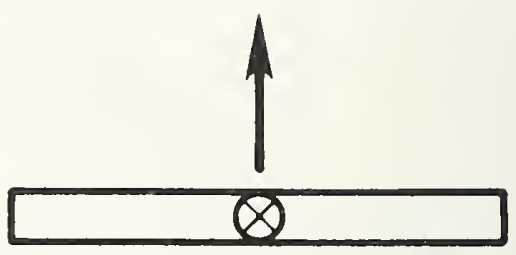

(b)

Case 1. (a) Beam impacts at c.g. (b) Rebound will be up.

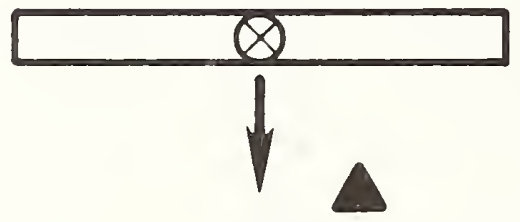

(a)

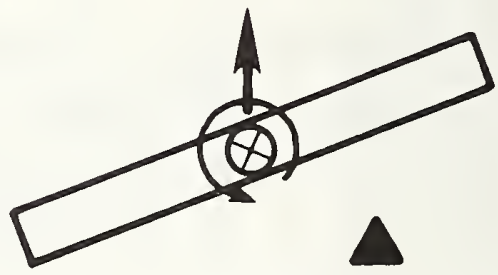

(b)

Case 2. (a) Offset between c.g. and impact point. (b) Tendency for beam to rotate. Whatever energy goes into rotation is not available for rebound.

Figure 28. Schematic Representation of Headform Rotation 


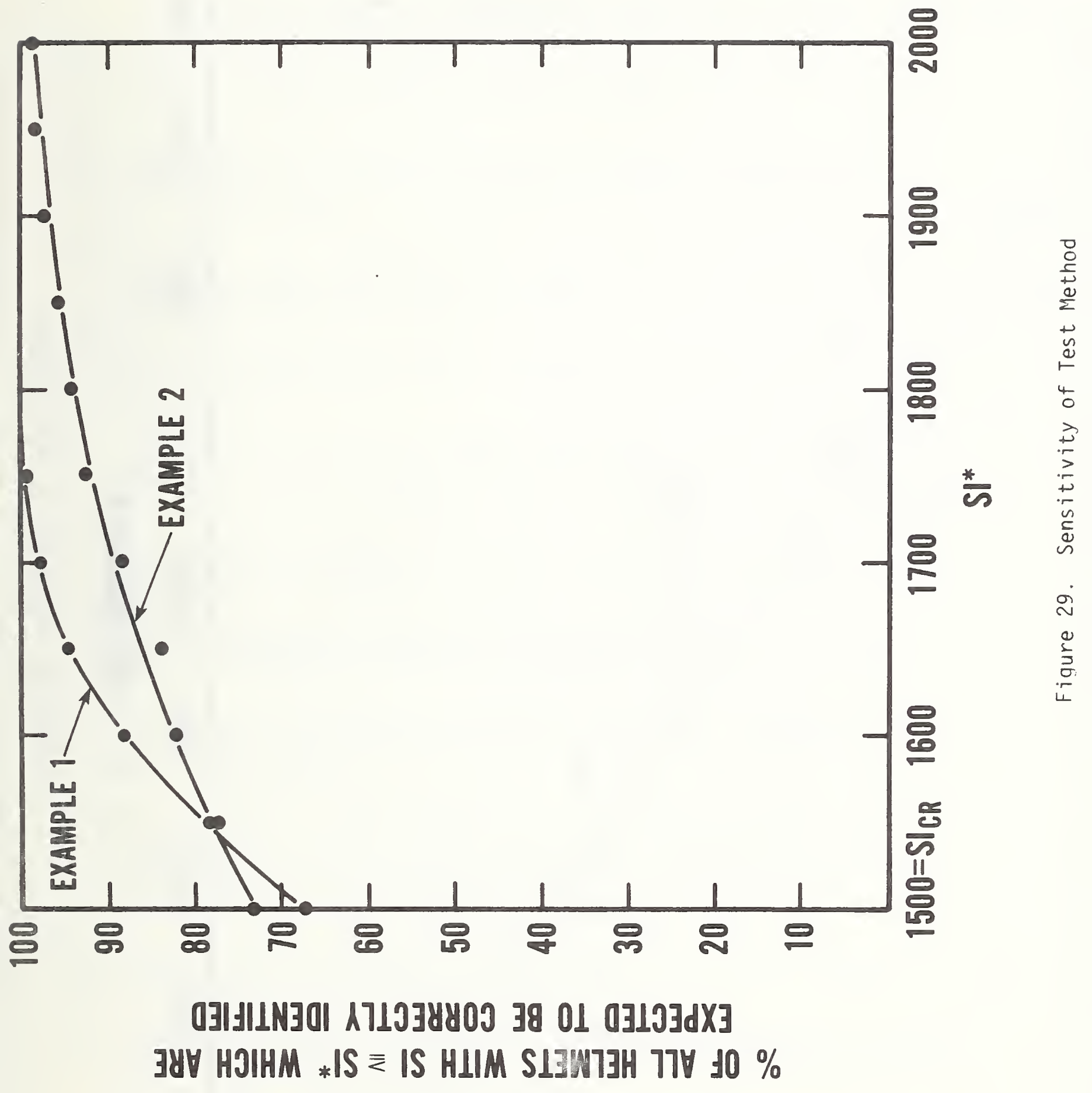




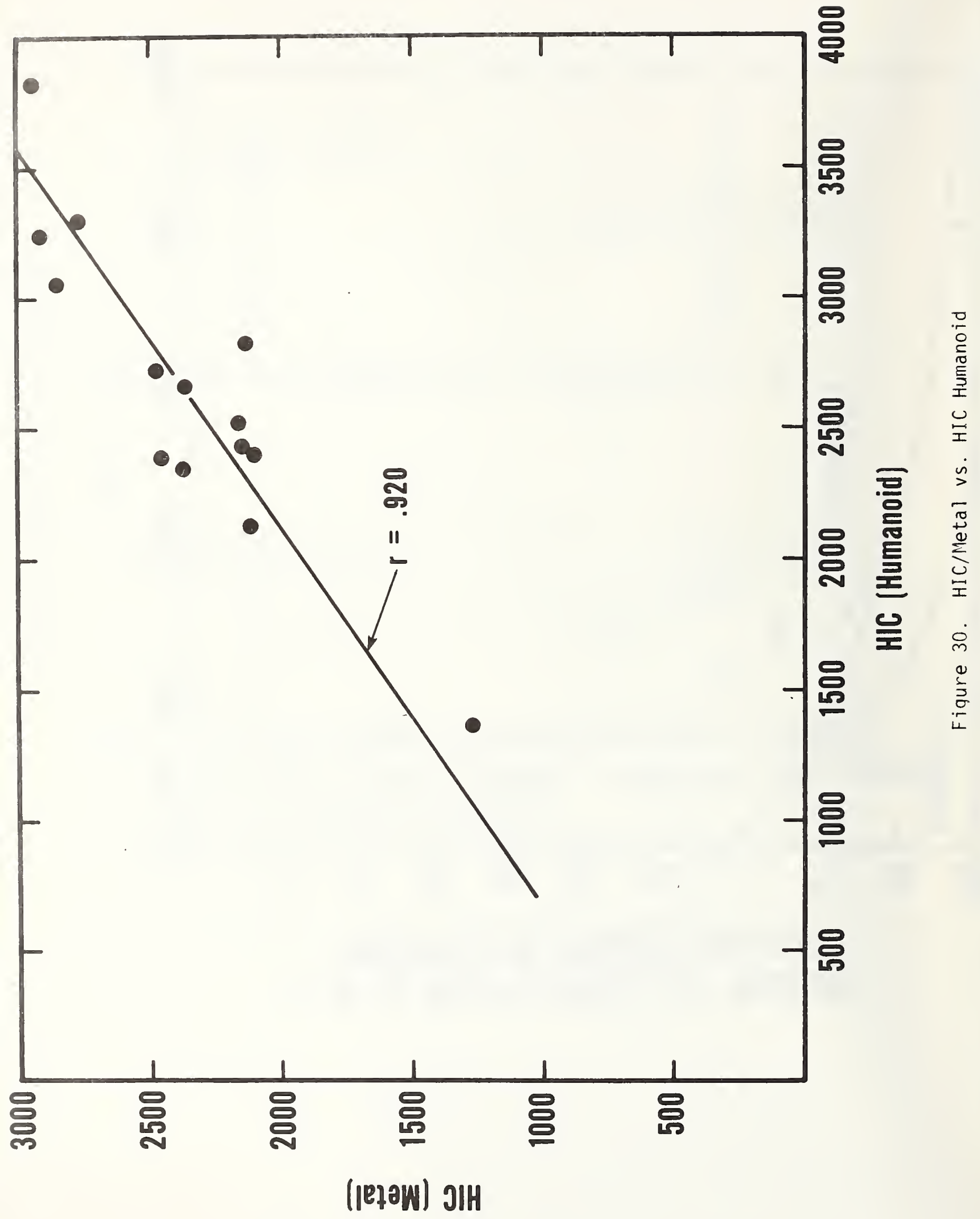




\section{REFERENCES}

1. Berger, R.E., Considerations in Developing Test Methods for Protective Headgear, National Bureau of Standards Report, NBSIR76-1107, August 1976.

2. Gurdjian, E.S., Recent Advances in the Study of the Mechanism of Impact Injury of the Head - A Summary of Clinical Neurosurgery, Vol. 19 pp. 1-42 (1972).

3. McElhaney, J.H., Stalnaker, R.L. and Roberts, V.L., Biomechanical Aspects of Head Injury, in Human Impact Response, Proc. of G.M. Symposium, Plenum Publishing Corp. (1972).

4. Advani, S.H. and Owings, R.P., Evaluation of Head Injury Criteria, Automotive Engineering, p-11, Society of Automotive Engineers, New York (1974).

5. Hodgson, V.R., National Operating Committee on Standards for Athletic Equipment Football Helmet Certification Program, Medicine and Science in sports, 7 (3) pp. 225-232 (1975).

6. Gurdjian, E.S., Lissner, H.R., and Patrick, L.M., "Protection of the Head and Neck in Sports," JAMA, Vol. 182, pp. 509-512 (1962).

7. Newman, J.A., On the Use of the Head Injury Criterion (HIC) in Protective Headgear Evaluation, Proceedings of the 19th Stapp Car Crash Conference, Society of Automotive Engineers, New York (1975).

8. Fan, W.R.S., "Internal Head Injury Assessment," Proceedings of 15th Stapp Car Crash Conference, Society of Automotive Engineers, New York, pp. 645-665 (1971).

9. Slattenschek, A., and Tauffkirchen, W., "Critical Evaluation of Assessment Methods for Head Impact Applied in Appraisal of Brain Injury Hazard, in Particular in Head Impact on Windshields," International Automobile Safety Conference Compendium, Society of Automotive Engineers, New York, Paper 700426, p. 30 (1970).

10. Hodgson, V.R. and Thomas, L.M., Head Injury Tolerance, in Aircraft Crashworthiness, K. Saczalski, ed. (1975).

11. Gadd, C.W., "Report to SAE Performance Criteria Subcommittee, "Vehicle Research Department, CM Research Laboratories, GM Technical Center, Warren, Mich. 48090 (March 8, 1972).

12. Versace, J., "A Review of the Severity Index Proceedings of 15th Stapp Car Crash Conference, Society of Automotive Engineers, New York, pp. 771-796 (1971). 
13. Andrews, L.M., Football Helmet Tests: Round Robin Using NOCSAE Recommended Test Method, National Bureau of Standards letter report to the Consumer Product Safety Commission (March 3, 1976).

14. Specifications for Protective Headgear for Vehicular Users, American National Standard ANSI 290.1-1971, American National Standards Institute, Inc. New York (1971); and Supplement ANSI 290.1a (1973).

15. Standard Method of Test for Shock Attenuation Characteristics of Protective Headgear for Football, ASTM F429-75, American Society for Testing and Materials, Philadelphia (1975).

16. Andrews, L.M., Football Helmet Tests: Comparison of Data Using Both NOCSAE and ASTM Recommended Test Methods, National Bureau of Standards letter report to the Consumer Product Safety Commission (March 3, 1976).

17. V.R., Hodgson, M.W. Mason, and L.M. Thomas, "Head Model for Impact," Paper 720969, Proceedings of 16th Stapp Car Crash Conference, P-45, New York, Society of Automotive Engineers, Inc. (1972).

18. Henderson, G., Correlation Anomalies Between Helmet Drop-Test Systems, paper presented at Technical Meeting, Safety Helmet Council of America, Los Angeles, California (November 1, 1974).

19. Dunham, T.D., Astteford, W.J., Sissung, M.A., Nazy, A., and Yeakley, L.M., Safety Helmet Performance Investigation, Volume I, Department of Transportation, National Highway Traffic Safety Administration, Report No. DOT HS-801429 (November 1974).

20. Saczalski, K.J., States, J.D., Wagar, I.J., and Richardson, E.Q., A Critical Assessment of the Use of Non-Human Responding Surrogates for Safety System Evaluation, Proceedings of 20th Stapp Car Crash Conference, Society of Automotive Engineers, New York (1976).

21. Hodgson, V.R., Personal communication, 1976. 
Consider a population of products which potentially pose the risk of injury. Suppose that a sample of these products is subjected to two

different tests: 1) a real life simulation for which the response, $x$, of the product is a measure of the injury potential, and 2) a more practical test method where, in general, some other response, y, is measured. Each product so tested can theoretically be represented by a pair of responses $\left(x_{i}, y_{i}\right)$ and a regression line,

$$
y=a+b x+e
$$

can be computed (see sketch below). e stands for the error between the predicted y value of the regression line and the actual y value.s of products which are assumed to be distributed about the line with standard deviation $\mathrm{S}_{\mathrm{S}}$. We further assume that the injury threshold, $\mathrm{x}_{0}$, is known. Then a test method threshold can also be calculated:

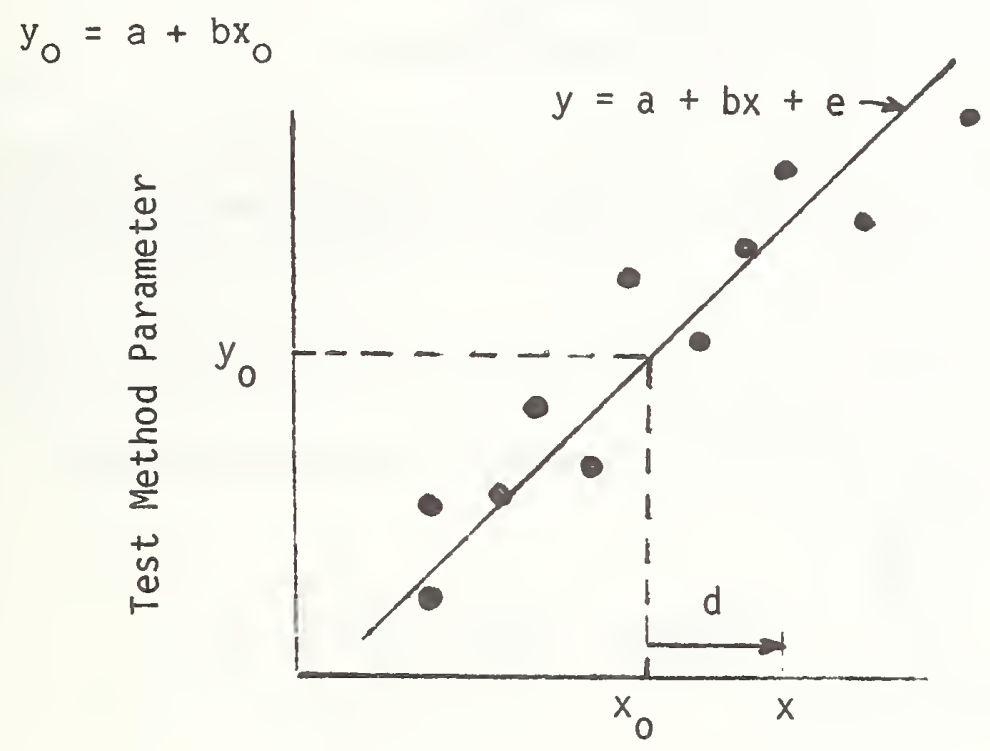

Real Life Simulation Parameter

The sensitivity, $p$, is the probability that the test method indicates injury when the simulation indicates injury:

$$
\begin{aligned}
p(x) & =\operatorname{Prob}\left(y>y_{0} \mid x>x_{0}\right) \\
& =\operatorname{Prob}\left(a+b x+e>a+b x_{0} \mid x>x_{0}\right) \\
& =\operatorname{Prob}\left(b\left(x-x_{0}\right)+e>0 \mid x-x_{0}>0\right) \\
& =\operatorname{Prob}(e>-b d \mid d>0)
\end{aligned}
$$


where $d=x-x_{0}$. That is, for all products with injury potential $x$, it is assumed that there is a distribution of $y$ values centered at $\mathrm{y}=\mathrm{a}+\mathrm{bx}$. The sensitivity is the area under the curve below.

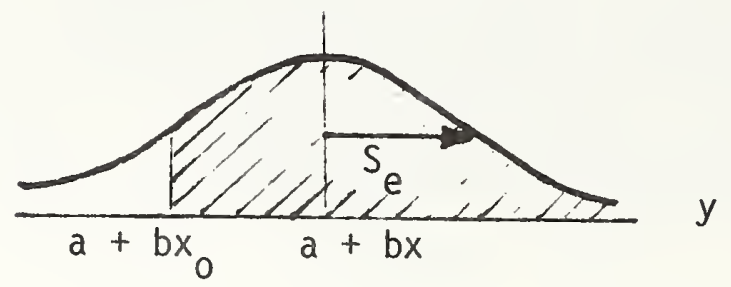

Or transforming to $e=y-(a+b x)$ we have

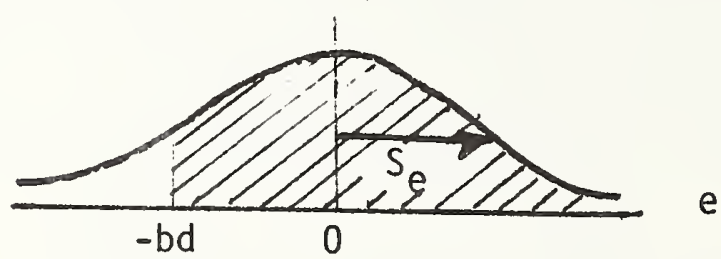

Using normalizing transformation, $z=e / S_{e}$, we calculate the probability that $z>-b d / S_{e}$, where $S_{e}$ is related to the correlation coefficient, $r$, and the distribution of $y$ values by

$$
S_{e}=S_{y}\left(1-r^{2}\right)^{1 / 2} .
$$

A normal distribution is assumed for $e$, and the sensitivity can be expressed mathernatically as

$$
p(x)=\int_{-b\left(x-x_{0}\right)}^{\infty} \frac{1}{s_{e} \sqrt{2 \pi}} \exp \left[-\frac{e^{2}}{2 s_{e}^{2}}\right] d e
$$

Obviously, the sensitivity calculated above has meaning only for fixed values of $x>x_{0}$. It is also possible to calculate a more general sensitivity $\mathrm{P}(\mathrm{x})$ which covers a range of $\mathrm{x}$ values greater than $\mathrm{x}^{\circ}$. For this purpose we assume that the $x$ values are normally distributed with standard deviation $\mathrm{S}_{\mathrm{x}}$.

$$
f(x)=\frac{1}{S_{x} \sqrt{2 \pi}} \exp \left[-\frac{(x-\bar{x})^{2}}{2 S_{x}^{2}}\right]
$$

Then $f(x) d x$ is the percentage of products with $x$ values between $x$ and $x+$ dx: 


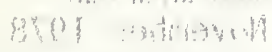

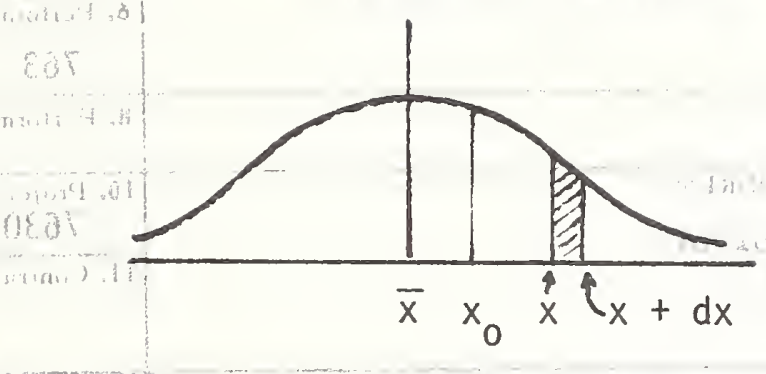

SAldit?

$+1030$

The general sensitivity, $P\left(x^{*}\right)$, is the proportion of all products with $x \geq$ $x^{*}$, where $x^{*} \geq x_{0}$, for which $y>y_{0}$. That is, of all products whose injury potential exceeds $x^{*}, P\left(x^{*}\right)$ is the percentage that is correctly identified in the test method. Mathematically, this may be expressed as

$\int_{x^{*}}^{\infty} p(x) f(x) d x$

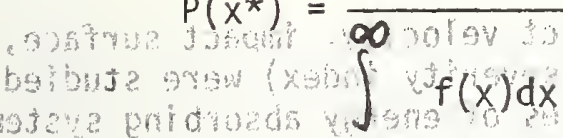

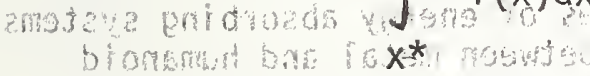

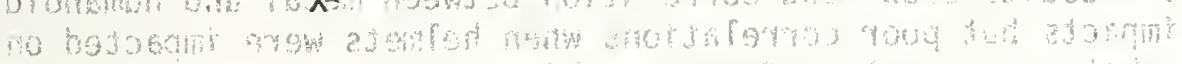

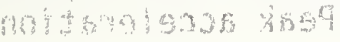




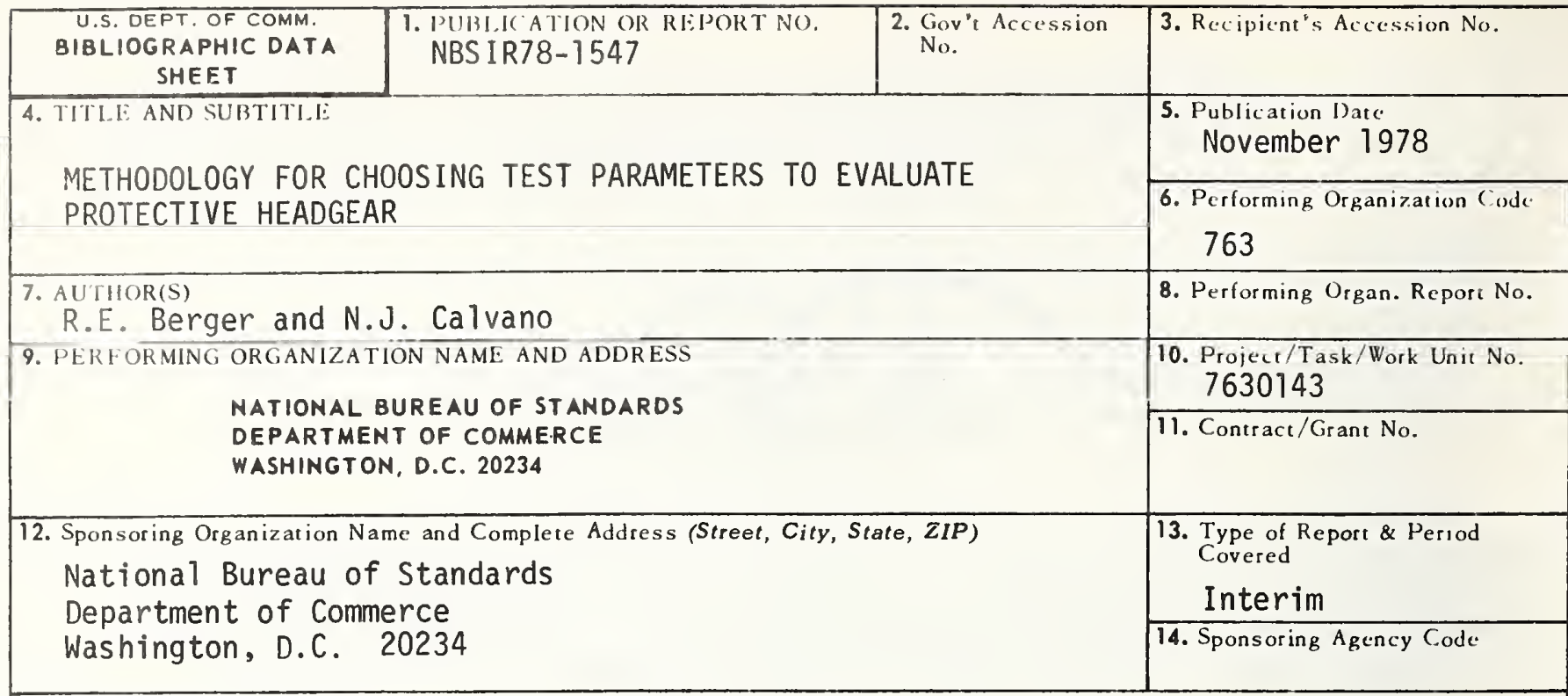

15. SUPPI.EMENTARY NOTES

16. ABSTRACT (A 200-word or less factual summary of most significant information. If document includes a significant bibliography or literature survey, mention it here.)

The effects of changing test variables (headform, impact velocity, impact surface, impact site) on output parameters (peak acceleration, severity index) were studied. Twelve football helmets representing six different types of energy absorbing systems were used in the test. Results show good correlation between metal and humanoid headforms during top impacts but poor correlations when helmets were impacted on the back. Correlation between impact surfaces was high. Peak acceleration correlated well with severity index.

17. KEY WORDS (six to twelve entries; alphabetical order; capitalize only the first letter of the first key word unless a proper name; separated by semicolons)

Head injury; headform; headgear; helmet; impact; test method.

18. AVAILABILITY E Unlimited

$[\neg$ For Official Distribution. Do Not Release to NTIS

[7 Order From Sup. of Doc., U.S. Government Printing Office Washington, D.C. 20402, SD Cat. No.C13

Order From National Technical Information Service (NTIS) Springfield, Virginia 22151

\begin{tabular}{|l|c|}
\hline $\begin{array}{l}\text { 19. SECURITY CLASS } \\
\text { (THIS REPURT) } \\
\text { UNCL ASSIFIED }\end{array}$ & 21. NO. OF PAGES \\
\hline $\begin{array}{l}\text { 20. SECURITY CLASS } \\
\text { (THIS PAGE) }\end{array}$ & 22. Price \\
UNCLASSIFIED & $\$ 6.00$ \\
\hline
\end{tabular}



